\title{
EFFECTS OF SPEECHREADING AND SIGNAL-TO-NOISE RATIO ON UNDERSTANDING MAINSTREAM AMERICAN ENGLISH BY AMERICAN AND INDIAN ADULTS
}

\author{
A Dissertation by \\ Yori Kanekama \\ Master of Arts, Wichita State University, 2004 \\ Bachelor of Arts, Wichita State University, 2001 \\ Bachelor of Arts, Meiji Gakuin University, Tokyo, Japan, 1998
}

Submitted to the Department of Communication Sciences and Disorders and the faculty of the Graduate School of Wichita State University in partial fulfillment of the requirements for the degree of Doctor of Philosophy 
(C) Copyright 2009 by Yori Kanekama

All Rights Reserved 


\section{EFFECTS OF SPEECHREADING AND SIGNAL-TO-NOISE RATIO ON UNDERSTANDING MAINSTREAM AMERICAN ENGLISH BY AMERICAN AND INDIAN ADULTS}

The following faculty have examined the final copy of this dissertation for form and content, and recommend that it be accepted in partial fulfillment of the requirement for the degree of Doctor of Philosophy with a major in Communication Sciences and Disorders.

David Downs, Committee Co-Chair

Barbara Hodson, Committee Co-Chair

Raymond Hull, Committee Member

Peggy Anderson, Committee Member

Alex Chaparro, Committee Member

Accepted for the College of Health Professions

Peter A. Cohen, Dean

Accepted for the Graduate School

J. David McDonald, Dean 


\section{DEDICATION}

To my parents, Ungan and Saeko Kanekama 


\section{ACKNOWLEDGMENTS}

There were many dark nights that I cried for.... and there were many bright days that I smiled for.... The writing of a dissertation can be a lonely and isolating experience, however, it is clearly not possible without the mental and physical support of my family, my American family, the faculty and staff of the CSD Department, the members of my committee, and my fellow doctoral students.

First and foremost, I want to thank Dr. David Downs, my doctoral advisor, for his support; patient guidance; words of encouragement; careful reading of all my writing; spending hours and hours of time, even on weekends, to review my dissertation; and his great humor during my PhD program. Dr. Downs always listened to me and opened up new windows to lead a breeze. When I could not find a way out, he lighted up an alley for me to see. Without him, the successful completion of this study would not have been possible. In the same vein, I would especially thank Dr. Barbara Hodson, my dissertation co-chair, for believing in me, and for her continued support, help, and advice. Her encouragement and "hugs” made me keep moving forward. My sincere thanks to Dr. Ray Hull for always supporting me and being there with great advice when I needed it. I would like to extend my gratitude to Dr. Peggy Anderson for her helpful comments and suggestions throughout this study. I also truly appreciated Dr. Alex Chaparro who was always there willingly sharing his thoughts from different perspectives.

I would like to thank Dr. Don Sims from the National Technical Institute for the Deaf for transferring the original laser disk version of the CID Everyday Speech Sentences to a highly user-friendly DVD especially for this study. I would like to extend my gratitude to Dr. Ray Hull and Dr. Barbara Hodson for helping to provide financial supports during the PhD program. 
I am also grateful to the many American graduate students from CSD and Psychology Departments and Indian graduate students from Engineering Department who participated in my study.

I would like to extend my gratitude to Dr. Kathy Coufal who has believed in me and always encouraged me. Her office door was always open and I was her frequent visitor to her office. She always prescribed me "magic pills" to cheer me up. The "magic pills" happened to be a chocolate. My sincere thanks to Dr. Charles Burdsal for guiding me thorough a black hole of statistics. What I learned from him was invaluable in completing this dissertation. Many thanks to the CSD office staff, Johanna Hutmacher and Jaymie Faust, for guiding me through the university system and always being there to help kindly. Every time when I had a nervous moment, they always tried to make me smile. My heartfelt gratitude to my friends and colleagues Masako Maeda, Meng-Ju Tsai, Mark Shaver, Christi Barb, and Phil Sechtem, as well as other fellow PhD students I got to know at WSU. Their unqualified support, the shared laughter, the discussions, and of course, lunches, dinners, and the occasional tea parties made this rough trip brighter.

I would like to thank Debbie and Terry Gowen who treated me as part of their family, taught me American culture, and, “Real American English.” They were always there for me when I had a rough time and a bright time. Without their understanding and support, I would have never completed my study.

Lastly, my sincere thanks to my parents, Ungan and Saeko Kanekama, for their love, support, encouragement, and understanding, and providing me with all the years of education and opportunity. My parents raised me as a unique individual and cherished the way I live. I am proud to follow my father's path as a researcher and teacher. I would like to extend my gratitude 
to my sisters, Yumi Fujiuchi and Shio Shinkawa for understanding and supporting their little sister. I am very grateful to my husband, Don Romadhon for his unwavering love, faith, support, encouragement, and patience. Without his support, I could have never moved into the next chapter of my life. 


\begin{abstract}
The purpose of this study was to measure effects of speechreading and signal-to-noise ratio (SNR) on understanding mainstream American English (MAE) heard by 30 Indian adults compared to 30 American adults. Participants listened to a recording of a female speaker of MAE saying 10 lists of 10 different Everyday Speech Sentences per list. Participants heard sentences from a TV loudspeaker at a conversational speech level while a four-talker babble played through two surrounding loudspeakers at a $+6,0,-6,-12$, or $-18 \mathrm{~dB}$ SNR. Participants heard and watched a different list of sentences at each SNR (i.e., through the Auditory-Visual modality) and only heard a different list of sentences at each SNR (i.e., through an Auditory modality). After listening to each sentence, participants wrote verbatim what they thought the speaker said. Each participant's speechreading performance at each SNR was computed as the difference in words correctly heard through Auditory-Visual versus Auditory modalities. Consistent with most previous research, American participants benefitted significantly more from speechreading at poorer SNRs than at favorable SNRs. The novel finding of this study, however, was that Indian participants benefitted less from speechreading than American participants at poorer SNRs, but benefitted more from speechreading than American participants at favorable SNRs. Linguistic (and, possibly, nonlinguistic) variables may have accounted for these findings; including an increased need for Indian participants to integrate more auditory cues with visual cues to benefit from speechreading, presumably because they only spoke English as a second language. These findings have theoretical implications for understanding the role of auditory-visual integration on cross-language perception of speech, and practical implications for understanding how much speechreading helps people understand a second language in noisy environments.
\end{abstract}




\section{TABLE OF CONTENTS}

I. INTRODUCTION 1

II. LITERATURE REVIEW

Scientific foundation of speechreading 5

Basic theories for auditory-visual integration in speech perception 10

Psychological evidence of auditory, visual and auditory-visual speech perception 12

Inter-lingual and cross-cultural study of McGurk effects 17

Speechreading and second-language speakers of English 23

$\begin{array}{ll}\text { Measurement of speechreading } & 29\end{array}$

Central Institute for the Deaf Everyday Speech Sentences Test 32

Administration of speechreading test

Speech comprehensibility and foreign accentedness ratings $\quad 45$

$\begin{array}{ll}\text { Participant population } & 46\end{array}$

A pilot study of effects of speechreading on understanding MAE

III. METHODOLOGY

Participants $\quad 52$

Facilities and instrumentations $\quad 59$

$\begin{array}{ll}\text { Procedures } & 62\end{array}$

$\begin{array}{ll}\text { Data analysis } & 66\end{array}$

$\begin{array}{lll}\text { IV. } & \text { RESULTS } & 70\end{array}$

Effects of SNRs and modality $\quad 70$

Effects of language group and SNR on AV-scores and A-scores $\quad 82$

Effects of language group and SNR on VE-scores 89

Effects of language group on AV-score @ (A) SNR-50 92

Correlation between (A) SNR-50 and AV-score @ (A) SNR-50 96

Association between AV-score @ (A) SNR-50 and linguistic measures 97

Effects of gender on AV-score @ (A) SNR-50 103 
TABLE OF CONTENTS (continued)

Chapter Page

$\begin{array}{lll}\text { V. SUMMARY AND DISCUSSION } & 105\end{array}$

$\begin{array}{ll}\text { Summary of present study } & 105\end{array}$

$\begin{array}{lr}\text { Nonlinguistic variables } & 106\end{array}$

$\begin{array}{ll}\text { Linguistic variables } & 107\end{array}$

$\begin{array}{ll}\text { Theoretical implications } & 108\end{array}$

$\begin{array}{ll}\text { Practical implications } & 110\end{array}$

$\begin{array}{ll}\text { Future research } & 111\end{array}$

$\begin{array}{lr}\text { REFERENCES } & 113\end{array}$

$\begin{array}{ll}\text { APPENDIXES } & 124\end{array}$

$\begin{array}{ll}\text { Participants pre-selection criteria } & 125\end{array}$

Consent form for American participants 126

$\begin{array}{ll}\text { Consent form for Indian participants } & 129\end{array}$

Questionnaire for American participants 132

Questionnaire for Indian participants $\quad 135$

Responses for questionnaire for American participants 138

Responses for questionnaire for Indian participants 142

$\begin{array}{ll}\text { Rainbow passage } & 149\end{array}$

Distance visual acuity test instruction, contrast sensitivity test instruction, $\begin{array}{ll}\text { and hearing test instruction } & 150\end{array}$

Participant instruction for ESS 151

Test form $\quad 152$

CHABA criteria $\quad 153$

CID everyday speech sentences $\quad 154$

Raw data showing AV-scores, A-scores, and VE-scores for American participants 158

Raw data showing AV-scores, A-scores, and VE-scores for Indian participants 161

Raw data showing (A) SNR-50 and AV-score @ (A) SNR-50

for American and Indian participants

164 


\section{LIST OF TABLES}

Table

Page

1. Two-way ANOVA testing effects of SNR and modality on scores of American participants. .73

2. Tukey test results of American participants comparing AV-scores between SNRs ...........75

3. Tukey test results of American participants comparing A-scores between SNR..............76

4. Tukey test results of American participants comparing AV-scores and A-scores at each SNR.

5. Two-way ANOVA testing effects of SNR and modality on scores of Indian participants .79

6. Tukey test results of Indian participants comparing AV-scores between SNRs

7. Tukey test results of Indian participants comparing A-scores between SNRs .81

8. Tukey test results of Indian participants comparing AV- and A-scores at each SNR ........82

9. Two-way ANOVA testing effects of language group and SNR on AV-cores. .85

10. Mean differences in AV-scores between American and Indian participants at each SNR.

11. Two-way ANOVA testing effects of language group and SNR on A-scores

12. Mean differences in A-scores between American and Indian participants at each SNR.

13. Two-way ANOVA showing effects of language group and SNR on VE-scores of American and Indian participants

14. Comparison of VE-scores between SNR for American participants

15. Comparison of VE-scores between SNR for Indian participants . .94

16. Comparison of VE-scores between American and Indian participants at each SNR..... .95

17. Correlation between AV-score @ (A) SNR-50 and linguistic measures .103

18. Mean AV-scores @ (A) SNR-50 for females and males of American and Indian participants. 


\section{LIST OF FIGURES}

Figure

Page

1. Distribution of judges' median ratings of comprehensibility

of the American and Indian participants of the Rainbow Passage .57

2. Distribution of judges' median ratings of perceived foreign accentedness

of the American and Indian participants of the Rainbow Passage .58

3. IAC sound booth with distance measures ................................................................60

4. A block diagram displaying instrumentation for speechreading..................................62

5. Psychometric functions showing means and SDs of AV- and A-scores

for American participants at each SNR.

6. Psychometric functions showing means and SDs of AV-and A-scores

for Indian participants at each SNR

7. Psychometric functions showing means and SDs of AV-scores

for American and Indian participants.

8. Psychometric functions showing means and SDs of A-scores

for American and Indian participants.....

9. Means and SDs of VE-scores at each SNR for American and Indian participants............90

10. Mean (A) SNR-50 and mean AV-score @ (A) SNR-50 for American participants...........96

11. Mean (A) SNR-50 and mean AV-score @ (A) SNR-50 for Indian participants ................98

12. Correlation between (A) SNR-50 and AV-score @ (A) SNR-50

for American participants.

13. Correlation between (A) SNR-50 and AV-score @ (A) SNR-50

for Indian participants.

14. Correlation between AV-score @ (A) SNR-50 and comprehensibility rating .101

15. Correlation between AV-score @ (A) SNR-50 and foreign accentedness rating. 


\section{LIST OF ABBREVIATIONS / NOMENCLATURE}

A

(A) SNR-50
AV
AV-score @ (A) SNR-50
CID
ESS
IBT
MAE
NTID
SNR

TOEFL

$\mathrm{VE}$
Auditory

SNR at 50\% A-only-score

Auditory-Visual

AV-score at SNR at 50\% A-score

Central Institute for the Deaf

Everyday Speech Sentences

Internet-Base Test

Mainstream American English

National Technical Institute for the Deaf

Signal-to-Noise Ratio

Test of English as a Foreign Language

Visual Enhancement 


\section{LIST OF SYMBOLS}

$\mathrm{dB}$

$\eta^{2}$

Decibel

Eta Squared 


\section{CHAPTER I}

\section{INTRODUCTION}

A growing number of people in the United States speak English as a second language (US Census Bureau, 2000). Researchers have suggested second-language speakers of English may have similar speech understanding to first-language speakers of English when listening to “everyday” English in quiet. Conversely, second-language speakers of English often have more difficulty understanding English than first-language speakers of English when they listen in background noise. Listeners can make listening in noise easier by speechreading: a multisensory strategy people use to help them understand spoken words by watching a speaker's lips, face, and gestures.

Although there is enormous variability in speechreading abilities among individual listeners, most people can only see about $30 \%$ to $40 \%$ of speech sounds in mainstream American English (MAE) on a speaker's face (e.g., b, p, m, t, d, f, v, s, th, oo, ee). Because these are often the speech sounds most difficult for listeners to hear as noise increases, several researchers have reported speechreading can help listeners understand better as the signal-to-noise ratio (SNR) get poorer (Erber, 1972, 1974; MacLeod, A., \& Summerfield, Q., 1987, 1990; Nielsen, 2004; Sumby \& Pollack, 1954). In other words, people tend to use and benefit from the visual cues they see on a speaker's face more when the quality of the auditory cues they hear decreases at poorer SNRs. Researchers of multisensory integration call this reciprocal relationship in which weaker auditory stimuli produce stronger visual benefits “inverse effectiveness.” Recently, however, Ross, SaintAmour, Leavitt, Javitt, and Foxe (2007) have suggested that some listeners may benefit from speechreading more at moderate SNRs, rather than poorer SNRs, possibly because more auditory and visual cues are available to integrate. 
Speechreading has been evaluated by scientists and clinicians, like audiologists, by using nonsense syllables, words, or discourse. More frequently, however, they evaluate speechreading with sentences employing common everyday words, so that a listener's vocabulary size is not a confounding variable. During "live-voice” evaluations, a speaker says a sentence face-to-face to a listener and the listener repeats what is said. To reduce speaker variability and bias many researchers and some clinicians use video-recorded sentences in which a listener writes down what a televised speaker supposedly said. Although sentences are thought to be a better predictor of speechreading than words (Liberman, Cooper, Shankweiler, \& Studdert-Kennedy, 1967), not all sentence tests have achieved routine clinical use due to a lack of standardized, equivalent lists of sentences (Hinkle, 1979) and no commercial audio-video recordings. The most commonly researched and validated of speechreading tests has been noncommercial recordings of the Central Institute for the Deaf (CID) Everyday Speech Sentences (ESS) (Barley, 1971; Healy \& Montgomery, 2006; Sims, 1975). They were recorded with an adult speaker of MAE saying ten lists of ten common sentences from which the tester scored 50 designated words within each list. ESS has been used clinically to measure speechreading abilities of clients with and without hearing impairment. The sentences are often spoken in a background of noise, like multiple-talker babble, to simulate many everyday listening situations and to force listeners to rely more on speechreading cues than they would when listening in quiet.

During speechreading measurements, researchers and clinicians typically analyze the relative contribution of auditory or visual cues to auditory-visual integration by scoring how well a listener understands spoken messages, like ESS, under two presentation conditions: (1) through the Auditory-Visual (AV) modalities in which a listener both hears and sees what a speaker is 
saying, and (2) through the Auditory (A) modality in which a listener just hears what a speaker is saying. Not surprisingly, when auditory and visual cues are integrated (i.e., the AV modality) understanding of speech is usually enhanced compared to the A modality, particularly when the spoken message is degraded by noise.

Statement of the Problem

The vast majority of research on speech perception across languages has been conducted when speech is presented through the A modality. A limited amount of research has shown that speechreading can help first-language speakers of English understand English spoken by a speaker with a foreign accent (Reisberg, McLean, \& Goldfield, 1987). The role of speechreading on understanding MAE by second-language speakers of English, however, has not been studied. Researchers, likewise, have shown that speechreading can help first-language speakers of English understand MAE spoken in a background of noise. Researchers have not studied, however, the interaction between speechreading and different SNRs on understanding MAE by second-language speakers of English using standardized speechreading measures of connected speech, like ESS. A basic question, therefore, is left unanswered: Does speechreading help second-language speakers of English understand MAE sentences more, or less, or the same as it does first-language speakers of English when the sentences are spoken by a first-language speaker of MAE and heard at different SNRs. Answers to this question may have theoretical implications for understanding the role of auditory-visual integration and inverse effectiveness on cross-language speech perception, and practical implications for understanding how much speechreading can help a growing number of second-language speakers of English in the United States better understand MAE, especially when they are listening to MAE in the various noisy environments they encounter daily. 
Purpose of the Study

The general purpose of the current research was to study the role of auditory-visual integration on perception of MAE by native speakers of different languages. The specific purpose was to measure effects of speechreading and SNR on understanding ESS spoken by a MAE speaker and heard by 30 Indian adults compared to 30 American adults. The investigator hypothesized that speechreading would help Indian participants understand ESS, but not as much as it would help American participants understand ESS. The investigator speculated that American participants would see facial movements of the videotaped MAE speaker looking similar to the facial movements they would make when speaking English. Accordingly, American participants would benefit more from watching the speaker’s face (i.e., they would have better auditory-visual integration and inverse effectiveness), especially when they could not understand ESS as well at poorer SNRs. Conversely, because Indian participants typically speak English with a foreign accent, they would see facial movements of the videotaped speakers looking less similar to the facial movements they make when speaking English. Therefore, they would benefit less from watching the speaker's face (i.e., they would have poorer auditory-visual integration and inverse effectiveness), especially when they heard the ESS at poorer SNRs. 


\section{CHAPTER II}

\section{LITERATURE REVIEW}

“All parts of the nervous system are connected together and no part of it is probably ever capable of reaction without affecting and being affected by various parts.”

(Sherrington, 1920, p. 8).

Scientific Foundation of Speechreading

Examining each of the senses independently leads, at best, to partial understanding of everyday perceptions. People, however, are rarely faced with single sensations. In face-to-face speech communication, a listener attends to both speaker's auditory and visual cues to understand speech. This is referred to speechreading. Speech can even be processed by the haptic system. Some individuals are with deafness and blindness acquire a full range of speech perception by touching the speakers which is known as the Tadoma method (Reed, 1985). This person feels articulatory movements by placing hands on speaker's face and neck. Primary cues are airflow at the lips and movements of the lips and jaw. Reed examined Tadoma users’ understanding of speech materials ranging from nonsense syllables to connected speech. Individuals with deaf-blindness in early childhood could understand speech with reasonable accuracy when spoken at slow to normal rates. Their own speech was reasonably intelligible, comparable in some areas to individuals with typical hearing abilities. Although speech perception is considered to be primarily an auditory process, speechreading can enhance speech understanding in face-to-face verbal communication, especially when auditory cues are unintelligible (Sumby \& Pollack, 1954) or when a speaker has a heavy “foreign accent” (Reisberg, McLean, \& Goldfield, 1987). 
Factors that influence speechreading tasks include (a) visible sounds and sound productions (Tye-Murray, 2004), (b) speaker effect (Daly, Bench, \& Chappell, 1996) , (c) age (Tye-Murray et al., 2007b), (d) gender (Johnson, Hicks, Goldberg, \& Myslobodsky, 1988; TyeMurray, 2007b), (e) cognitive skills (Anderson, Lyxell, Rönnberg, \& Spens, 2001), and (f) visual and hearing sensitivity (Tye-Murray, 2004).

\section{$\underline{\text { Visible Sounds and Sound Productions }}$}

When sounds are visible on a speaker's face and these sounds are associated with visible mouth movement, it is easier for listeners to recognize words. For instance, bilabial consonants

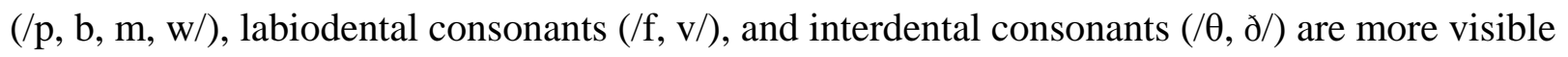
on the face. Some consonants such as alveolar consonants (/t, d, n, s, z/) and velar consonants (/k, g, $\mathrm{y} /$ ) which are produced in the mouth have limited visibility. Consonants that are visible on the speaker's face are called visemes and appear to be same on the lips (i.e., /p, m, b/). Words that appear to be identical on the mouth but would have different meanings are called homophones (e.g., /sea/ vs. /see/). When listeners perceive only either auditory cues or visual cues in degraded environments only, listeners cannot discriminate voiced vs. voiceless from visible mouth movements and also may have difficulty detecting vowels because vowels are not highly visible (Tye-Murray, 2004). Vowels, however, tend to be acoustically salient for listeners because vowels are higher in intensity, longer in duration, and have a slower change in frequency composition. Recognition of visible sounds is also related to rapidity of speech. When visible words are spoken fast, listeners may not have enough time to identify a particular word and may not even realize the occurrence of every word (Tye-Murray, 2004). 


\section{Speaker Effects}

Speechreading may be confounded by speaker's effects such as the degree of mouth opening (e.g., speaker's individual difference), accented speech (e.g., speaker does not speak different regional dialect), and gender of the speaker (Daly et al.,1996). Daly et al. reported that Australian-English listeners are better at speechreading sentences spoken by female AustralianEnglish speakers. The researchers hypothesized that gender differences are related to differences in nonverbal communication (e.g., gestures) and articulation style (e.g., speaking more slowly than usual as in a telling story or giving a lecture). Female speakers demonstrated wider mouth apertures than males which made speechreading easier (Daly et al.,1996). Petkovsek (1961) also reported that female speakers were easier to speechread, suggesting that female speakers use freer expression and more gestures. Lipstick also drew attention to their lips.

\section{$\underline{\text { Age }}$}

Younger adults are better speechreaders than older adults (Dancer, Krain, Thompson, Davis, \& Glenn, 1994; Sommers, Tye-Murray, \& Spehar, 2005; Tye-Murray, 2004). Dancer et al. (1994) conducted a study of speechreading on adults from 20 to 69 years of age. Young adults (20 to 29 and 30 to 39 years of age) speechread better than older adults (60 to 69 years of age). Speechreading ability decreases as a function of increasing of age which may be due to the cautiousness, prolonged visual-neural conduction times, reduced visual and auditory sensitivity, and hemispheric changes (Dancer, et al., 1994). Findings of Sommers et al. (2005) involving adults with typical hearing which demonstrated age-related declines in speechreading were consistent with the Dancer et al. 1994 study. They suggested that speechreading might be related more to a decline in one or more capacities that are necessary to encode visual speech cues rather than their hearing abilities (Sommers et al., 2005). Young children, however, do not speechread 
as well as older children indicating their speechreading performances are influenced by cognitive and phonological developmental levels (Kishon-Rabin \& Henkin, 2000). Thus, cognitive and phonological developments are necessary to benefit fully from speechreading.

\section{$\underline{\text { Gender }}$}

Some researchers suggested that there is a gender difference for speechreading performance. Plant and Macrae (1981) reported that females performed better than male on identification of sentences. Johnson et al. (1988) also reported that females performed better on identification of phonemes and sentences than males; however, males did better in identifying visemes (e.g., /b, m, p/). Results of studies by Dancer et al. in 1994 and Watson, Qiu, Chamberlain, and Li in 1996 were consistent with previous studies indicating females performed better on identifying sentences than males. A recent study by Tye-Murray et al. (2007b) reported, however, that differences in speechreading performances between females and males in identifying consonants, words, and sentences were not significant. The general effect of speechreading shown in Submy and Pollack's early study (1954) has been replicated many times. Many studies of speechreading, however, have not reported the gender differences in their studies (e.g., Erber, 1969, 1972; MacLeod \& Summerfield, 1987, 1990; Nielsen, 2004; Sumby \& Pollack, 1954). Tye-Murray (2007b) stated that gender differences may exist their current study but the difference is slight.

\section{Cognitive Skills}

With face-to-face communication, listeners perceive speaker’s auditory and visual cues, speaker's facial expressions and gestures, and any other available cues (Tye-Murray, 2004). When people speechread, some cognitive skills are required to figure out what is being said after 
extracting speech cues from lips and face movements. These cognitive skills are involved in phonological processing of spoken words, visual word decoding, lexical identification speed, and verbal inference making (Anderson et al., 2001). The speed of retrieving information from working memory, which involves simultaneously storing and manipulating items in memory, also can influence speechreading performance. When the quality of auditory information is degraded, usually the degration slows the speech encoding process but it does not slow the speech retrieval process (Seitz, \& Grant, 1997). The ability to speechread long sentences depends on the person's working memory capacity. These cognitive skills are also related to listeners' chronological ages. Younger children do not recognize some phonological contrasts or words compared to older children (Kishon-Rabin \& Henkin, 2000). If the person's cognitive skills have not developed, the person's speechreading performance may be poorer than those who can utilize more cognitive skills.

\section{Vision and Hearing Acuity}

Older adults extracted less speech information from complex visual cues and demonstrated declined abilities to detect human faces (Dancer et al., 1994). Dancer et al. also stated that more light was required for the older adults, and there is an increased sensitivity to glare. As age increases, the ability to perceive rapidly changing visual-facial movements declines and so does speechreading (Dancer et al., 1994). Poor visual acuity (e.g., from cataracts) and inappropriate use of eyeglasses appear to hinder performance. Hearing acuity also affects speechreading performance. Generally, the greater the amount of residual hearing, the better the speechreading performance. Tye-Murray (2004) indicated that the nature of the hearing loss (i.e., conductive hearing loss and/or sensorineural hearing loss) also affects speechreading performance. Sensorineural hearing loss may cause poorer speech discrimination than 
conductive hearing loss (Tye-Murray, 2004). Speechreading performance also is influenced by a person's use of appropriate amplification (Tye-Murray, 2004). When a person speechreads, the person integrates what is heard with what is seen. The person's brain processes the sounds that were heard and combine this information with facial movements that were seen. There are several theories for auditory-visual integration.

Basic Theories for Auditory-Visual Integration in Speech Perception

Psycholinguists questioned whether people combine auditory and visual cues to understand speech. If so, why are visual cues combined with auditory cues when auditory cues are available to accurately understand speech? These psycholinguists theorized the purpose of speech perception was whether they are auditory related or articulatory related in nature (Green, 1996). Cognitive psychologists also proposed auditory and articulatory theories to explain auditory-visual integration in speech perception.

\section{Auditory Theory}

Diehl and Kluender (1989) proposed the auditory enhancement hypothesis which includes: (a) listeners primarily are sensitive to auditory cues, and (b) only humans are able to speak in different languages. In terms of speech sounds (i.e., vowels and consonants), the auditory and articulatory theorists were in agreement that speech sounds are recognized articulatorily as sets of coordinated gestures. For instance, a vowel, typically involves movements of the tongue body and tip, lips, soft palate/velum, jaw, and larynx. Some of these articulatory movements can be analyzed into articulatory components. The articulatory components tend to work with certain auditory cues across sounds indicating selected components have mutually enhancing auditory cues (Diehl \& Kluender, 1989). For example, 
tongue-body movements and lip rounding are anatomically related gestures. In terms of their articulatory components to produce sound, rounded front vowels and unrounded back vowels are less extreme than the corresponding unrounded front vowels and rounded back vowels (Diehl \& Kluender, 1989). Lip protrusion lengthens the front cavity and constriction of the labial aperture independently, contributing to a lower F2 frequency. Back vowels, therefore, are more distinct than front vowels acoustically and auditorily due to these movements. Further lowering the larynx lengthens the cavity and reduces F2 frequency. Even under normal speaking conditions, speakers apparently tend to lower the larynx for back vowels and to raise it for front vowels (Diehl \& Kluender, 1989).

Furthermore, tongue-blade elevation and lip spreading involve different articulators; however, they have common acoustic/auditory effects. Speakers can differentiate high and low vowels by changing tongue, jaw height, and vocal pitch. Thus, human speech perception closely follows acoustic changes by comparing articulatory parameters (Rosenblum, 2008). Auditory theorists claim that listeners are sensitive primarily to the auditory components of speech sounds rather than to the articulatory components. Listeners can identify the spoken message without actually detecting movements of the articulatory components or their underlying control structures.

\section{Motor Theory}

Liberman and Mattingly (1985) proposed the "motor theory" of speech perception, which tries to explain the strong influence of visual cues that affect the perception of spoken language. Motor theorists claim that the objects of speech perception are the intended articulatory movements of a speaker. The brain commands to call for movements of articulators 
through certain linguistically significant mouth movements (Liberman \& Mattingly, 1985). In other words, people see the speaker's face and compare if the sounds are produced as they would pronounce them. If what they see is similar to what listeners would do, the sound is perceived as the same articulatory gestures. Speech perception and speech production are intimately linked, and this link is innately specified (Liberman \& Mattingly, 1985). The motor theory assumes that human beings are equipped with knowledge about the vocal tract. Moore (2001) claimed that the motor theory is incomplete because it does not specify the process of translation from acoustic cues to perceived gestures. If this is not clear, the motor theory is just a philosophy rather than a theory of speech perception (Moore, 2001).

Many researchers have investigated the McGurk effect (a phenomenon that is caused by an auditory-visual incompatibility in speech perception) (Fuster-Duran, 1996; Massaro, Cohen, \& Smeele, 1995; Massaro, Tsuzaki, Cohen, Gesi, \& Heredia, 1993; Sekiyama, 1997; Sekiyama \& Tohkura, 1993). The McGurk effect will be described in a later section, as evidence for motor theory because it provides a good description of why auditory and visual cues are integrated during perception. By integrating auditory and visual cues, both cues provide information about articulatory gestures. Auditory theorists (e.g., Rosenblum, 2008) claim however, that the McGurk effect showed that experience can link visual cues onto associated human auditory abilities. The question regarding roles of human auditory abilities or articulatory movement abilities continues to be an important issue in the area of speech perception.

Psychological Evidence of Auditory, Visual, and Auditory-Visual Speech Perception

Many investigators refer to combining auditory and visual cues to understand speech as auditory-visual integration or visual enhancement (VE). A large number of psychological and 
physiological studies of audio-visual integration in speech have been conducted during the last five decades (Liberman \& Mattingly, 1985; Massaro, Tsuzaki, Cohen, Gesi, \& Heredis, 1993; Sumby \& Pollack, 1954). When speech is presented in the Auditory only (A-only) condition, a listener just hears what a speaker is saying.

\section{Auditory Speech Perception}

Many researchers examined how people perceive consonants depending on the vowel following. Shigeno (2000) discussed prior findings of Fujisaki and Kunisaki (1975) that auditory perceptions of stop consonants depend on the vowel following. Generally, consonants are produced by relatively brief, rapid articulatory movements with rapid changes in the acoustical spectrum (Shigeno, 2000). On the other hand, vowels require slower movements and a longer time duration, leading to sounds that are more static spectrally. When a stop consonant centered at $1600 \mathrm{~Hz}$ was presented followed by a vowel /i/ or /u/, listeners reported /p/, but if it followed by a vowel /a/, they reported / $\mathrm{k} /$. The acoustical analysis showed the noise spectrum of fricative consonants changed based on the vowel that followed. This vowel dependency seemed to be a consequence of lip rounding for vowels (i.e., /u/ and /o/) which contributed to this phenomenon, resulting in lowering of the fricative noise spectrum (Mann \& Repp, 1980) which people perceived as a particular consonant. Shigeno (2000) reported results of a study by Cooper (1974) that presented the voiced consonant in the syllable /da/ and the voiceless consonant in the syllable /ti/, and then tested the participant's ability to identify both /bi/-/pi/series and /ba/-/pa/ series. Cooper (1974) found that the /bi/-/pi/ series yielded a reliable category boundary shift toward a /pi/, because the voiceless /ti/ and the stimulus series shared the vowel /i/. Furthermore, the /ba/-/pa/ series shifted toward a voiced /ba/ due to the common vowel /a/ in common. 


\section{$\underline{\text { Visual Speech Perception }}$}

For many years, individuals with hearing impairment, their teachers, their parents, and those who work in noisy environments have appreciated the fact that speechreading can supplement hearing in speech perception. They found that utilizing visual cues in white noise is equivalent to improving the SNR by up to $20 \mathrm{~dB}$. MacLeod and Summerfield (1987) also found a benefit of speechreading at an average of $11 \mathrm{~dB}$. MacLeod and Summerfield (1990) also measured auditory and auditory-visual speech-reception thresholds for sentences in noise. To conduct the test, MacLeod and Summerfield (1990) presented speech lists at SNRs to estimate auditory and auditory-visual speech perception on $50 \%$ of the trials. Their results indicated that the VE for speech sentences in noise was $2.3 \mathrm{~dB}$. According to Summerfield, MacLeod, McGrath, and Brooke (1989), VE occurs when the movements of the visible articulators (the lips, teeth, and tongue) provide rapidly changing low-intensity spectral information on the midto-high frequency part of the speech spectrum.

Traditionally, researchers estimated the benefit of speechreading was the difference between the auditory and audio-visual percentage scores (AV-A). MacLeod and Summerfield (1990) criticized these studies, stating that traditional methods cannot provide a precise measure of how much benefit is obtained. One reason is that the relationship between speech understanding ability and percent correct is not linear; because percent correct scores are not interval scales of measurement. The range of percent correct is demonstrated between 0 and $100 \%$; thus, the size of the change in performance that a participant can demonstrate is limited (MacLeod \& Summerfield, 1990). Another measurement of VE has been employed by several investigators (Grant, Walden, \& Seitz, 1998; Rabinowitz, Eddington, Delhorne, \& Cueno, 1992; Sommers et al., 2005; Tye-Murray et al., 2007). These investigators measured VE relative to a 
participant's A-only performances in which a participant's A and AV performances are compared, using the following formula: $\mathrm{VE}=(\mathrm{AV}-\mathrm{A}) /(1-\mathrm{A})$. Tye-Murray et al. (2007a) suggested applying this formula rather than the simple difference score of $\mathrm{A}$ and $\mathrm{AV}$ modalities (AV-A). The (AVA)/(1-A) formula avoids the bias that higher scores of A-only leads to lower VE. Basically the differences in A-only performance are controlled by normalizing AV performance relative to the maximum possible improvement. Traditionally, it was assumed that the largest VE would be obtained during the most degraded listening conditions (Erber, 1969; Sumby \& Pollack, 1954). This is consistent with a principle of multisensory integration, "invert effectiveness," in which the combination of weaker auditory stimuli and strong visual stimuli produces the largest VE. Ross et al. (2007) examined a VE at various SNRs (-24 dB, $-20 \mathrm{~dB},-16 \mathrm{~dB},-12 \mathrm{~dB},-8 \mathrm{~dB},-4$ $\mathrm{dB}$, and $0 \mathrm{~dB}$ ) on American participants. The general result of their study was in agreement with “inverse effectiveness," indicating VE was obtained at degraded listening conditions. Their result showed, however, that the largest VE was not obtained at poorest SNR (-24 dB SNR). It was obtained at an intermediate noise level (-12dB SNR). This finding was not consistent with previous studies. Ross et al. commented that minimum levels of auditory cues are necessary with concurrent visual cues before yielding greater VE, suggesting “inverse effectiveness” did not always apply to multisensory integration.

\section{Audio-Visual Integration in Speech Perception}

The study of auditory speech perception revealed the influence of vowel environment in the perception of stop consonants (Shigeno, 2000). McGurk and MacDonald (1976) demonstrated the influence of visual cues on speech perception. They tested preschool and primary school children and adults. The participants answered what they perceived from video 
demonstration of a young female speaker saying the syllable /ba/ which had been dubbed onto lip movements for /ga/. McGurk and McDonald found that when acoustic/ba/ was presented with a face saying /ga/, participants reported /da/ (McGurk \& MacDonald, 1976). This is called "McGurk effect,” which is caused by an auditory-visual incompatibility (less auditory-visual integration). The auditory /b/ in this study was a bilabial voiced stop that was created at the lips. The visible /g/ was a velar voiced stop that was created as the back of the tongue touched the velum. The perceived /d/ was an alveolar voiced stop that was created as the tongue tip contacts the alveolar ridge. The listener perceived /d/, in part, because it had articulation characteristics that could be heard, and seen between the way /b/and /g/ were said. This "McGurk effect" occurs robustly even when participants are aware of auditory-visual incompatibility of consonants (Repp, Manuel, Liberman, \& Studdert-Kennedy, 1983).

The McGurk effect is consistent with a "motor theory of speech perception" (Liberman \& Mattingly, 1985) which theorizes that theoretically, people perceive speech sounds by an unconscious reference to how they actually produced the sounds with their tongue, lips, vocal folds, etc. The studies of McGurk effect have been replicated with different vowel contexts. For Instance, Green, Kuhl, and Meltzoff (1988) used /i/, /a/, and /u/ vowels and found the largest McGurk effect in the /i/ context and almost nonexistent in the /u/ context. Massaro et al. (1993) replicated Green's study, but they did not find significant differences among these syllables. Therefore, the vowel context on the McGurk effect is still controversial.

Some researchers motivated audio-visual integration from different perspectives, examining how conflicting visual cues influence phonetic processing of auditory cues. Green and Kuhl (1989) investigated if a change in the perceived place of articulation affected the processing of other dimensions of the auditory signal such as voice-onset-time (VOT). VOT is a major 
property of distinguishing voiced from voiceless stop consonants. VOT is the length of time between the release of the consonant and the onset of vocal fold vibration. Voiced consonants are typically produced with shorter VOT than voiceless consonants (Green \& Miller, 1985). Green and Kuhl (1989) found that the perception of voicing was affected by auditory-visual integration, indicating that visual information does not simply influence the phonetic decision made on the basis of the auditory cues.

Green and Miller (1985) also investigated whether critical rate information (speech signal rate and visual rate) affected auditory-visual integration by using the McGurk paradigm. They found that the change in visual rate information across the syllables influenced the rate judgment of integrated auditory-visual syllables and also affected their identification. Visual cues about speaking rate are important to the perception of voicing, suggesting that rate-dependent speech processing has auditory and visual components (Green \& Miller, 1985).

Inter-Lingual and Cross-Cultural Study of McGurk Effects

Studies of auditory-visual speech perception primarily have been carried out with English speakers using English syllables on McGurk paradigms. Some researchers started to investigate whether the McGurk effect can be extended to non-English cultures (e.g., FusterDuran, 1996; Massaro, Cohen, \& Smeele, 1995; Sekiyama, 1997; Massaro et al., 1993; Sekiyama \& Tohkura, 1993). Prior studies indicated that individuals with various native language backgrounds showed the McGurk effect. There have been extensive studies of Japanese speech perception with visual cues. Sekiyama and Tohkura (1991) investigated whether the McGurk effect could be extended to Japanese participants listening to Japanese syllables. They combined the auditory and visual cues for 10 Japanese syllables (/ba/, /pa/, /ma/, /wa/, /da/, /ta/, 
/na/, /ra/, /ga/, /ka/). These tasks were presented under quiet and noise conditions. Sekiyama and Tohkura found that Japanese participants obtained the weaker McGurk effect with limited to ambiguous auditory cues in quiet. Furthermore, the McGurk effect was very strong and widespread under noise condition.

Sekiyama and Tohkura (1993) also reported on inter-lingual or cultural differences in auditory-visual speech perception. The researchers tested a group of Japanese participants with 10 Japanese syllables, another group of Japanese with 10 corresponding English syllables, American listeners with Japanese syllables, and another group of American participants with ten English syllables. They found that American participants were more often visually influenced than were Japanese participants, indicating non-native syllable stimuli produced a larger visual bias. The Japanese participants utilized auditory cues to identify the sound stimuli based on auditory cues until visual cues were necessary to compensate auditory cues due to environmental noise (Sekiyama, Braida, Nishino, Hayashi, \& Tuyo, 1995). In other words, the McGurk effect was absent. The Japanese participants utilized visual cues more when they listened to a foreign speaker to capture as much information as possible from speakers to compensate for comprehension difficulty (Sekiyama \&Tohkura, 1993).

Sekiyama (1994) theorized that visual cues were processed in an early stage of auditoryvisual integration and then participants figured out its incompatibilities between visual and auditory cues. Their smaller McGurk effects (less auditory-visual integration) indicated that Japanese participants tend to separate visual cues from the auditory cues. On the other hand, the American participants' larger McGurk effects (more auditory-visual integration) indicated that American participants tend to integrate both auditory and visual cues (Sekiyama, 1994). Sekiyama (1997) found that the Japanese and Chinese participants showed weaker McGurk 
effects than American listeners, suggesting cultural/linguistic factors. Chinese participants who have lived longer in Japan evidence a stronger McGurk effect; therefore, there was a correlation between the magnitude of the McGurk effect and the length of residence in a foreign country. Hardison (2003) mentioned that Japanese use facial cues more as a result of having lived in the United States for at least 2 years due to American customs.

There are cultural and linguistic factors which may affect the manner of auditory-visual integration on Japanese who are relying on auditory cues. In terms of a cultural factor, the Japanese tend to avoid looking at the face of the speaker. This cultural habit may develop a certain type of processing which does not utilize visual cues for speech perception even when they are looking at the speaker’s face (Sekiyama \& Tohkura, 1991). In terms of a linguistic factor, there is less need to utilize visual cues compared to English; Japanese does not have consonant clusters (i.e., two continuous cluster), has only five vowels, and has no visuallydistinct consonants (e.g., /v/ or /ð/) (Sekiyama \& Tohkura, 1991). In a word list of 115,600 Japanese words, a labial followed by an alveolar or a velar only occurred three times (.003\%) (Massaro et al., 1993). Use of visual cues in speech perception depends on both combination of phonemes in a particular language and usefulness of visual cues to help understand ambiguous sounds (Massaro et al., 1993).

Guion, Flege, Akahane-Yamada, and Pruitt (2000) examined the relation between the perceived phonetic distance of second language and first language consonants and discrimination of those consonants. In their experiment, native speakers of Japanese identified English and Japanese consonant stimuli based on Japanese consonant categories. Japanese individuals did not achieve $100 \%$ on consonant identification; however, identification rates were high for most of the consonants. The Japanese participants had some difficulty identifying some English-English 
and English-Japanese contrasts, indicating that these contrasts were difficult to discriminate. Guion et al. suggested that Japanese participants used the closest first-language consonant as a reference to perceive a second-language consonant. When speech stimuli are not clear enough to identify even when people have the same phonemic category in their language, extra information is required to perceive the stimuli; visual cues are maximally utilized by American-English speakers listening to Japanese speech and vice versa (Guion et al., 2000). Therefore, there are increased reliance on visual cues in processing ambiguous auditory speech stimuli.

Werker, Frost, and McGurk (1992) examined how particular language experiences influence speech perception. They reported that speakers of Canadian French with some knowledge of English tended to report that an auditory /ba/-visual /ð/ as either a /da/ or /ta/, unlike native English speakers. The French speakers who do not have a phoneme /ð/ in their language assimilated the visible interdental to the closest phonemic place of articulation, thus reporting an alveolar/dental sound. The rate of /ða/ identifications, however, increased as a function of English language experience, suggesting some influence of English phonology on auditory-visual speech perception (Werker et al., 1992). Burnham (1998) commented that this influence could be perceptual, meaning French participants may perceive /ð/ based on the perceptual bias through their language experience. French participants may perceive /ð/ just as often as native English speakers do but could have a response bias against reporting /ð/ as /th/ due to their language experience (Burnham, 1998). Burnham (1998) examined the effect of phonology on auditory-visual speech perception using one of the McGurk paradigms in which auditory $/ \mathrm{m} /$ paired with visual $/ \mathfrak{y} /$ were presented either in syllable-initial or syllable-final position for Thai and English participants under AV, V, and mismatch auditory [/m/] visual [/p/] modalities. Thai language contains the phoneme $/ \mathfrak{y} /$ in both word-initial and word-final positions, 
but English does not contain the phoneme /y/ in word-initial position. Thus, Burnham (1998) hypothesized that English participants would respond more with $/ \mathrm{n} /$ in the initial position than in the final position due to visual ambiguity of $/ \mathrm{y} /($ visual $/ \mathrm{y} /$ looks like visual $/ \mathrm{n} /$ ) and their language experience (Burnham, 1998). The investigator found that English participants tend to perceive as $/ \mathrm{n} /$ when $/ \mathfrak{n} /$ in the initial position was presented under AV and $\mathrm{V}$ modalities. The $/ \mathrm{n} /$ response was higher when the $/ \mathrm{y} /$ was presented in final position under mismatch auditory [/m/] visual $[/ \mathrm{y} /]$ modality. When the $/ \mathrm{y} /$ in the initial position was presented under AV and $\mathrm{V}$ modalities, Thai participants tended to perceive $[/ \mathfrak{y} /]$ as $/ \mathrm{n} /$ less than English participants. The $/ \mathbf{n} /$ response was higher, however, when the $/ \mathfrak{y} /$ was presented in final position under mismatch auditory [/m/] visual [/y/] modality. Burnham (1998) stated that even mean $/ \mathrm{n} /$ response (\%) of English participants was higher than Thai participants', there was no significant difference between English and Thai participants and both participants groups on initial and final position. The investigator concluded that there was no effect of phonological bias on the McGurk effect, suggesting the perceived /n/ was not influenced by word position or native language. If auditoryvisual speech perception follows phonetic system, then phonetic manipulations should affect speech perception.

Green (1996) demonstrated the perception of "d" and "th" when mismatch auditory [/b/] visual [/g/] was paired with vowel moved from /a/ to /i/. 85\% of English participants perceived auditory [/ba/] visual [/ga/] as "tha” and15\% of them perceived as /da/. $40 \%$ of English participants perceived auditory [/bi/] visual [/gi/] as "thi" and $60 \%$ of them perceived as “di.” From these findings, Green (1996) concluded that the McGurk effect occurs phonetically (i.e., vowel context) not phonologically (listener's language). The cross-language studies revealed that this auditory-visual integration occurs at an earlier phonetic level of 
processing and that integration is affected by phonetic factors (Green, 1996).

There is a consideration in the previous cross-cultural and interlingual studies of McGurk effect. Sekiyama (1997) noted that the native-foreign language effect was often found in cross-language studies on the McGurk effect. These results, however, also indicated that the magnitude of the visual effect was influenced not only by the native-foreign language factor, but also by the quality of each speaker's speech in the studies. Both factors also may be responsible for auditory ambiguity. In terms of the quality of each speaker's speech, the researchers used two different speakers to produce the different language stimuli in most of their studies. For instance, the studies of Sekiyama (1997) and Sekiyama and Tohkura (1993) used Japanese and AmericanEnglish speakers to produce the speech stimuli. Each speaker has a different voice quality. The variation in the speech sample quality that can be attributed to anatomy (i.e., formant, and formant transitions) was not controlled by using two different speakers. The articulators (i.e., tongue, jaw, and lips) change the vocal resonances to form specific vowel sounds. The vocal formant (the peaks in the vowel spectra) arises from vocal resonance. Because of the resonant origin, formants tend to stay essentially the same when the fundamental frequency is changed. Formants in speech sound are particularly important because formants are essential components in the intelligibility of speech (Gelfand, 2004). The "normal” ear is able to clearly distinguish formant differences. Each individual has different formant frequencies due to individual articulator differences. Therefore, if the researchers use a single speaker in their study, voice quality variations can be controlled. The researchers could eliminate one confounding variable that can influence the results of inter-lingual and cross-cultural studies of McGurk effect. 
Speechreading and Second-Language Speakers of English

Detecting visible articulatory cues is an important part of speech perception. Visual cues help people understand ambiguous auditory cues which are difficult to hear often but are relatively easy to see (Rosenblum \& Saldaña, 1996). Visible cues are often quite informative about place of articulation but do not provide much information about manner. Only about 30 to $40 \%$ of all speech sounds in MAE, however, are visible on a speaker's face. Auditory cues, for manner of articulation are relatively stable in noisy environments; however, information for place of articulation is considerably more vulnerable. The benefit of visual cues has been examined for (a) individuals with hearing impairment (Erber, 1972), (b) individuals with “normal” hearing (Sumby \& Pollack,1954), (c) people listening to heavy foreign-accented speech (Reisberg, McLean \& Goldfield,1987), (d) children developing language (Kuhl \& Meltzoff, 1984), and (e) individuals acquiring a second-language (Hardison, 2003). Many investigators conducted the studies of speechreading on first-language speakers of English (e.g., Liberman \& Mattingly, 1985; Massarro et al., 1993; Sumby \& Pollack, 1954). Recently, some investigators have started to pay more attention to effects of speechreading on second-language speakers of English. Inter-lingual and cross-cultural studies have been conducted extensively by using McGurk paradigms (e.g., Sekiyama, 1997; Sekiyama \& Tohkura, 1993). The vast majority of research on speech understanding across languages has been conducted when speech is presented under A modality, rather than under AV modality in which a listener both hears and sees what a speaker is saying or V modality in which a listener sees only what a speaker is saying. Usually, second-language speakers of English show similar speech understanding ability under A modality (quiet condition) as first-language speakers have. Difficulties of secondlanguage speakers of English, however, are revealed when background noise is introduced. 


\section{$\underline{\text { Factors Affecting Second-language Speech Perception }}$}

Second-language speech perception is a complex process that involves many other factors in addition to the influence of a learner's first-language experience. It is commonly discussed that the age of second-language learning experience contributes to second-language speech perception.

\section{Age of Second-Language Acquisition}

It is generally believed that there is a critical period to learn the first-language. Yet, there has been a long debate among professionals as to whether a critical period exists in secondlanguage acquisition or not. There are some people who believe people can learn a secondlanguage at any point in their life, and there are others who purport that becoming proficient in a language is dependent on learning it at a young age. Lenneberg (1967) originally proposed the Critical Age Hypothesis (CAH) which stated foreign accent cannot be overcome easily after puberty. In addition, length of residence does not influence second-language pronunciation of people who began learning second-language as an adult. Over the past four decades, however, many researchers have discussed the $\mathrm{CAH}$, but have not yet reached complete agreement. In terms of accent of speech, the effect of age of arrival in the second-language environment and the effect of age of learning on the level of success in pronunciation have been investigated. There is, however, no agreement on the exact age of learning a second-language that a speaker's accent will not be detected (Flege, 1988).

Although investigators do not agree on whether there is a critical age in secondlanguage speech learning, they tend to agree that “ younger equals better.” Lenneberg (1967) stated that children learn language between 2 or 3 years of age due to interaction of maturation 
and their innate ability to learn. According to Lenneberg, people who are between the ages of 3 years and early teens appear to learn a second-language more easily and to preserve some innate flexibility of brain functions to smoothly integrate the complex speech and language. After puberty, this flexibility is reduced and the brain acts as if it has become set in its ways (Lenneberg, 1967). Therefore, if the CAH is true, it is assumed that people who are past this critical period are less successful with second-language acquisition.

Extensive studies of infant speech perception reported that dramatic changes occur toward the end of the first year (Conboy, Rivera-Gaxiola, Klarman, Aksoylu, \& Kuhl, 2007; Kuhl, Tsao, \& Liu, 2003; Mayo, Florentine, \& Buss, 1997). Kuhl et al. (2003) found that early in life, infants are capable of discriminating the differences among the phonetic units of all languages. According to Kuhl et al., between 6 and 12 months of age, the ability to discriminate foreign-language phonetic units declines sharply, suggesting that this is directly related to firstlanguage learning. Their brains are set to the acoustic properties of their native language by being exposed to their first-language. The set brain interferes with second-language processing and causes difficulty in second-language speech perception in adulthood (Kuhl et al., 2003). Therefore, infants are better than adults at acquiring second-language pronunciations due to incomplete brain setting and the language learning process.

Mayo et al. (1997) investigated how age of language acquisition influences perception of second-language speech in noise. They conducted a study on native Mexican-Spanish speaking listeners who learned English before age 6 years or after age 14 and monolingual American-English speakers. Mayo et al. (1997) found that second-language listeners who learned English after age 14 performed more poorly in noise than those who learned before age 6 , even though they performed at a very high level in the quiet condition. The results also 
indicated that people who learned English before age 6 take better advantage of context. Early English learners showed better speech discrimination performance in noise than the later English learners, even though their function was not the same as monolingual listeners. They suggested that early acquisition of second-language can take better advantage of understanding speech in noise (Mayo et al.).

\section{Second-Language Learning Experience}

Flege and Liu (2001) conducted a study to determine if Chinese adults living in the United States would resemble first-language speakers of English more closely as their length of residence in the United States increased. The hypothesis in this study was that performance of adult second-language would improve over time, but only if they received the rich secondlanguage input as typical children who immigrate to North America. The participants were divided into one of four groups based on length of residence in the United States and primary occupation (students vs. non-students). Flege and Liu (2001) found that the students who had lived longer scored the highest in the Chinese group. The scores, however, were lower than scores of first-language speakers of English. Effects of length of residence for non-students were not significant. Flege concluded that to become successful second-language learner, rich secondlanguage input is important.

There are few studies examining the relationship between length of residence and speech perception in noise. Stevens (2006) discussed a study by Johnson and Newport in 1989, which considered length of residence in their analysis. They conducted a correlation analysis between length of residence in the United States and test performance score and also between length of residence and age at immigration to the United States. They found low correlations 
between length of residence and test scores, and age at immigration. They concluded that the length of residence was not related to speech perception in noise. Mayo et al. (1997) also investigated how age of acquisition influences perception of second-language speech by using a speech-in-noise (SPIN) test. They found that monolinguals and early bilinguals received higher scores than later bilinguals even though late bilinguals are exposed to second-language longer than early bilinguals. Length of language exposure was less important than age of secondlanguage acquisition (Mayo et al., 1997).

Taken together, it seems that the age of second-language acquisition does influence second-language speech in noise. In terms of the relationship between length of language exposure and speech perception in noise, age of the second-language acquisition is more important than length of second-language exposure.

\section{Necessity of Language Questionnaire}

Baker (1993) defined "bilingualism" as anyone who knows two languages. Some defined bilingualism as persons who are equally fluent in both languages, known as "balanced bilinguals” or “ambilinguals” (von Hapsburg \& Peña, 2002). Balanced bilinguals, however, are rarely found because bilinguals do not usually maintain equal competency in all language skill areas in both languages (Fishman, 1971). Grosjean (1998) stated that many finings relating to bilingualism need to be carefully interpreted. Grosjean suggested that investigators need to obtain language profiles such as the nature of bilingualism (elective or circumstantial bilinguals) and participant-related factors (language status, language history, language stability, language competency, and language demands) which potentially affect research outcomes. Elective bilinguals are individuals who choose to become bilingual and who acquire a second language 
through coursework or study-abroad programs (von Hapsburg \& Peña, 2002). Circumstantial bilinguals are individuals who must learn a second-language out of necessity. Previous studies reported that bilinguals process language differently from monolinguals in background noise (Mayo et al., 1997). A perception of bilinguals in each language may vary depending on how much time is spent using specific language or when the second-language was learned (von Hapsburg \& Peña, 2002). Thus, detailed descriptions of bilinguals (a linguistic profile) should be obtained, when conducting any studies related to bilinguals. Grosjean (1997) also suggested that creating a linguistic profile makes it possible to compare research results or interpret results within and across studies.

There are five main areas suggested by Grosjean in 1997: (1) language status (i.e., whether participants are monolingual or bilingual), (2) language history (i.e., age of secondlanguage learning, order of first-language and second-language acquisition, and how the secondlanguage was acquired), (3) language stability (i.e., whether a participant is in the process of acquiring or losing a language or language skill or whether a participant has reached a maintenance level in acquisition), (4) language competency (i.e., language performance such as reading, writing, speaking, and listening), and (5) demand for language use (i.e., how the two languages are used and language mode such as monolingual situations vs. bilingual situations). Language experience can affect the homogeneity of a population being studied. Furthermore, performance on various speech perception studies may vary from individual to individual depending on language background. Therefore, a linguistic profile needs to be obtained, and also data should be interpreted with caution. 
Measurement of Speechreading

Previous researchers have evaluated speech understanding or intelligibility by using the identification of phonemes (Culter, Weber, Smits, \& Cooper, 2004), nonsense syllables (Arsenault \& Punch, 1999), isolated words or sentences (Schiavetti, Sitler, Metz, \& Houde, 1984). No published study, however, has assessed the effects of speechreading on secondlanguage speakers of English at the sentence level. The Central Institute of Deaf (CID) Everyday Speech Sentences (ESS) test has been used to evaluate a benefit of speechreading for individuals with impaired hearing and normal hearing. Previous researchers in the areas of speechreading, however, screened for vision and hearing prior to speechreading test to control for influences of reduced visual acuity, contrast sensitivity, and hearing sensitivity. Thus, vision and auditory screening tests will be discussed first in this section.

\section{$\underline{\text { Vision and Auditory Screening Tests }}$}

\section{$\underline{\text { Distance Vision Acuity Test }}$}

A Dutch eye doctor, Herman Snellen created the Snellen eye chart in 1862, and this chart has been widely accepted to measure visual acuity (Watt, 2007). A typical Snellen eye chart for adults consists of rows of random alphabetical letters. The top row has the largest and fewest letters. Subsequent rows have increasing numbers of letters that decrease in size. The smallest row that can be read accurately indicates the participant’s visual acuity. The Snellen fractions, 20/20, 20/30, etc are measures of visual acuity. For instance, 20/20 indicates that a human being with normal vision can see when standing 20 feet away from an eye chart (International Council of Ophthalmology, 2007). The 20/40 standard and the 20/40 with corrected vision are the criteria most widely used for driver's license eye test in the United States (International Council of 
Ophthalmology). The 20/40 implies that individuals can read 20/40 on a well-lighted chart. They are generally assumed to still be safe drivers in a moving environment and under adverse conditions such as driving after dark and/or driving in rain or fog. In their speechreading study, Sommers et al. (2005) and Tye-Murray et al. (2007a) used a Snellen eye chart to assess normal or corrected visual acuity. Both groups of researchers excluded participants whose visual acuity was poorer than 20/40 binocularly.

\section{Contrast Sensitivity Test}

The Pelli-Robson contrast sensitivity test has been accepted as quick and reliable in clinical practice and used to describe visual performance (Pelli, Robson, \& Wilkins, 1988). The Pelli-Robson chart is sensitive enough to show a significant change in score with age (Elliott, Sanderson, \& Conkey, 1990). Denis Pelli and John Robson developed the Pelli-Robson contrast sensitivity chart in the 1980s. This chart measures contrast sensitivity using a single large letter size (20/60 optotype), with contrast varying across groups of letters. The Pelli-Robson contrast letter chart consists of 16 groups of three letters ("triplets"). Participants usually read this chart at one meter from the chart. The letter size is fixed, and the contrast is varied. As the participant reads down the chart, the letters reduce in contrast. The last triplet with at least two correct letters is scored. Each correct letter is scored as .05 units (Elliot et al., 1990). Poor contrast sensitivity adversely affects reading ability (e.g., reading a newspaper). Usually, a contrast sensitivity of 1.0 or better is required to read high-contrast print at a normal speed (Woods \& Woods, 1995). Most people with contrast sensitivity of 1.0 or less may read text slowly and may have a difficulty with their walking speed. A person with contrast sensitivity less than 1.3 may have difficulty in identifying the faces of individuals from a distance and have an increased incidence of automobile accidents (Woods \& Woods, 1995). At one meter, the average Pelli-Robson score 
would reduce from about $1.90-1.85$ at age 20 to 30 years to about $1.80-1.75$ at age 70 years (Woods \& Wood). Elliot et al. (1990) also stated that most people under 50 years of age would score 1.80 or above on the Pelli-Robson chart.

\section{Hearing Screening Test}

A pure tone hearing test is given to find the faintest tones a person can hear at selected frequencies from low to high. During this test, headphones are worn, and the sound travels through the air in the ear canal to stimulate the tympanic membrane and then the auditory nerve. The participant taking the test is instructed to give some type of response (i.e., raising a finger or hand, pressing a response button, or saying "yes") to indicate that the sound was heard [American Speech-Language-Hearing Association (ASHA), 1997]. Pure tone screening, however, may not identify individuals with middle ear disorders unless the hearing loss is 20 to $25 \mathrm{~dB}$ HL or greater (ASHA, 1997). ASHA recommends a screening level of $25 \mathrm{~dB}$ HL from 1000 through $4000 \mathrm{~Hz}$ for adult hearing screenings. American National Standards Institute (ANSI) (1989), however, takes more stringent criteria, a screening level of $20 \mathrm{~dB}$ HL from 250 to $4000 \mathrm{~Hz}$ for adult. Tye-Murray et al. (2007a) screened at level of $20 \mathrm{~dB}$ HL in their speechreading study for 250 to $4000 \mathrm{~Hz}$ and excluded participants with asymmetric hearing loss greater than $10 \mathrm{~dB}$ HL. Individuals who has with asymmetric hearing loss greater than $10-\mathrm{dB}$ threshold difference between the two ears may have difficulties in localizing sound and understanding speech in presence of background noise (Sargent, Herrmann, Hollenbeak, \& Bankaitis, 2002) due to the lack of the head shadow effect (attenuation of sound by the head), the squelch effect (improvement in speech intelligibility in noise due to interaural phase and intensity difference), and binaural summation (cumulative effect of sound reaching both ears) to improve speech perception in noise. 
Central Institute for the Deaf (CID) Everyday Speech Sentence (ESS) Test

Various tests have been developed that use sentences as test items to evaluate ability to hear and understand everyday speech. The Armed Forces-National Research Council Committee on Hearing and Bio-Acoustic (CHABA) developed guidelines for sentence tests (Appendix L) in the mid-1950's to represent everyday speech (Hinkle, 1979). Especially, they focused on a particular portion in sentence lists (i.e., declarative, imperative, and interrogative sentences) and length within the sentence lists. Any list of sentences that follows this guideline was considered to be valid in terms of representing everyday speech (Hinkle, 1979).

An ESS test has been used to evaluate speechreading to determine how well persons perform in various listening conditions (Sims, 1975; Watson, Qiu, Chamberlain, \& Liu, 1996). Cienkowski and Speaks (2000) indicated that the advantage of identifying phonemes, nonsense syllables, isolated words, or sentences is that the investigators can control the signal characteristics easily. Investigators also can express the performance as the percentage of the correct test items as a function of signal intensity or SNR. Some researchers objected, however, that these measurements might not reflect the level of understanding of ordinary everyday communication accurately (Bilger, Nuetzel, Rabinowitz, \& Rzeczkowski, 1984; Speakes, Parker, Harris, \& Kuhl, 1972). Speech contains a rich context, therefore, speech intelligibility may not be measured by identifying phonemes, nonsense syllables, isolated words or sentences. When the persons listen to a speaker, they not only perceive auditory cues, but also use contextual cues from speech. When auditory cues are ambiguous to identify particular words and sentences due to a degraded listening environment, contextual cues such as lexical, semantic, and syntactic may help listeners understand speech. 
The ESS test (Silverman \& Hirsh, 1955) is the first sentence test developed at the CID. Silverman and Hirsh applied the CHABA criteria to generate the ESS. Hood and Dixon (1969) rearranged the original ESS lists to make sentence length and surface structure be more consistent with the CHABA criteria (Hinkle, 1979). The sentences provide information about the time domain of everyday speech, and listeners can use contextual cues of conversational speech. The words used in the test are well-known words, frequently used in English language (Davis \& Silverman, 1978). The vocabulary is appropriate for adults, and contextual redundancy is high. The words appear with high frequency in one or more of the well-known word counts of the English language, and the grammatical structures vary (Davis \& Silverman, 1978). The ESS test contains 10 lists, 10 sentences per list, and 50 key words per list. Many investigators have revised the ESS to produce scores that fall within an equivalency range for that particular usage (Rippy, Dancer, \& Pittenger, 1983). Harris, Haines, Kelsey, and Clark (1961) made sentence length more consistent by revising the ESS, resulting in reduced response variability. The researchers used sentences containing from six to nine words in length. These lists are known as the Revised CID Sentence Lists (R-CID). Rippy et al. (1983) conducted a study to determine whether the R-CID Sentence Lists have the equivalent sentence lists at three SNRs (0 dB, $-3 \mathrm{~dB}$, and $-6 \mathrm{~dB}$ ). They found that R-CID lists were not equivalent at any level on the basis of + or -10 \% standard error of measurement (95\% confidence interval). They concluded that R-CID ESS should not be used for intra-individual comparisons. This was consistent with a previous study (Giolas \& Duffy, 1973). Rippy et al. (1983) indicated that the formation of equivalent sentence lists is a critical factor to be accepted for routine clinical use.

Davis and Silverman (1978) published the original version of ESS to represent “Everyday American Speech.” These sentences also followed CHABA criteria. Davis and 
Silverman (1978) made up of 10 sets of 10 sentences each with 50 "targets.” They designed this test to measure discrimination of running speech. In 1972, the National Technical Institute for the Deaf (NTID) chose to employ these test materials for a communication profile system (Sims, 1975). Sims (1975) examined the ESS test of auditory speech discrimination to validate inter-list consistency within each list and the differences in mean scores between CID W-22 list, PB-K list, and the Pickett Rhyme test list. The ESS test of auditory speech discrimination provided concurrent validation of the CID W-22 list, PB-K list, and the Pickett Rhyme test list (Sims, 1975). Barley (1971) examined the ESS test under V modality in which participants only saw the speaker. The researcher found that the two lists which they evaluated (each used a different set of sentence lists) were equivalent. Because the ESS lists have been validated, this test has been used in over 50 studies (Healy \& Montgomery, 2006). In 1985 the NTID recorded the ESS on a Laserdisc and transferred it to DVD in 2007. Specifically, a female adult talker of MAE spoke each of the 100 different ESS, which were divided 10 lists of 10 sentences. She was filmed with her head and torso contrasted against a light blue background. The DVD included a two-sentence practice set, an auditory-only reading of the Rainbow Passage to set volume to comfort levels, the particular test lists 1 to 10 , and the individual 10 sentences within a list. They also created a manual booklet along with the DVD. The booklet included: (a) test purpose, (b) instructions (score calculation, rules for scoring, and list equivalency correction), and (c) ten lists of ESS and 10 equivalency correction lists. The NTID obtained interlist equivalency data for speechreading under V modality in which listeners just see what a speaker saying. They reported that the study was done around 1985 with NTID students using the same speaker on another recorded version of the test, however, the number of participants were unknown. The data, therefore, were only a rough estimate of interlist equivalency (Sims \& Bick, 2008). 
Demorest and Bernstem (1992) estimated variability in speechreading sentences explained by three sources of variability (the participant, the talker, and the sentence materials) by using generalizability theory. They found that the sentences were a major source of variability and that interactions of participants and sentences were even greater. Demorest and Bernstem suggested that if the test has a sufficient number of items, variability can be controlled. Demorest and Bernstem (1992) also found that generalizability is greater when all participants are tested in the same manner. Variations in test administration (e.g., different talkers for different participants or different test lists for different participants), increase score variability, leading to lower generalizability. Speaker effects were greater than list effects in their study, suggesting different speakers lower generalizability more than different lists (Demorest \& Bernstem, 1992).

\section{Administration of Speechreading Test}

\section{$\underline{\text { Stimulus Presentation Modes }}$}

Three modes of stimulus presentation have been used to assess speech perception for sentences: (1) A, (2) V, and (3) AV modalities. Previous researchers used these three stimulus presentation modes to assess hearing ability, speechreading ability, and the integration of auditory and visual cues (Cienkowski \& Speaks, 2000; Dent, Simmons, White, \& Roberts, 1987; Schiavetti, Metz, \& Sitler, 1981; Sommers et al., 2005; Tye-Murray et al., 2007a). Although it is impossible to compare each study because each study used different sentences, stimulus environments, presentation levels, and presentation modes, it is possible to discuss the presentation modalities used in their studies.

Some investigators presented speech stimuli under A modality. For instance, Cienkowski and Speaks (2000) examined the relationship between rated intelligibility and correct key word repetitions of sentences in listeners with normal hearing and listeners with hearing loss. The 
researchers employed the Revised Speech Intelligibility Rating test and the ESS test for this study. Cienkowski and Speaks presented the speech stimuli under A-only modality at five SNRs. Schiavetti et al. also (1981) conducted a study of construct validity of direct magnitude estimation and interval scaling of speech intelligibility in listeners with hearing loss. The researchers presented the ESS at $70 \mathrm{~dB}$ SPL in A modality. Sommers et al. (2005) examined the effects of age on the ability to benefit from combining auditory and visual cues relative to A modality or AV modality alone. They presented the sentence lists counterbalanced across participants in the A, V, and AV modalities. Tye-Murray et al. (2007a) investigated the effects of age-related hearing loss on the ability of speechreading and the auditory-visual integration responses. The researchers presented consonants, words, and sentences under the A, V, and AV modalities with six-talker babble. Noise is commonly used to simulate degraded listening environments; however, a distracting signal has not been used very often during V modality.

\section{$\underline{\text { Intensity Levels of Stimulus Presentation }}$}

Many researchers (Hinkle, 1979; Sims, 1975; Sommers et al., 2005, Tye-Murray et al., 2007a) have used different intensity levels in their speechreading studies. Sims (1975) used a most comfortable level (MCL) to validate the ESS test on individuals with severe hearing loss. Hinkle (1979) criticized this procedure saying it ignored the fact that participants cannot readily adjust the intensity level of conversational speech. Hinkle questioned the content validity of measurements using MCL. A study by Sommers et al. (2005) described in the previous section, applied a fixed signal level of $60 \mathrm{~dB}$ SPL in their study. Giolas and Duffy (1973) employed a fixed signal level of $72 \mathrm{~dB}$ SPL in the study of equivalency of ESS. Rippy, Dancer, and Pittenger (1983) employed a 65 dB SPL to determine list equivalency of R-CID ESS. Of these presentation 
levels, the one that most closely reflects everyday speech communication appeared to be the intensity level of conversational speech.

\section{Noise Levels and Types of Masker}

Effects of noise level have been examined on individuals with normal hearing as an acceptable noise level (ANL). Franklin, Thelin, Năbělek, and Burchfield (2006) defined that the ANL as the speech stimulus intensity level selected by a person at as the most comfortable level (MCL) minus the maximum background noise level (BNL) that a person is willing to accept while listening to speech. Originally, ANL was developed for listeners with hearing impairment to measure hearing aid use. It has been found, however, that ANL does not depend on their degree of hearing loss (Năbělek, Tampas, \& Burchfield, 2004) or age or gender (Rogers, Harkrider, Burchfield, \& Năbělek, 2003). The understanding of speech in noise and ANL have been studied by using the speech in noise (SPIN) test on individuals with hearing loss (Franklin, Thelin, Năbělek, \& Burchfield, 2006). Năbělek et al. (2004) tested the reliability of individuals' ANL with the reliability of SPIN scores. They found that there was no significant relationship between word recognition and ANL when speech was presented at $8 \mathrm{~dB}$ SNR. They suggested that speech understanding in noise may not be as important as is the willingness to listen in the presence of noise. Yet, there is evidence to indicate how speech understanding depends on SNRs. Basically, the SNR was increased when speech was presented at or near MCL, resulting in word recognition ability improvement. A number of studies indicated that maximum word recognition was obtained at a SNR of +10 to +15 dB (Bentler, 2000; Studebaker, Shebecoe, McDaniel, \& Gwaltney, 1999). 
The ANL has been examined in languages other than English. Results indicated that second-language speakers of English had difficulty understanding speech in noise (Buss, Florentine, Scharf, \& Canevert, 1986; Florentine, 1985; Takata \& Năbělek, 1990). Florentine (1985) studied second-language English speakers’ perception of American-English in noise. The results indicated that second-language speakers of English have more difficulty understanding speech in noise than native listeners, even though they speak proficient English. Van Wijngaarden, Steeneken, and Houtgast (2002) measured speech intelligibility in noise for Dutch participants who spoke German and English as second languages. The researchers found that participants required a 1 to $7 \mathrm{~dB}$ better SNR than did first-language speakers of English to obtain $50 \%$ sentence intelligibility. Buus et al. (1986) reported that second-language speakers of English performed 50\% correct scores at less SNRs with increased years of exposure to English. For most proficient listeners, the noise level was $3 \mathrm{~dB}$ lower than for first-language speakers of English (Buus et al., 1986).

Crandell and Smaldino (1996) reported that greater knowledge was required with decreased SNR environment. Therefore, children who speak English as a second language would be expected to result in reduced speech perception in noisy environments due to the incomplete or immature linguistic knowledge, indicating the larger SNRs were required. Takata and Năbělek (1990) found, however, that Japanese listeners would be more influenced by the adverse conditions than American listeners. The investigators suggested that individuals who came to United States in their later lives might show more reduced perceptual abilities than children, although the listeners in their study came to the United States at relatively young ages. In the study of speechreading on younger and older adults with normal hearing, Sommers et al., (2005) investigated the SNRs to produce similar performance in the A modality 
across groups and not to produce ceiling level scores in the AV modality. The researchers measured SNRs for each participant to obtain approximately 50\% correct words in sentences under the A modality. Then VE was measured under conditions in which A performance was approximately 50\%. Tye-Murray et al. (2007a) adopted this procedure in their study of speechreading for older adults with normal and impaired hearing. The researchers commented that this procedure is useful to measure relative VE at a level of approximately 50\% correct under A modality. Yet, the limitation of this procedure was that Tye-Murray et al. (2007a) did not test the participants under everyday listening conditions. Thus, the researchers commented that the results could not be generalized to other listening environments (Tye-Murray et al., 2007a).

Listening to speech in competing speech is a complex perceptual task that has been studied over the years. In general, speech maskers are less effective than noise maskers (Freyman, Balakrishnan, \& Helfer, 2004). One of the characteristics of competing speech is its fluctuation over time, compared to a continuous masker. Therefore, a continuous masker is more effective than a competing speech masker (Freyman et al.). The competing speech contains brief pauses at phrase and sentence boundaries, closures during stops, and very weak consonants, such as /f/ and / $\theta /$. In addition, the spectrum of the competing speech fluctuates freely from the spectrum of the target speech (Freyman et al.). Therefore, the listener perceives these spectral and amplitude fluctuations when the SNR is favorable, indicating listeners can easily detect target speech. Freyman et al. provided an example that a high frequency /s/ sound in competing speech may present simultaneously with a lower frequency vowel sound in target speech. There, however, are conditions that competing speech produces additional masking effects beyond those existing for noise maskers known as "the informational masking." 
Simpson and Cooke (2005) discussed a study of Miller’s classic study of masking (Miller, 1947). Miller, who was the first to investigate intermediate values of a number of talkers, investigated the intelligibility of words in listening conditions with one, two, four, six, and eight talkers. The difference in masking effect for a single talker, comparing to two talkers was equivalent to a speech reception threshold (SRT) difference of about $8 \mathrm{~dB}$ (Miller, 1947). Babble with four, six, and eight talkers produced an additional 3dB to $4 \mathrm{~dB}$ of masking, comparing to the two-talker condition. Miller concluded that as the number of talkers increase, speech intelligibility decreases. Festen and Plomp (1990) found the SRT for sentences in modulated noise was $4 \mathrm{~dB}$ to $6 \mathrm{~dB}$ lower than for steady-state noise; for sentences masked by a competing voice, this difference was $6 \mathrm{~dB}$ to8 $\mathrm{dB}$.

Simpson and Cooke (2005) measured for vowel-consonant-vowel tokens gated with number of talker babble noise and babble-modulated noise for an extensive range of numbers, at a fixed SNR. In the natural babble condition (six- to 128- talker babble), identification rates were not declined as the number of talkers increased. The investigators concluded that there was no simple relationship between identification rates and number of talkers; however, identification rates in babble-modulated noise declined with number of talkers. The difference between natural babble and babble-modulated noise also varied with number, reaching a maximum at eighttalkers. Simpson and Cooke (2005) found that when there were more than two-talkers in noise, lower speech intelligibility scores were obtained in natural babble compared to babblemodulated noise. This result is consistent with Sperry's study in 1997. The difference between the effects of natural babble and babble-modulated noise suggests that linguistic interference plays a role in the effects of natural multi-talker babble on identifying speech. Carhart, Johnson, and Goodman (1975) examined masked threshold for spondees under steady-state speech 
spectrum noise, speech spectrum noise modulated by seven talker combinations. The results showed averaged masked threshold $6.2 \mathrm{~dB}$ with one talker and $7.2 \mathrm{~dB}$ with two-talkers. The maximum (9.8 dB) was reached with three talkers; however, after three talkers, it decreased and plateaued at about $3 \mathrm{~dB}$ with 64 talkers.

Freyman et al. (2004) investigated the influence of informational masking and release from informational masking in speech perception. They used nonsense sentences spoken by a female talker as target stimuli. The masker was a mixture of three, four, six, or ten female talkers. The investigators found that information masking grew (increased demand on central processing in the auditory system) as the number of masking talkers was increased from one to two, yet information masking decreased (less demand upon the central processing in the auditory system) as the number of maskers was increased further. This is consistent with Carhart's previous study. In terms of the releasing from informational masking, Freyman et al. (2004) measured listeners' speech recognition performance with both target and masker presented from a front loudspeaker or with a masker presented from two loudspeakers with the right leading the front by $4 \mathrm{~ms}$. In the latter condition, listeners seem to hear target and maskers from different locations. Freyman et al. (2004) obtained improved recognition performance for one- and two-talker maskers but not for noise. As the number of masking talkers increased to 10, improvement in the latter condition diminished but did not disappear. They suggested that informational masking could be overcome by improving listeners' auditory function toward the target speech. Freyman et al. concluded that there were sufficient speech cues in the target plus two-talker waveform, suggesting some level of separation of the target, even in the nonspatial condition. The researcher also noted that even though speech cues are available, three-mixed utterances are difficult to sort out in the short attention time with the target talker. As the number of masker talkers increases, the similarity of 
the masker and target speech increases, causing a difficulty sorting out masker and target speech.

Second-language speech perception has been studied extensively from the aspect of production as well as perception. Lately second-language speech perception in noise has gained more attention (Buus et al., 1986; Cooke, Garcia Lecumberri, \& Barker, in press; Florentine, 1985; Takata \& Năbělek, 1990). Studies of speech perception in various types of background noise have shown that noise with linguistic content affects listeners differently than nonlinguistic noise (e.g., Festen, \& Plomp, 1990; Freyman et al., 2004; Carhart, Johnson, \& Goodman, 1975). Few studies of multi-talker babble, however, have employed background babble in languages other than the target speech language. The linguistic factors influence the effects of multi-talker noise (Simpson \& Cooke, 2005; Sperry, Wiley, \& Chial, 1997). In these experiments, the language spoken in the babble has typically matched the language spoken in the target. Van Engen and Bradlow (2007) noted that the precise linguistic features (phonemes, words, and prosodic characteristics) are most responsible for the greater masking effects of speech noise than non-speech noise. Recently, Garcia Lecumberri and Cooke (2006) investigated English and Spanish listeners' perceptions of English with various masker types (speech shaped noise, 8talker babble, and competing English and Spanish speech). The results indicated that Spanish participants performed more poorly in quiet than English participants, and that relatively larger differences were found in the masking conditions. They found that both groups performed well in the competing speech condition but not in the babble noise condition. Garcia Lecumberri and Cooke (2006) concluded that second-language speakers of English are more adversely affected than first-language speakers of English by both competing masking and informational masking. First-language speakers of English (i.e., native English speakers) performed slightly better in Spanish noise than in English noise. 
Van Engen and Bradlow (2007) investigated English sentence perception in the presence of multi-talker babble with varying numbers of talkers in the babble, varying SNRs, and varying languages in the background noise. There was a range of noise characteristics (some SNRs and types of noise). The linguistic content of the noise influenced the recognition of target speech (Van Engen, \& Bradlow, 2007). Van Engen and Bradlow (2007) also expanded their findings by using two noise languages (English and Mandarin Chinese) for first-language speakers of English from the previous studies. The results indicated that native English listeners performed poorer English sentence recognition in six-talker babble than in two-talker babble, regardless of the language of the babble. They also found that first-language speakers of English were more adversely influenced by English babble in two-talker babble than by Mandarin Chinese babble. This study has shown that the noise language can affect the intelligibility of the target speech. This is consistent with previous studies (e.g., Garcia Lecumberri \& Cooke, 2006; Rhebergen, Versfeld, \& Dreschler, 2005).

A study by Van Engen and Bradlow in 2007 provided evidence regarding effect of the language as a masker. Linguistic interference plays a role in the perception of speech in noise under certain conditions. Van Engen and Bradlow stated that six-talker babble contains the greater spectral and temporal density of six-talker noise, producing greater masking to the signal and causes target speech intelligibility to be reduced. In addition, because of the characteristics of six-talker babble, the difference between the two noise languages was eliminated. Differential linguistic effects only affected the performance when the listener was able to obtain the linguistic content of the noise (Van Engen \& Bradlow, 2007). 


\section{$\underline{\text { Scoring procedures }}$}

Different forms of sentence tests require specific response behaviors. For instance, TyeMurray et al. (2007) used the Iowa Sentences Test in the study. In order for a word to be scored as being correct, participants had to repeat it. The researchers scored based on the five to seven key words presented in each sentence. This scoring method is called a "key word approach." Basically, the researcher scores these sentences in terms of the number of key words correctly identified in each list. This key word approach has been accepted by many researchers (e.g., Harris et al., 1961; Silverman \& Hirsh, 1955; Sims, 1975). Giolas and Duffy (1973) and Duffy and Giolas (1974), however, used an "alternative scoring approach" in their studies in addition to the original key word approach due to the certain difficulties with the key word procedure (e.g., incomplete contractions, misspelling of words).

An alternative scoring approach includes homophonous words, identifiable misspelled words, contractions of words, and both words being spelled out being counted as correct. Hinkle (1979) stated that the alternative scoring approach appears to be the most acceptable scoring method to permits reasonable alternations in key words. The alternative scoring approach provides for scoring of key words which are most important to the meaning of the sentence. The CID ESS list prepared by the NTID suggested using original key word scoring; however, they also accepted certain exceptions to key word scoring as recommended by Giolas and Duffy (1974). The key word scoring is highly correlated to scoring all words and the key words are phonetically balanced (Sims \& Bick, 2008). In the ESS list, there are 50 key words for each list. The NTID suggested calculating the percent correct by giving two-points for each correct key word written by the participant regardless or spelling, word order, or use in or out of contractions. 
Speech Comprehensibility and Foreign Accentedness Ratings

Speech intelligibility especially for second-language speakers of English is one of the affecting factors for auditory-visual integration study. Motor theorists of speech perception claim that the strong influence of visual speech (gestural) information affects the perception of spoken language. In other words, speech perception and production are greatly linked (Liberman \& Mattingly, 1985). From this perspective, it was hypothesized that individuals with stronger foreign accent do not process the visual speech information as individuals with less foreign accent do even when they speak the same foreign language. Therefore, if second-language speakers of English are used in any studies, their speech intelligibility needs to be assessed. Speech comprehensibility (Derwing \& Rossiter, 2003; Derwing, Munro, \& Wiebe, 1998; Eisenstein \& Verdi, 1985; Gass \& Varonis, 1984) and foreign accentedness (Munro \& Derwing, 1995a; Munro \& Derwing, 1995b; Derwing \& Rossiter, 2003) have been used on a 9-point Likert scale to judge speech intelligibility of foreign accentedness speech. Southwood and Flege (1999) reported that a 7-point scale is frequently used to rate speech comprehensibility and foreign accentedness; however, a 7-point scale may not be sensitive enough for listeners to discriminate among speech sentences, causing ceiling and floor effects. Therefore, 9-point or 11-point scale might improve discrimination sensitivity among speech utterances for listeners. Southwood and Flege (1999) also suggested that introducing reference speech utterances reduced sequential contraction bias when listeners rate speech comprehensibility and foreign accentedness. Exposure and familiarity with foreign accent may create different internal standards, and experienced listeners may rate lower on foreign accentedness ratings (Southwood \& Flege, 1999). To control internal standards of variability minimally, listeners at least should be selected from the same experience group (i.e., experienced group or non-experienced group). 
Derwing and Rossiter (2003) defined speech comprehensibility as how difficult or easy an utterance is to understand. Foreign accentedness was defined as the extent to which a listener judges second-language speech as being different from first-language speakers of English. Munro and Derwing (1995) measured speech comprehensibility, foreign accentedness, and speech intelligibility using 9-point semantic differential scale in first-language speakers of English and first-language speakers of Mandarin who learned English after puberty. Speech comprehensibility and foreign accentedness were judged by first-language speakers of English.

The 9-point semantic differential scale for speech comprehensibility was defined as $1=$ extremely easy to understand and 9= impossible to understand and for foreign accentedness rating was defined as $1=$ no foreign accent and 9= very strong foreign accent. A first-language speaker of English group was highly rated on both speech comprehensibility and foreign accentedness ratings indicating both ratings were positively skewed severely. The results showed that for speech comprehensibility, 22\% of the Mandarin speakers were rated as " 1 ” and 64\% were rated in "1,” "2,” and "3.” The distribution of speech comprehensibility rating was positively skewed. For foreign accentedness rating, ratings were fairly evenly distributed from " 2 " to "8," with $4 \%$ being rated as "1."

\section{Participant Population}

$\underline{\text { Indian Multilingualism }}$

India includes 24 states and eight union territories. Originally the British divided Indian territorial divisions into provinces or states for administrative purposes during the British rule. British established presidencies, states, or provinces (Mallikarjun, 2004). By drawing the borders of provinces, British India created the various ethnic, religious, social, and linguistic lines. After 
India regained independence, most states remained multilingual. There were more than 1,650 mother tongues as per the 1971 count, which are grouped into five different language families, currently reduced to 200 languages (Mallikarjun, 2004). The five different languages families are: (a) Austro-Asiatic 1.13\% of the total population, (b) Dravidian with $22.53 \%$, (c) IndoEuropean (Indo- Aryan with $75.28 \%$, and Germanic with .02 \%), (d) Semito-Harmitic with .01 \%, and (e) Tibeto-Burman with .97 \%. Thus, a large number of people speak Indo-Aryan languages in India (Mallikarjun, 2004).

Traders from Europe brought English to India in the seventeenth. English was distinguished from other languages because English came with the European advantage in science and industry. After Indian regained independence English remained in India and became the modern language of industrial culture, representing the science and the pop cultures. English, therefore, was added and integrated to a multilingual network (Annamalai, 2004). The Constitution of India listed 18 languages representing regional streams of linguistic and cultural heritage (Annamalai, 2004). The large numbers of speakers $(337,272,114)$ speak Hindi, an amalgam of languages varieties in the Northern region (The Census of India, 1999). Hindi is a part of Indo-European language family which is composed of several hundred related languages and dialects, including most of the major languages of Europe, the northern Indian subcontinent (South Asia), the Iranian plateau (Southwest Asia), and much of Central Asia (Ruhlen, 1975). For governing the country, the question of the official language of India was raised. After prolonged debate, the Congress Party and Constituent Assembly decided Hindi to be the national language (Annamalai, 2004). There, however, was violent opposition to this change in some linguistic regions of the country. After the argument, the conflict was settled by having both Hindi and 
English as the official languages of India. English has remained the official language of India, but shares it with Hindi.

Many parents prefer sending their children to English medium schools. English is treated as a first language in these schools because it is the medium of instruction providing an English advantage. Although for students going to English schools, English is still a second-language for them (Pai, 2005).

\section{Indian cultural habit}

As reviewed in the previous sections, one of the reasons for the Japanese auditory reliance may be due to their cultural habit in which Japanese tend to avoid looking at the face of the speaker (eye contact is considered to be rude and impolite). This cultural habit may cause Japanese individuals to develop a certain type of processing which does not utilize visual cues in speech perception even when they are looking at the speaker's face. Many Indians also feel it is impolite to look the speaker in the eye if the person is older or in a senior position even though this is less common among young Indians (Storti, 2007). This cultural habit may also affect the processing of visual cues with Indians.

\section{Test of English as A Foreign Language}

Most of the universities in United States require undergraduate and graduate international students to obtain a pre-determined score on the Test of English as a Foreign Language (TOEFL) when applying for admission to institutions [Educational Testing Services (ETS), 2007]. The National Council was concerned about English proficiency of secondlanguage speakers of English. They developed the TOEFL in 1963 (ETS). The aim of the TOEFL is to assess English proficiency of people who speak English as a second-language and 
wish to study at colleges and universities in the United States and Canada. Currently, the TOEFL is administered in 6,000 institutions (more than 2,400 institutions in the United States and Canada) in 110 countries (ETS, 2007). There are different formats depending on a test-taker's location [Internet-based test (IBT) and paper-based test (PBT)]. Rosenfeld, Oltman, \& Sheppard (2004) investigated the validity of the TOEFL examination. Rosenfeld et al. found that the items on the TOEFL are representative of the knowledge and skills required to demonstrate English proficiency in undergraduate and graduate programs throughout United States and Canada.

IBT-TOEFL measures listening comprehension, reading comprehension, speaking, and writing abilities of foreign students' English proficiency. The paper-based test (PBT) essentially measures the same skills as the IBT, although they have some differences, noticeably the number of questions, higher in the PBT, and the score scales. The score range of IBT is from 17 to 120 and PBT is from 333 to 677. The PBT measures listening comprehension, structure and written expression, reading comprehension, and writing. The writing section is referred as a Test of Written English (TWE). Test-takers can take TWE as a part of PBT. The PBT does not include a speaking part; however, the Test of Spoken English is available for people who need scores of spoken English. Test-takers are mainly asked about the main idea of a passage, details, inferences, sentence restatements, sentence insertion, vocabulary, function, and overall ideas on the test.

\section{A Pilot Study of Effects of Speechreading on Understanding MAE by Second-language Listeners of English}

The purposes of the pilot study were: (1) to delineate the background noise levels to be used in the main study in which first-language and second-language speakers of English perform less than a 100\% level with and without speechreading (thereby avoid a ceiling effect in data 
collection), and (2) to test and refine recruitment, participant selection, and experimental procedures with a small sample of participants before conducting the dissertation study with a larger sample of participants.

The investigator recruited 10 Indian students from Indian as second-language speakers of English for the pilot study. These students were born and raised in India, have spoken an Indian language as their first language, and now speak English as a second language. Originally, the investigator planned to recruit 10 American English students as first-language speakers of English at the WSU College of Engineering; however, due to the limited availability of American English students in the College of Engineering, the investigator could not recruit American English students from the College of Engineering. All participants were graduate students enrolled in WSU who were between 20 to 40 years of age, and their hearing and vision were within the normal limits.

Participants sat at a table in the same sound booth while facing a TV screen with two loudspeakers at its side. Following instructions and a practice list of sentences, participants listened to 10 lists of ESS spoken by a MAE female speaker. Sentences were spoken through the loudspeaker of the television at a normal conversational level (65 dB SPL) for all lists while background conversation noise was presented from both loudspeakers for an entire list at one of five intensity levels ( $60 \mathrm{~dB}, 65 \mathrm{~dB}$. $70 \mathrm{~dB}, 75 \mathrm{~dB}$, or $80 \mathrm{~dB}$ SPL). Five lists of sentences were presented in an $\mathrm{AV}$ modality, and five lists were presented in an A (created by covering the TV screen with a black cloth). The investigator randomized among participants the order of presentation for the 10 lists, the five noise levels, and the A versus AV modalities.

The results indicated that first, under A-only modality, Indian participants plateaued at between $0 \mathrm{~dB}$ and $+5 \mathrm{~dB}$ SNRs under and approached to plateau at between $-15 \mathrm{~dB}$ and $-10 \mathrm{~dB}$ 
SNRs. The results also indicated that everyone was above $50 \%$ at $0 \mathrm{~dB}$ SNR, below $30 \%$ at -15 dB SNR, and $50 \%$ were at $-5 \mathrm{~dB}$ SNR. The lowest $50 \%$ part for a participant was $-11 \mathrm{~dB}$ SNR. There was considerable variability across participants. There were a few participants at a few levels when the score was higher than at a lower level or lower at a high intensity of noise. Second, under AV modality, participants plateaued at between 0 and $+5 \mathrm{~dB}$ SNRs and may approach a 35\% plateau at -15 dB SNR. Nearly all SNR levels for all participants performed better than A modality. At 50\% level, eight of 10 participants demonstrated VE and overall VE was $30.8 \%$. Most of the participants did not achieve $100 \%$, even at the highest SNR, and only two participants achieved $100 \%$. None of the participants achieved $100 \%$ at $-5 \mathrm{~dB}$ SNR.

Overall, the results of the pilot study suggested that the upper range of the noise level needs to be at least $0 \mathrm{~dB}$ and the lower at least $-11 \mathrm{~dB}$ SNR with A modality. Because the American participants achieved 50\% at a lower SNR, the noise range needed to be larger but with smaller increments. Therefore, it was recommended that the following would be used for the dissertation study, [-18 dB to $+6 \mathrm{~dB}$ noise range by $6 \mathrm{~dB}$-increment (a total of 5 levels)]. 


\section{CHAPTER III}

\section{METHODOLOGY}

This prospective comparative study was designed to measure effects of speechreading and SNR on understanding MAE heard by American and Indian adults. This chapter details methodologies used in this study.

\section{Participants}

Recruitment: The investigator recruited 60 participants into this study: 30 American graduate students and 30 Indian graduate students. To foster homogeneity among the two language groups, the investigator first tried to recruit all American and Indian participants from the Wichita State University (WSU) College of Engineering. As of 2007, WSU enrolled nearly 1,200 foreign students (Koh Chin \& Rajika, 2007), of which the College of Engineering enrolled approximately 300 engineering majors from India. These engineering students from India were the most accessible large population of second-language speakers of English of any bilingual group of students at WSU. The investigator, unfortunately, had difficulty recruiting American participants from the College of Engineering. Therefore, the investigator expanded recruitment to other colleges at WSU by posting advertisements on bulletin boards at the College of Health Professions, the College of Liberal Arts and Sciences, and the College of Engineering. The investigator also contacted the Indian Student Association and the College of Engineering to email the advertisement to their Indian graduate students. The advertisement listed pre-selection criteria (Appendix A) as well as how to contact the investigator to schedule an appointment to be in the study. To control for similar age, education, vision, and hearing, the advertisement 
requested all participants be from 20 to 40 years old, graduate students enrolled at WSU, and have normal vision (with eyeglasses, if needed) and normal hearing. The advertisement also stated all participants would receive \$10/hour for their participation.

The investigator scheduled each prospective participant for an individual 60-minute to 90-minute session in the WSU Department of Communication Sciences and Disorders (CSD) laboratories at Hubbard Hall. The first part of the session (a final recruitment of participants) lasted 20 to 30 minutes. The investigator verbally explained the study to participants. Participants read the consent form and signed it if they agreed to continue in this study (Appendixes B and C). Participants then completed a questionnaire (Appendixes D and E). Questions were asked about a participant's age, TOEFL score (for Indian participants), and history of vision and hearing problems. Participants also rated present language competencies for MAE on a 5-point Likert Scale (1= poor, 5 = excellent). Raw data for the questionnaire are shown in Appendixes F and G.

\section{Demographic Characteristics}

The 30 American participants were born in the United States: 25 in midwestern states and five in northeastern, southern, or southwestern states. Twenty-eight of the American participants were graduate students majoring in Speech-Language Pathology and Audiology and two American participants were graduate students majoring in Psychology. All 30 Indian participants were born in India and were graduate students in the College of Engineering. American participants ranged in age from 23 - 39 years old (mean $=25.9$ years, SD = 4.9 years), and Indian participants ranged in age from $21-33$ years old (mean $=22.8$ years, $\mathrm{SD}=2.5$ years). A t-test for independent samples indicated the ages of American and Indian participants differed 
significantly $[t(58)=3.09, p<.01]$. That is, American participants were significantly older (by three years on average) than Indian participants. An Eta Squared $\left(\mathrm{y}^{2}\right)$ strength-of-association measure indicated only $4.5 \%$ of the variance in age between groups was accounted for by their nationality. Genders of American participants were 26 females and 4 males, whereas genders of the Indian participants were 7 females and 23 males. A 2 X 2 Chi-Square test indicated the distribution of participants' genders differed significantly $\left[\mathrm{X}^{2}(1, \mathrm{~N}=60)=25.8, p<.001\right]$. That is, there were a significantly higher number of females than males among American participants and a significantly lower number of females than males among Indian participants.

\section{$\underline{\text { Linguistic Characteristics }}$}

All American participants were fluent only in English. As detailed in Appendix F, 27 American participants were raised in the Great Plains, midwestern, or western states where native speakers traditionally speak MAE. Only three American participants were raised in states (i.e., Oklahoma, Texas, and Florida) where many speakers traditionally do not speak MAE. All American participants rated their speaking, writing, and speech comprehension of MAE on the questionnaire as “very good” or “excellent.”

All Indian participants were raised in India and spoke various Indian dialects (Appendix G). Eighteen Indian participants spoke Telugu as their first-language, whereas the other 12 Indian participants spoke either Hindi, Kannada, Marathi, Tamil, or Tulu as their first-language. Indian participants started to learn English from the ages of $3-11$ years $($ mean $=4.8$ years, $\mathrm{SD}=1.9$ years); they lived in the United States from 2 - 96 months (mean = 9.0 months; SD = 17.9 months); and they achieved a passing score of 79 or better on the Internet Base version of the TOEFL when they applied for admission to WSU. Specifically, their TOEFL scores ranged from 
79 to108 (mean $=89.8, \mathrm{SD}=8.7$ ), indicating the English proficiency of all Indian participants was considered sufficient to be admitted into graduate school. On the questionnaire, all Indian participants rated their speaking skills for Indian dialect as "very good” or "excellent” and rated their reading and speech comprehension of Indian dialect as "good," "very good" or "excellent." Indian participants rated their writing of their Indian dialect as "fair," "good," "very good," or “excellent.” Conversely, Indian participants rated their verbal and speech comprehension of American English from "fair" to "excellent” and rated their reading and writing of American English from "poor” to "excellent."

After completing the questionnaire, participants were audio-recorded reading aloud the Rainbow Passage (Appendix H) using an Olympus, DS-50 digital reorder. The Rainbow Passage is a brief, written, English paragraph which, when spoken properly, contains all English speech sounds (Bernthal \& Bankson, 1993). After all 60 participants had completed the study, the investigator selected three WSU professors experienced in judging characteristics of secondlanguage speakers of English. The Judges needed to listen to the recordings of 59 participants one time to form a first-impression judgment of their speech (Gordon-Brannan \& Hodson, 2000); they needed to listen to one participant's speech twice to form a first-impression judgment. The investigator played a recording of the Rainbow Passage spoken by an adult female MAE speaker as a reference of a MAE accent before the $1^{\text {st }}, 11^{\text {th }}, 21^{\text {st }}, 31^{\text {st }}, 41^{\text {st }}$, and $51^{\text {st }}$ recordings. The judges rated each participant’s recording on a 9-point semantic differential scale (Munro \& Derwing, 1995). For comprehensibility ratings, judges rated how easily they understood each speaker’s speech from 1 = "extremely easy to understand" to 9 = "impossible to understand." For accentedness ratings, judges rated each speaker’s foreign accent from $1=$ "no foreign accent" to $9=$ "very strong foreign accent.” The order of presentation was randomized among American 
and Indian participants' recordings. An exploratory raw data analysis of judges' ratings suggested one judge's ratings of both speech comprehensibility and foreign accentedness were consistently higher than the ratings of the other two judges. A Kruskal-Wallis test further indicated the rating of comprehensibility of the 60 participants differed significantly among the three judges [(H (2) $=6.82, p<.05)]$. Another Kruskal-Wallis test indicated rating of foreign accentedness of the 60 participants also differed significantly among the three judges $[(\mathrm{H}(2)=8.79, p<.05)]$. A post-hoc Dunn’s multiple comparison test, however, indicated no significant differences $(\mathrm{p}<.05$ familywise error rate) between ratings of pairs of judges for either comprehensibility or foreign accentedness.

The median rating of the three judges for comprehensibility and foreign accentedness was determined for each American and Indian participant. As shown in Figure 1, the median rating of comprehensibility for American participants was “1” for 27 participants, “2” for two participants, and "3" for one participant. Conversely, the median rating for the 30 Indian participants ranged from "2" to "7," with most participants having a rating of "3." A Wilcoxon rank sum test indicated that the group ratings of speech comprehensibility differed significantly $(z=-4.73$, $p<.001$ ) between American and Indian participants. Likewise, as shown in Figure 2, the median rating of a foreign accentedness among the three judges for American participants was " 1 ” for all participants. Conversely, the median rating of foreign accentedness among judges for Indian participants ranged from " 3 " to "8,"with most of the participants having ratings of “3,” " 4 ,” or “5.” A Wilcoxon rank-sum test indicated that the group ratings of foreign accentedness differed significantly $(\mathrm{z}=-4.81, p<.001)$ between American and Indian participants. Interestingly, the distribution of judges' ratings of a speech comprehensibility and foreign accentedness for Indian participants resembled the distribution among foreign speakers in the study of Munro and 
Derwing (1995), showing the same positive skew of their participants' comprehensibility ratings and fairly even distribution of their participants' foreign accentedness ratings.

\section{FIGURE 1}

DISTRIBUTION OF JUDGES' MEDIAN RATINGS OF COMPREHENSIBILITY

OF THE AMERICAN AND INDIAN PARTICIPANTS FOR THE RAINBOW PASSAGE

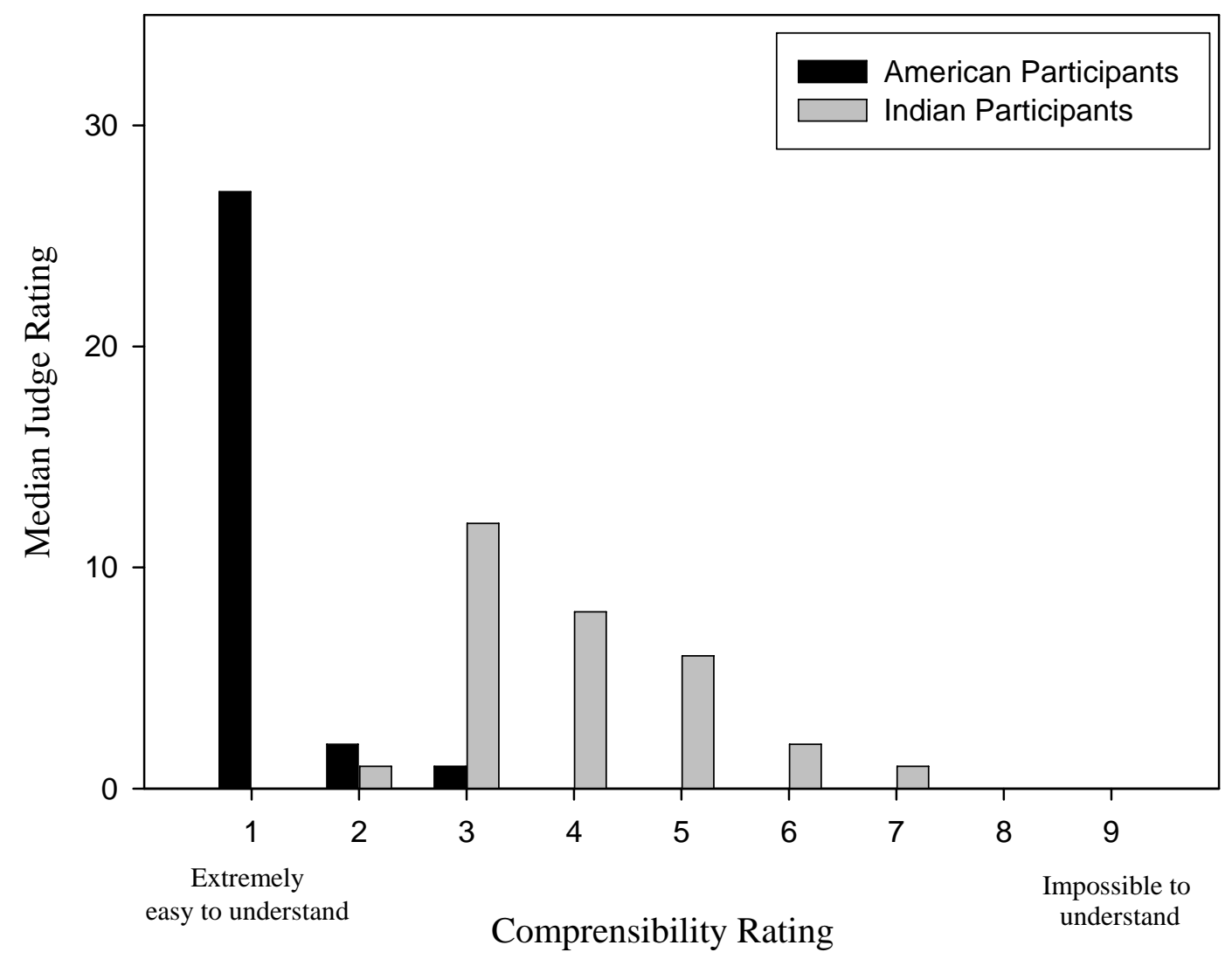


FIGURE 2

DISTRIBUTION OF JUDGES' MEDIAN RATINGS OF FOREIGN ACCENTEDNESS

OF THE AMERICAN AND INDIAN PARTICIPANTS FOR THE RAINBOW PASSAGE

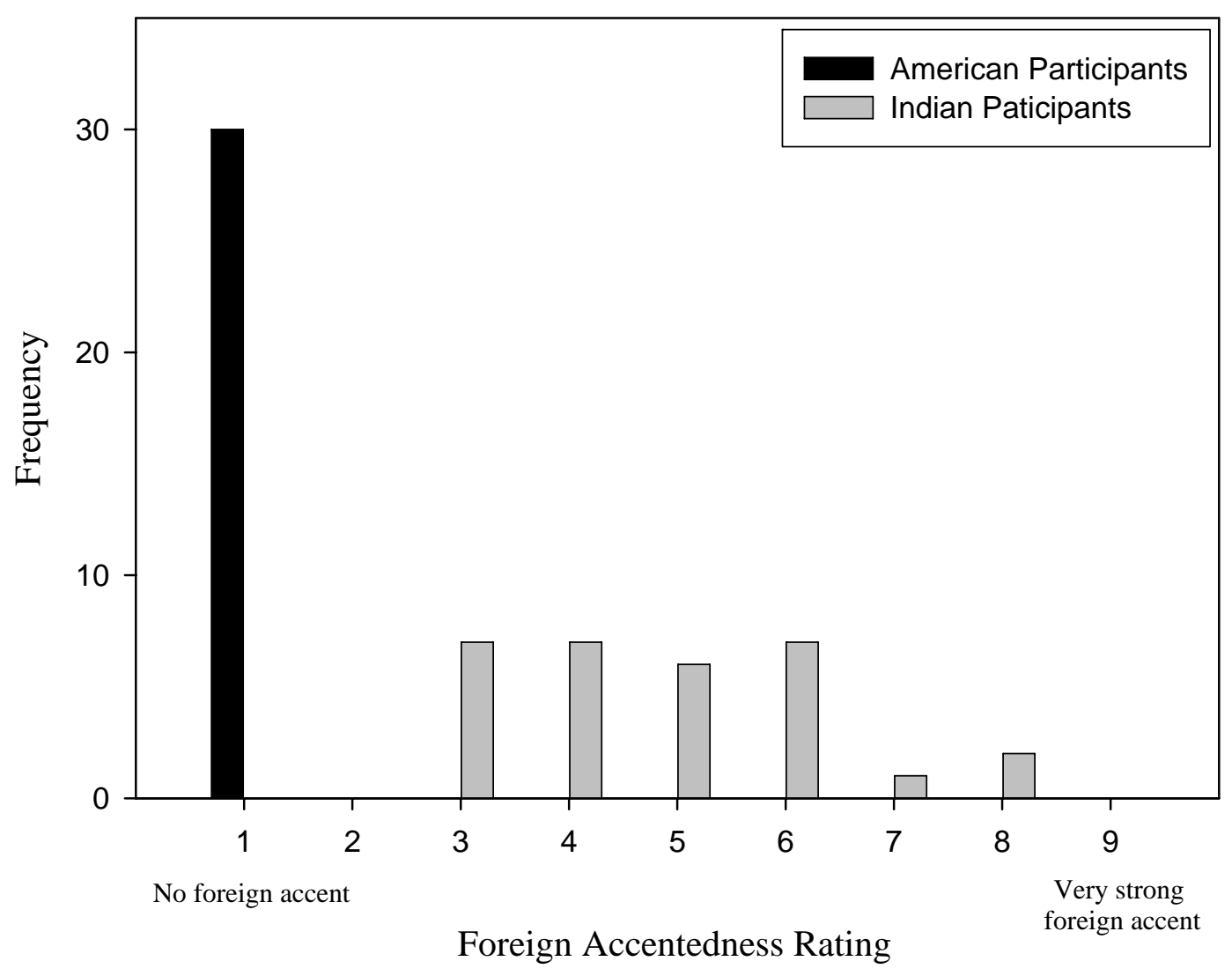

\section{$\underline{\text { Vision and Hearing }}$}

All American and Indian participants reported no history of vision and hearing problems on their questionnaires. Visual screenings of their visual acuity and contrast sensitivity (with eyeglasses as if needed) were completed by the investigator in a well-lit room. Participants completed a binocular distance visual acuity test while viewing a Snellen chart (see Appendix I-1 for verbal instructions). A participant stood four meters from the Snellen chart with the center of the chart at eye level. Visual acuity for all participants was better than or equal to 20/40, which is acceptable for speechreading everyday speech communication (Tye-Murray, 2004). Participants also completed a binocular contrast sensitivity test (Pelli, Robson, \& Wilkins, 1988) (see 
Appendix I-2 for verbal instructions). A participant stood one meter from a Pelli-Robson contrast sensitivity chart, which measured sensitivity at approximately one cycle per degree (Pelli et al., 1998). All participants scored at or below 1.8 binocularly, suggesting their visual contrast sensitivity was within normal limits (Pelli, Robson, \& Wilkins, 1988; Woods \& Woods, 1995).

The investigator screened participants' hearing sensitivity in each ear at octave frequencies from 250 through $8000 \mathrm{~Hz}$ (see Appendix I-3 for verbal instructions). Sixty participants' hearing thresholds were better than 20 dB HL from 250 through $8000 \mathrm{~Hz}$, suggesting their hearing sensitivity was within normal limits. Two potential participants' hearing sensitivity was poorer than $20 \mathrm{~dB}$ HL. Therefore, they were excluded from this study and were referred for further testing.

Facilities and Instrumentation

The experiment was conducted in the same sound-treated booths as the hearing screening (Figure 3). The examiner’s booth was a single-wall IAC booth, and the participant's booth was a double-wall IAC booth that met ambient noise standards (ANSI S3.1-1991) for threshold testing. Participants sat in a chair with their head about $91 \mathrm{~cm}$ from a 32-inch, flat, digital TV (Westinghouse Digital Electronics, HDTV720P, 80w X 56h). An opaque black cloth covered the TV monitor under the A modality condition during speechreading testing. Participants sat 1.5m from two Grason-Stadler loudspeakers situated at $+135^{\circ}$ and $-135^{\circ}$ azimuth. The height of the diaphragm of the loudspeakers and the height of the center of the TV approximated the average ear-level and eye-level of participants. Participants wrote responses during speechreading testing on a small table immediately in front of them. 
FIGURE 3

IAC SOUND BOOTH WITH DISTANCE MEASURES

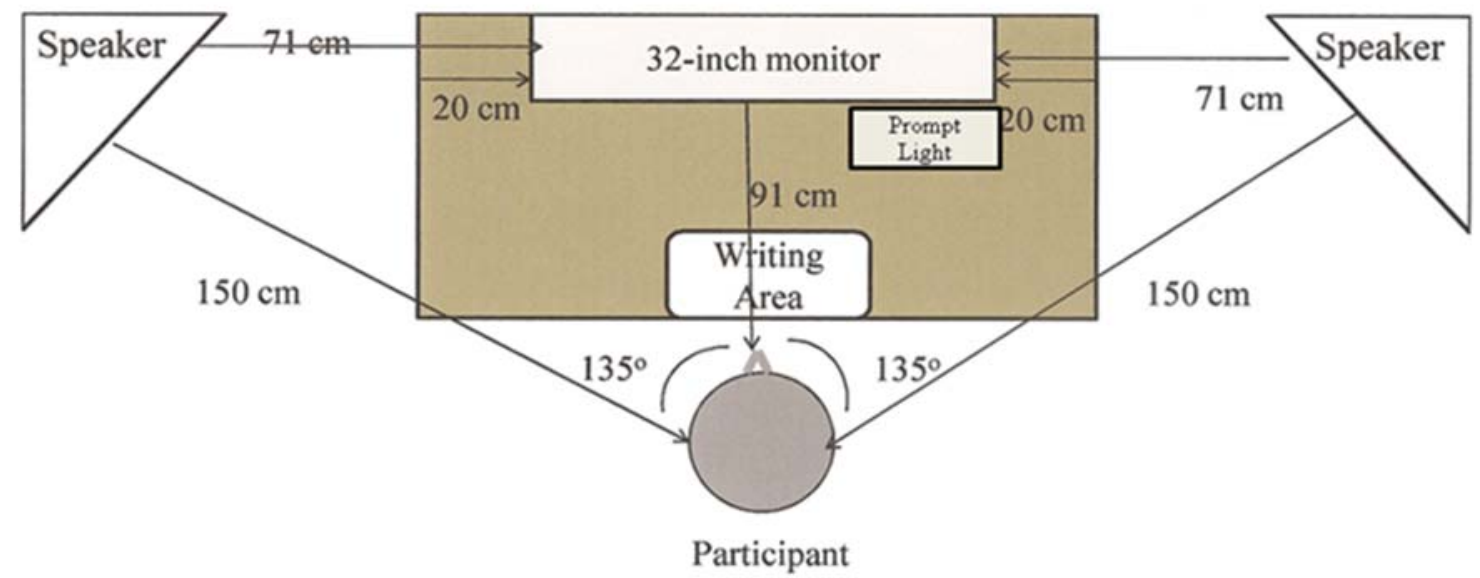

Participant's Sound Booth

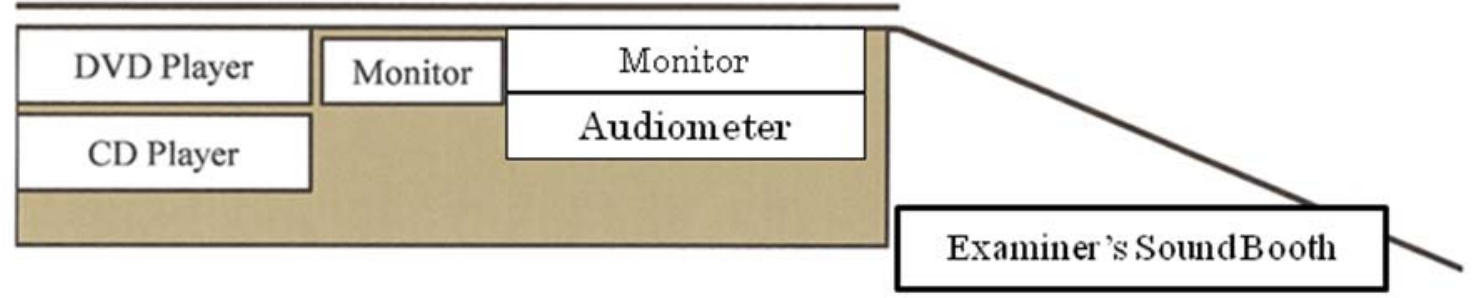

Figure 4 displays a block diagram of instrumentation used for the speechreading test. ESS were routed from a DVD player (LG Upconverting DVD/VHS Recorder, RC797T 1080i) to a 15-inch monitor (Insignia, NS-LCD15-09) in the examiner's booth and to the TV in the participant booth. A commercially available Auditec CD recording of four-talker babble was routed from a CD player (Symphonic, CD 5800) to the attenuator of GSI 16 audiometer, to a stereo amplifier (Samson, Servo 120 Stereo Amplifier), and then to the two GSI loudspeakers. A video camera recorder (Sony DCR-PC110) was placed under the TV in the participant booth. Live pictures of the head and torso of participants were captured by the video camera and routed to a 15-inch flat monitor (Audiovox, FEP1506) in the examiner's room. During speechreading 
testing, the investigator prompted participants to the next ESS by a switch in the tester booth connected to a small red light under the TV.

The investigator calibrated the ESS presentation level using a Quest 1700 precision impulse sound level meter coupled to a Quest OB-300 1/3-1/1 octave filter set. The microphone on the sound level approximated the average center of participants' heads (see Figure 3). The investigator calibrated average presentation levels of ESS by adjusting and setting the volume control of the TV to $+65 \mathrm{~dB}$ SPL. Each loudspeaker and its accompanying amplifier were calibrated separately to assure their outputs were within $1 \mathrm{~dB}$ SPL of one another. The investigator then calibrated noise levels at $47 \mathrm{~dB}, 53 \mathrm{~dB}, 59 \mathrm{~dB}, 65 \mathrm{~dB}$ and $71 \mathrm{~dB} \mathrm{SPL}$ when the babble was presented through both loudspeakers. All of these calibrations were conducted before testing the first participant, and after testing the $30^{\text {th }}$ and $60^{\text {th }}$ participants.

\section{Speechreading Materials}

The investigator measured speechreading performance using a non-commercial DVD of the ESS provided to our laboratory by courtesy of the National Technical Institute for the Deaf (NTID). In 1985, the NTID recorded the ESS on a Laserdisc and transferred it to DVD in 2007. Specifically, a female adult talker of MAE spoke each of the 100 different ESS, which were divided into10 lists of 10 sentences. She was filmed with her head and torso contrasted against a light blue background. The DVD was manually driven so the investigator could select a print instruction set, a two-sentence practice set, an auditory-only reading of the Rainbow Passage to set volume to comfort levels, the particular test lists 1-10, and the individual 10 sentences within a list. 
FIGURE 4

A BLOCK DIAGRAM DISPLAYING INSTRUMENTATION FOR SPEECHREADING

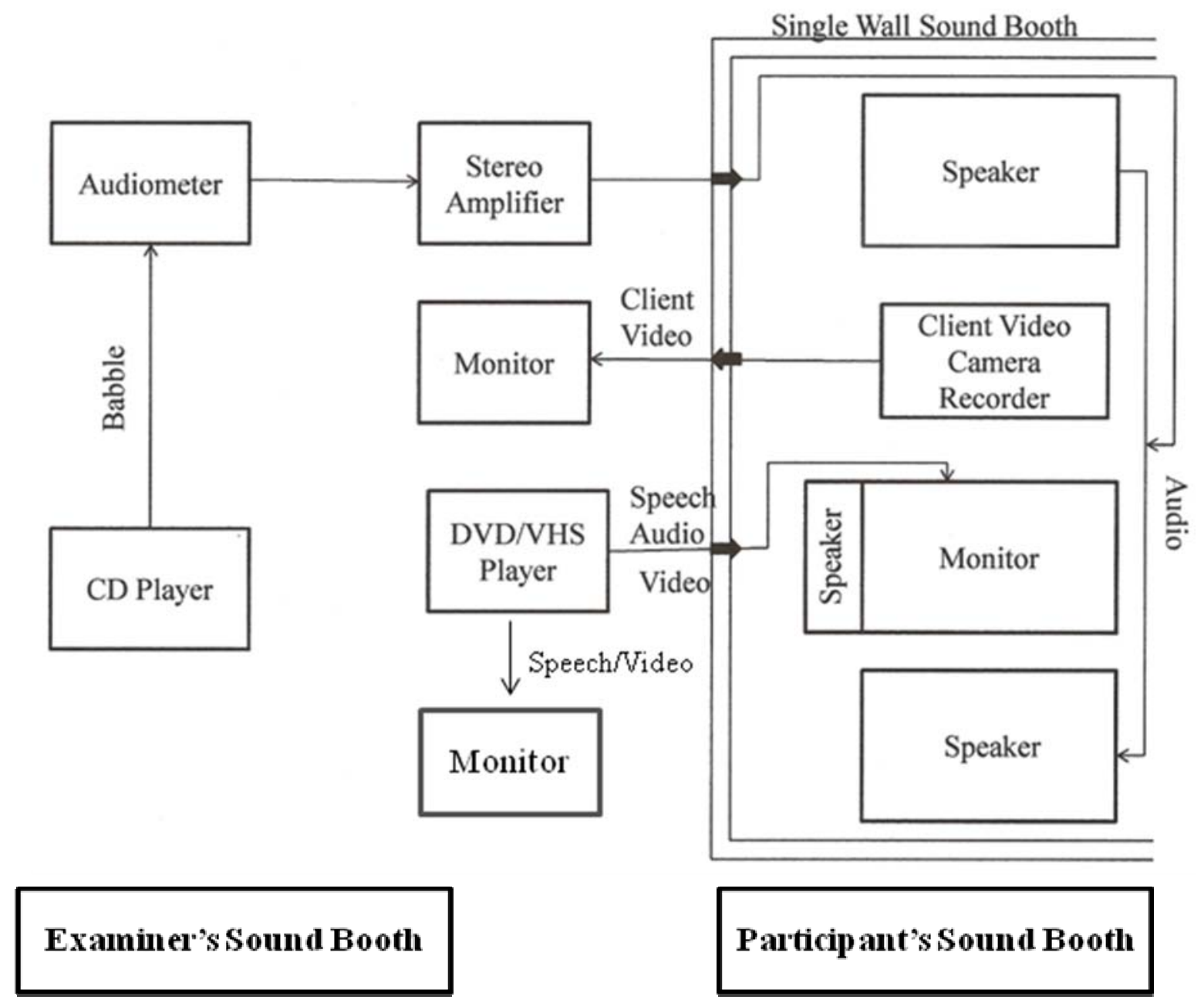

Procedures

The experimental portion of the study lasted between 40 and 45 minutes. Participants sat in the sound booth at the table with a stack of answer sheets - one sheet was for practice sentences and one sheet each was for each of the ten lists of test sentences (Appendix M). The investigator verbally instructed participants they would hear (or hear and see) a speaker on the TV saying a sentence; and participants should write, word for word, each sentence they heard (or 
heard and saw) on the answer sheet (Appendix K). As shown in Appendix J, the instructions encouraged participants to write complete sentences even if they had to guess words or phrases they did not understand. The investigator asked participants to raise a hand after writing each sentence. The investigator then presented the next sentence within 2 seconds. The investigator covered the TV screen with the black cloth for sentences presented under the A modality and alerted participants to the next sentence by turning on the prompt light in front of the TV. The investigator uncovered the TV screen under the AV modality, and alerted participants to the next sentence by turning on the picture of the female speaker on the TV screen.

To further familiarize participants with the speechreading task, they first listened to two practice sentences at $65 \mathrm{~dB}$ SPL and babble at a $+20 \mathrm{~dB}$ SNR. One practice sentence was presented under the AV modality and one practice sentence was presented under the A modality. Each participant then listened to the 10 lists of sentences at $65 \mathrm{~dB}$ SPL with babble at five different noise levels ( $+6 \mathrm{~dB}, 0 \mathrm{~dB},-6 \mathrm{~dB},-12 \mathrm{~dB}$, and $-18 \mathrm{~dB}$ SNRs). Five lists were presented under the AV modality and five of the lists were presented under the A modality. The investigator randomized the order of presentation of the ten lists, the five SNRs, and the two modalities among the 60 participants.

\section{$\underline{\text { Scoring }}$}

The investigator took several steps to reduce bias when scoring participants' answer sheets. First, the investigator did not score any answer sheets until all participants' data were collected. Second, the investigator coded each answer sheet for each list so they could be scored with the scorer blind to the SNR or modality of the presentation and to the participant's name or other identifying information including their language group. Third, the investigator employed a 
standardized scoring system for ESS (Duffy \& Giolas, 1974; Hinkle, 1979, Sims \& Bick, 2008). Specifically, the investigator scored each list of sentences as the percentage of the 50 spoken key words in each list that participants wrote correctly according to the following criteria: the written word was scored as correct if it matched the key word and was spelled correctly; the written word was scored as correct if it was misspelled but was identifiable as the keyword from the context of the sentence; the written word was scored as correct if it was written as a contraction that correctly matched a key word that was not spoken as a contraction; two written words were scored as correct if they were not written as a contraction, but they correctly matched the key word spoken as a contraction; and the written word was scored as correct if it changed the plurality, but not the meaning, of the of key word. Finally, the investigator employed an alternate scorer to estimate inter-scorer reliability (Hinkle, 1979). The investigator first familiarized the alternate scorer with the scoring criteria. The alternate scorer then independently scored all 10 lists of 15 participants randomly selected from the American and Indian participants. The alternate scorer also was blind to the SNR or modality of the presentation and to the participant's name or other identifying information including their language group. The alternate scorer and the investigator scored $99.6 \%$ of the key words the same from the 150 lists that they commonly scored. A Pearson Product-Moment Correlation Coefficient of $r=.99$ indicated excellent interscorer reliability suggesting the investigator's scoring of all sentences in the study was unbiased and valid.

After all answer sheets were scored for all 60 participants, the investigator computed six different measures for each participant:

1. A-score: An auditory-only score computed as the percentage of correct key words in each lists presented in the A modality at each of the five SNR. 
2. AV-score: An auditory-visual score computed as the percentage of correct key words in each list presented in the AV modality at each of the five SNR.

3. VE-score: A visual enhancement score computed using the following formula:

VE-score $=(A V$-score $)-(A$-score $) /[1-(A-s c o r e)]+1$

This formula is a slight modification of the traditional formula for computing visual enhancement: $\mathrm{VE}=(\mathrm{AV}-\mathrm{A}) /(1-\mathrm{A})$. The modification was employed because a few participants (mainly American participants) had an A-score of 100\% at favorable SNRs. This resulted in an indefinite number due to a "0" in the denominator when computing the VE-score using the traditional formula. A constant of " 1 " therefore was added to the denominator (Tabachnick \& Fidell, 2007).

4. Psychometric Functions: Plotted on a graph with SNR on the abscissa and either the A-score or the AV-score or the VE-score on the ordinate.

5. (A) SNR-50: Determined by plotting each participant's A-score at each SNR as one of five points on a graph and connecting these five points with a curved line (i.e., the psychometric function for the A modality). A horizontal line was drawn from the $50 \%$ correct level on the ordinate to the point it intersected the psychometric function. A vertical line was drawn from this point on the psychometric function down to the point it intersected the ordinate. The (A) SNR-50 was interpolated as the SNR corresponding to this point on the abscissa (see Figures 6 and 7 for graphs showing how (A) SNR-50 was derived).

6. AV-score @ (A) SNR-50: Determined by using the same graph used to determine the (A) SNR-50. The investigator plotted each participant's AV-score at each SNR as one of five points on the graph and connected these five points with a curved line (i.e., the 
psychometric function for the AV modality). A vertical line was extended upwards from the (A) SNR-50 to the point it intersected the psychometric function for the AV modality. A horizontal line was then drawn from this point on the psychometric function to the point it intersected the ordinate. Finally, the AV-score @ (A) SNR-50 was interpolated as the percentage correct corresponding to this point on the ordinate (See Figures 6 and 7 for graphs showing how AV-score @ (A) SNR-50 was derived). Finally, the investigator computed mean scores and psychometric functions for each of these six measures separately for the 30 American participants and the 30 Indian participants.

\section{Data Analysis}

The purpose of this study was to measure effects of speechreading and SNR on understanding MAE heard by Indian participants compared to American participants. Specifically, the investigator employed inferential statistical methods to 19 null hypotheses corresponding to the 19 main experimental questions addressed in this study.

The first six questions (and their corresponding null hypotheses) addressed effects of SNR and modality on ESS-scores separately for American participants and for Indian participants when all participants were evaluated at the same SNRs.

(1) Do AV-scores of American participants differ significantly among SNRs? $\mathrm{H}_{0} 1$ : AV-scores of American participants do not differ significantly among SNRs.

(2) Do A-scores of American participants differ significantly among SNRs? $\mathrm{H}_{0} 2$ : A-scores of American participants do not differ significantly among SNRs.

(3) Do AV-scores and A-scores of American participants differ significantly at each SNR? $\mathrm{H}_{0} 3$ : AV-scores and A-scores of American participants do not differ significantly at each SNR. 
(4) Do AV-scores of Indian participants differ significantly among SNRs?

$\mathrm{H}_{0} 4$ : AV-scores of Indian participants do not differ significantly among SNRs.

(5) Do A-scores of Indian participants differ significantly among SNRs?

$\mathrm{H}_{0} 5$ : A-scores of Indian participants do not differ significantly among SNRs.

(6) Do AV-scores and A-scores of Indian participants differ significantly at each SNR?

$\mathrm{H}_{0} 6$ : AV-scores and A-scores of Indian participants do not differ significantly at each SNR.

The next two questions (and their corresponding null hypotheses) addressed effects of language group and SNR on ESS-scores when all participants were evaluated at the same SNRs.

(7) Do AV-scores at each SNR differ significantly between American and Indian participants?

$\mathrm{H}_{0}$ 7: AV-scores at each SNR do not differ significantly between American and Indian participants.

(8) Do A-scores at each SNR differ significantly between American and Indian participants?

$\mathrm{H}_{0}$ 8: A-scores at each SNR do not differ significantly between American and Indian participants.

The next three questions (and their corresponding null hypotheses) addressed effects of SNR and language group on VE-scores when all participants were evaluated at the same SNRs.

(9) Do VE-scores for each language group differ significantly among SNRs?

$\mathrm{H}_{0} 9$ : VE-scores for each language group do not differ significantly among SNRs.

(10) Do VE-scores at each SNR differ significantly between American and Indian participants? 
$\mathrm{H}_{0} 10$ : VE-scores at each SNR do not differ significantly between American and Indian participants.

(11) Do SNR and language group show a significant interaction on VE-scores?

$\mathrm{H}_{0} 11$ : SNR and language do not show a significant interaction on VE-scores.

(12) Do VE-scores of American and Indian participants differ significantly among SNRs? $\mathrm{H}_{0} 12$ : VE-scores of American and Indian participants do not differ significantly among SNRs.

The next two questions (and their corresponding null hypotheses) addressed effects of language group on AV-score @ (A) SNR-50.

(13) Do (A) SNR-50 values differ significantly between American and Indian participants?

$\mathrm{H}_{0} 13$ : (A) SNR-50 values do not differ significantly between American and Indian participants.

(14) Do ESS-scores for AV-score @ (A) SNR-50 differ significantly between American and Indian participants?

$\mathrm{H}_{0} 14$ : ESS-scores for AV-score @ (A) SNR-50 differ significantly between American and Indian participants.

The next two questions (and their corresponding null hypotheses) addressed the association between each participant's (A) SNR-50 and AV-score @ (A) SNR-50 separately of American and Indian participants. 
(15) Does (A) SNR-50 correlate significantly with AV-score @ (A) SNR-50 of American participants?

$\mathrm{H}_{0}$ 15: (A) SNR-50 does not correlate significantly with AV-score @ (A) SNR-50 of American participants.

(16) Does (A) SNR-50 correlate significantly with AV-score @ (A) SNR-50 of Indian participants?

H016: (A) SNR-50 does not correlate significantly with AV-score @ (A) SNR-50 of Indian participants.

The next three questions (and their corresponding null hypotheses) addressed the association between AV-scores @ (A) SNR-50 and linguistic measures of American and Indian participants.

(17) Do AV-scores @ (A) SNR-50 correlate significantly with various linguistic measures of Indian participants?

Ho17: AV-scores @ (A) SNR-50 do not correlate significantly with various linguistic measures of Indian participants.

(18) Do AV-scores @ (A) SNR-50 correlate significantly with speech comprehensibility ratings of all participants?

H018: AV-scores @ (A) SNR-50 do not correlate with speech comprehensibility ratings of all participants.

(19) Do AV-scores @ (A) SNR-50 correlate significantly with foreign accentedness ratings of all participants?

Ho19:AV-scores @ (A) SNR-50 do not correlate with foreign accentedness ratings of all participants. 


\section{CHAPTER IV}

\section{RESULTS}

This study was designed to measure effects of speechreading and SNR on understanding MAE heard by American adults versus Indian adults. The first six experimental questions are addressed in the section "Effects of SNR and Modality on AV-scores and A-scores," whereas experimental questions 7 and 8 are addressed in "Effects of Language Group and SNR on AVscores and A-scores." Experimental questions 9, 10, 11, and 12 are addressed in "Effects of SNR and Language Group on VE-scores.” The “Effects of Language Group on AV-score @ (A) SNR50” addresses experimental questions 13 and 14, whereas experimental questions 15 and 16 are addressed in “Correlation between (A) SNR-50 and AV-score @ (A) SNR-50.” The “Association between AV-score@ (A) SNR-50 and Linguistic Measurements” addresses experimental questions 17, 18, and 19. Lastly, effects of gender on speechreading are addressed. Raw data related to experimental questions are presented in Appendixes $\mathrm{N}, \mathrm{O}$, and $\mathrm{P}$.

\section{Effects of SNRs and Modality}

Figure 5 compares mean psychometric functions between AV and A modalities for American participants. The psychometric function for the AV modality showed a gradual slope with a mean $\mathrm{AV}$-score of $76 \%$ achieved at the poorest (-18 dB) SNR and a plateau near $100 \%$ achieved at and above $-6 \mathrm{~dB}$ SNR. In contrast, the psychometric function for the A modality showed a more classic ogive with a mean A-score of $8 \%$ achieved at -18 dB SNR, sharply rising to a plateau near $100 \%$ at and above $0 \mathrm{~dB}$ SNR. Standard deviations (SDs) for both psychometric 
functions showed minimal variability in scores among participants at favorable SNRs and large variability in scores among participants at poorer SNRs for both AV and A modalities.

FIGURE 5

PSYCHOMETRIC FUNCTIONS SHOWING MEANS AND SDS OF AV- AND A-SCORES FOR AMERICAN PARTICIPANTS AT EACH SNR

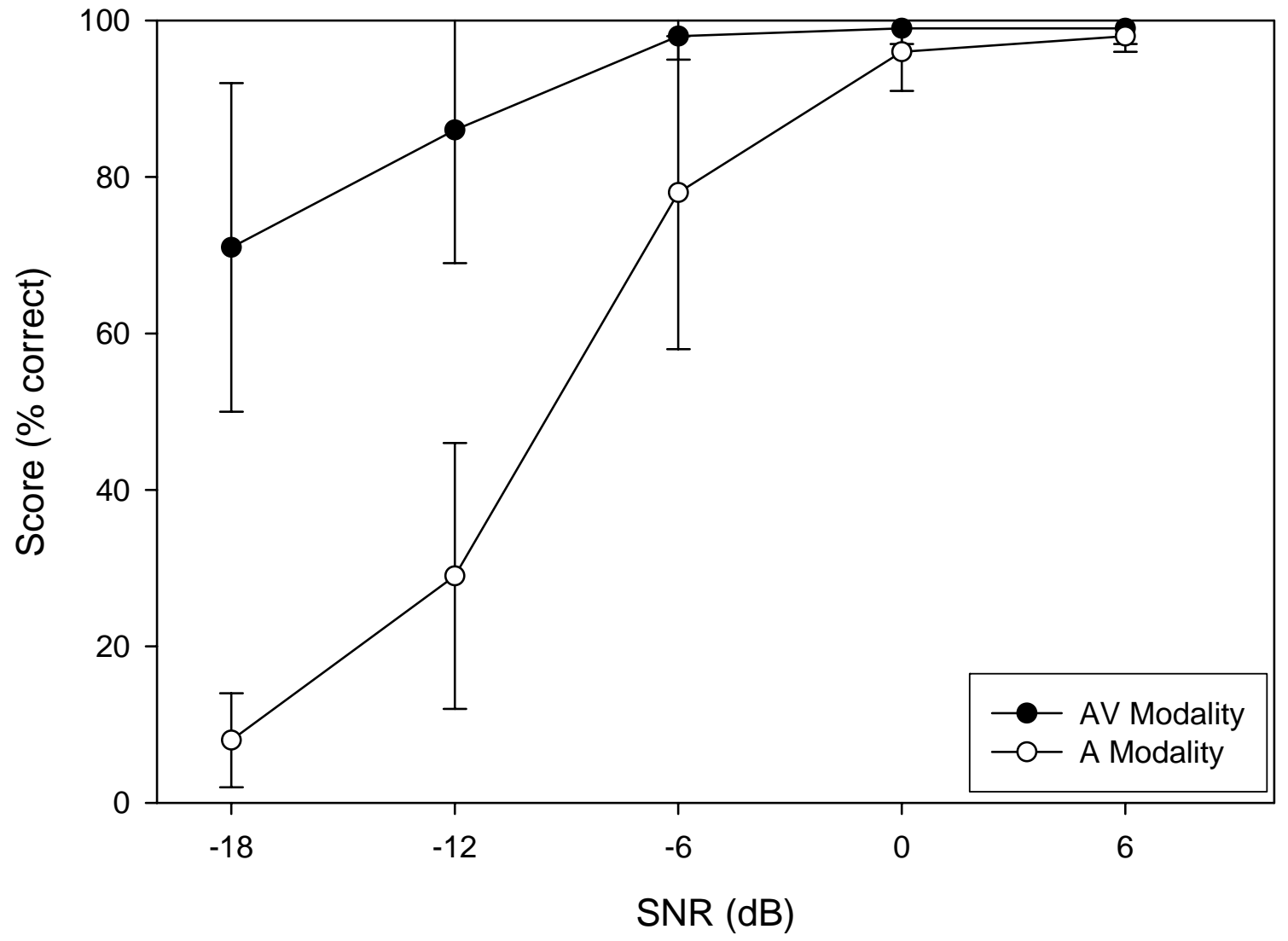

Effects of SNR and modality on scores were tested for statistical significance for American participants with a two-way (within-subject X within-subject) ANOVA. As shown in Table 1, significant differences $(p<.001)$ in scores were measured among the five SNRs and between the two modalities. A significant interaction $(p<.001)$ between SNR and modality also was measured. Therefore, null hypotheses $\mathrm{H}_{0} 1, \mathrm{H}_{0} 2$, and $\mathrm{H}_{0} 3$ were not accepted. A Partial Eta Squared $\left(\mathrm{n}^{2}\right)$ strength-of-association measure indicated that effects of SNR were related to $80 \%$ of the variability in scores; effects of modality were related to $59 \%$ of the variability in scores; 
and an interaction between SNR and modality was related to 55\% of the variability in scores. A Tukey HSD post-hoc test was conducted to evaluate pairwise differences between modalities among mean scores of the American participants at the five SNRs. As shown in Table 2, mean AV-scores differed significantly ( $\mathrm{p}<.05$, family-wise error rate) among all SNRs, except between the $+6 \mathrm{~dB}$ and the $0 \mathrm{~dB}$ SNRs, between the $+6 \mathrm{~dB}$ and the $-6 \mathrm{~dB}$ SNRs, and the $0 \mathrm{~dB}$ and $-6 \mathrm{~dB}$ SNRs. As shown in Table 3, mean A-scores for the A modality differed significantly $(\mathrm{p}<.05$, family-wise error rate) among all SNRs. A Tukey HSD post-hoc test was also conducted to evaluate pairwise differences between mean scores of the American participants for each modality at each SNR. Table 4 shows mean AV-scores were significantly higher ( $\mathrm{p}<.05$, familywise error rate) than mean A-scores at every SNR, except at $+6 \mathrm{~dB}$ SNR where mean scores differed by only $1 \%$ between modalities.

Figure 6 compares mean psychometric functions betweens the AV and A modalities for Indian participants. The psychometric function for the AV modality showed a broad ogive, with a mean AV-score of $23 \%$ achieved at the poorest (-18 dB) SNR, that rises gradually to near $90 \%$ at and above $0 \mathrm{~dB}$ SNR. In contrast, the psychometric function for the A modality showed an ogive, with a mean A-score of $3 \%$ achieved at the poorest (-18 dB) SNR, that rises more sharply to a slight plateau near $80 \%$ at and above $0 \mathrm{~dB}$ SNR. SDs for both psychometric functions showed less variability among participants at favorable SNRs and more variability among participants at poorer SNRs for both AV and A modalities. 
TABLE 1

TWO-WAY ANOVA TESTING EFFECTS OF SNR AND MODALITY ON SCORES OF AMERICAN PARTICIPANTS

\begin{tabular}{|l|c|c|c|c|c|c|}
\hline \multicolumn{1}{|c|}{ Source } & $\begin{array}{c}\text { Type III } \\
\text { Sum of } \\
\text { Squares }\end{array}$ & df & $\begin{array}{c}\text { Mean } \\
\text { Square }\end{array}$ & F & Sig. & $\begin{array}{c}\text { Partial } \\
\text { Eta } \\
\text { Squared }\end{array}$ \\
\hline Corrected Model & $28.249(\mathrm{a})$ & 9 & 3.139 & 210.788 & .000 & 0.867 \\
Intercept & 174.315 & 1 & 174.315 & 11706.3 & .000 & 0.976 \\
SNR & 16.935 & 4 & 4.234 & 284.322 & .000 & 0.797 \\
Sodality & 6.129 & 1 & 6.129 & 411.599 & .000 & 0.587 \\
Error & 5.185 & 4 & 1.296 & 87.051 & .000 & 0.546 \\
Total & 4.318 & 290 & 0.015 & & & \\
\hline
\end{tabular}

Effects of SNR and modality on scores were tested for statistical significance for Indian participants with a two-way (within-subject X within-subject) ANOVA. As shown in Table 5, differences in scores were significant $(p<.001)$ among the five SNRs and between the two modalities. A significant interaction $(p<.001)$ between SNR and modality also was measured. Therefore, $\mathrm{H}_{0} 4, \mathrm{H}_{0} 5$, and $\mathrm{H}_{0} 6$ were not accepted. $\mathrm{A}^{2}$ measure indicated that effects of SNR were related to $81 \%$ of the variability in scores; effects of modality were related to $31 \%$ of the variability in scores; and an interaction between SNR and modality was related to $7 \%$ of the 
variability in scores. Moreover, the interaction $\left(\mathrm{y}^{2}=.07\right)$ between SNR and modalities for Indian participants was considerably smaller than the interaction $\left(y^{2}=.546\right)$ between SNR and modality for American participants. This smaller interaction was reflected by how much more the AV and A psychometric functions paralleled one another for Indian participants (see Figure 6) than they did for American participants (see Figure 5). A Tukey HSD post-hoc test was conducted to evaluate pairwise differences between mean scores of the Indian participants at the five SNRs for each modality. As shown in Table 6, mean AV-scores differed significantly ( $p<.05$ family-wise error rate) among all SNRs, except between the $+6 \mathrm{~dB}$ and the $0 \mathrm{~dB}$ SNRs. As shown in Table 7, mean A-scores differed significantly ( $p<.05$ family-wise error rate) among SNRs, except between $+6 \mathrm{~dB}$ and $0 \mathrm{~dB}$, and between $-12 \mathrm{~dB}$ and $-18 \mathrm{~dB}$ SNRs. A Tukey HSD post-hoc test was also conducted to evaluate pairwise difference between mean scores of Indian participants for each modality at each SNR. Table 8 shows mean AV- and A-scores differed significantly $(p<.05$ family-wise error rate) at every SNR except at the +6 dB SNR where the mean AV-and A-scores differed by only $8 \%$. 
TABLE 2

TUKEY TEST RESULTS OF AMERICAN PARTICIPANTS COMPARING AV-SCORES BETWEEN SNRS

\begin{tabular}{|c|c|c|c|c|}
\hline $\begin{array}{c}\text { AV Modality } \\
\text { SNR (dB) }\end{array}$ & & $\begin{array}{c}\text { AV Modality } \\
\text { SNR (dB) }\end{array}$ & Mean Difference & Significance \\
\hline+6 & versus & 0 & $.3 \%$ & \\
\hline+6 & versus & -6 & $.9 \%$ & \\
\hline+6 & versus & -12 & $13 \%$ & $*$ \\
\hline+6 & versus & -18 & $28.6 \%$ & $*$ \\
\hline 0 & versus & -6 & $.6 \%$ & \\
\hline 0 & versus & -12 & $13 \%$ & $*$ \\
\hline 0 & versus & -18 & $28 \%$ & $*$ \\
\hline-6 & versus & -12 & $12 \%$ & $*$ \\
\hline-6 & versus & -18 & $28 \%$ & $*$ \\
\hline-12 & versus & -18 & $15 \%$ & $*$ \\
\hline
\end{tabular}

$*$ = significance level at $p<.05$ family-wise error rate 
TABLE 3

TUKEY TEST RESULTS OF AMERICAN PARTICIPANTS COMPARING A-SCORES BETWEEN SNRS

\begin{tabular}{|c|c|c|c|c|}
\hline $\begin{array}{c}\text { A Modality } \\
\text { SNR (dB) }\end{array}$ & & $\begin{array}{l}\text { A Modality } \\
\text { SNR (dB) }\end{array}$ & Mean Difference & Significance \\
\hline+6 & versus & 0 & $2 \%$ & $*$ \\
\hline+6 & versus & -6 & $20.8 \%$ & $*$ \\
\hline+6 & versus & -12 & $68.9 \%$ & $*$ \\
\hline+6 & versus & -18 & $90.6 \%$ & $*$ \\
\hline 0 & versus & -6 & $18.8 \%$ & $*$ \\
\hline 0 & versus & -12 & $66.9 \%$ & $*$ \\
\hline 0 & versus & -18 & $88.6 \%$ & $*$ \\
\hline-6 & versus & -12 & $48.1 \%$ & $*$ \\
\hline-6 & versus & -18 & $69.8 \%$ & * \\
\hline-12 & versus & -18 & $21.7 \%$ & $*$ \\
\hline
\end{tabular}

* = significance level at $p<.05$ family-wise error rate 
TABLE 4

TUKEY TEST RESULTS OF AMERICAN PARTICIPANTS COMPARING AV-SCORES AND A-SCORES AT EACH SNR

\begin{tabular}{ccccc}
\hline \hline $\begin{array}{c}\text { AV Modality } \\
\text { SNR (dB) }\end{array}$ & & $\begin{array}{c}\text { A Modality } \\
\text { SNR (dB) }\end{array}$ & $\begin{array}{c}\text { Mean Difference (AV- } \\
\text { A) }\end{array}$ & Significance \\
\hline \hline+6 & versus & +6 & $1 \%$ & \\
0 & versus & 0 & $2 \%$ & $*$ \\
-6 & versus & -6 & $21 \%$ & $*$ \\
-12 & versus & -12 & $56 \%$ & $*$ \\
-18 & & -18 & $63 \%$ & $*$ \\
\hline
\end{tabular}

$*$ significance level at $p<.05$ family-wise error rate 


\section{FIGURE 6}

PSYCHOMETRIC FUNCTIONS SHOWING MEANS AND SDS OF AV- AND A-SCORES FOR INDIAN PARTICIPANTS AT EACH SNR

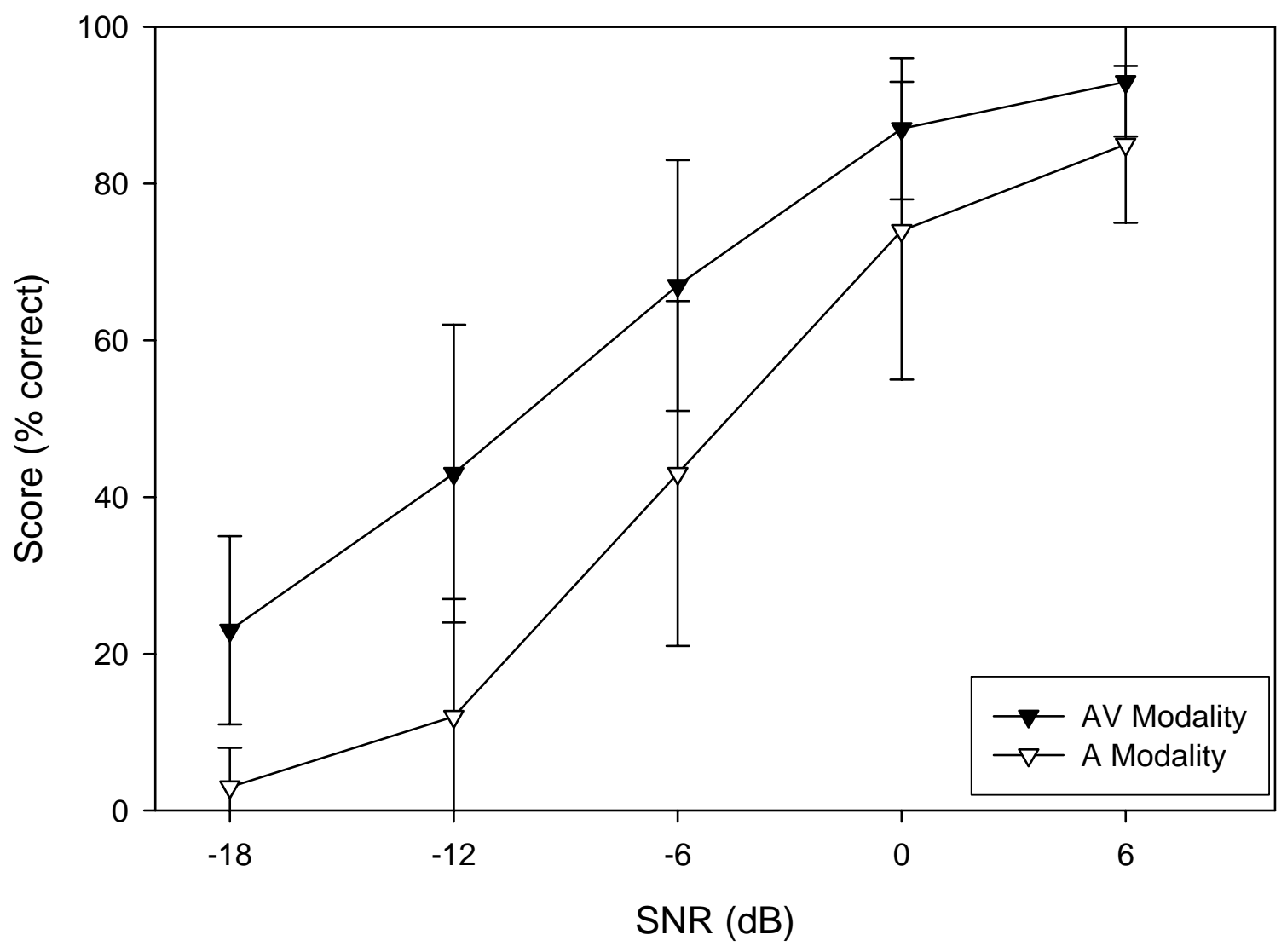


TABLE 5

TWO-WAY ANOVA TESTING EFFECTS OF SNRS AND MODALITY ON SCORES OF INDIAN PARTICIPANTS

\begin{tabular}{|c|c|c|c|c|c|c|}
\hline Source & $\begin{array}{c}\text { Type III } \\
\text { Sum of } \\
\text { Squares }\end{array}$ & df & $\begin{array}{c}\text { Mean } \\
\text { Square }\end{array}$ & F & Sig. & $\begin{array}{c}\text { Partial } \\
\text { Eta } \\
\text { Squared }\end{array}$ \\
\hline Corrected Model & $29.191(\mathrm{a})$ & 9 & 3.243 & 154.012 & .000 & 0.827 \\
Intercept & 84.185 & 1 & 84.185 & 3997.5 & .000 & 0.932 \\
SNR & 26.033 & 4 & 6.508 & 309.044 & .000 & 0.81 \\
Modality & 2.689 & 1 & 2.689 & 127.664 & .000 & 0.306 \\
SNR x Modality & 0.469 & 4 & 0.117 & 5.567 & .000 & 0.071 \\
Error & 6.107 & 290 & 0.021 & & & \\
Total & 119.483 & 300 & & & & \\
Corrected Total & 35.298 & 299 & & & & \\
\hline
\end{tabular}


TABLE 6

TUKEY TEST RESULTS OF INDIAN PARTICIPANTS COMPARING AV-SCORES BETWEEN SNRS

\begin{tabular}{|c|c|c|c|c|}
\hline $\begin{array}{l}\text { AV Modality } \\
\text { SNR (dB) } \\
\end{array}$ & & $\begin{array}{c}\text { AV Modality } \\
\text { SNR (dB) } \\
\end{array}$ & Mean Difference & Significance \\
\hline+6 & versus & 0 & $.6 \%$ & \\
\hline+6 & versus & -6 & $26 \%$ & * \\
\hline+6 & versus & -12 & $51 \%$ & $*$ \\
\hline+6 & versus & -18 & $71 \%$ & * \\
\hline 0 & versus & -6 & $21 \%$ & $*$ \\
\hline 0 & versus & -12 & $45 \%$ & * \\
\hline 0 & versus & -18 & $65 \%$ & $*$ \\
\hline-6 & versus & -12 & $24 \%$ & $*$ \\
\hline-6 & versus & -18 & $44 \%$ & $*$ \\
\hline-12 & versus & -18 & $20 \%$ & * \\
\hline
\end{tabular}

* = significance level at $p<.05$ family-wise error rate 
TABLE 7

TUKEY TEST RESULTS OF INDIAN PARTICIPANTS COMPARING A-SCORES BETWEEN SNRS

\begin{tabular}{|c|c|c|c|c|}
\hline $\begin{array}{l}\text { A Modality } \\
\text { SNR (dB) }\end{array}$ & & $\begin{array}{c}\text { A Modality } \\
\text { SNR (dB) }\end{array}$ & Mean Difference & Significance \\
\hline+6 & versus & 0 & $11 \%$ & \\
\hline+6 & versus & -6 & $43 \%$ & $*$ \\
\hline+6 & versus & -12 & $62 \%$ & $*$ \\
\hline+6 & versus & -18 & $82 \%$ & $*$ \\
\hline 0 & versus & -6 & $31 \%$ & $*$ \\
\hline 0 & versus & -12 & $-62 \%$ & $*$ \\
\hline 0 & versus & -18 & $-71 \%$ & $*$ \\
\hline-6 & versus & -12 & $-31 \%$ & $*$ \\
\hline-6 & versus & -18 & $-40 \%$ & $*$ \\
\hline-12 & versus & -18 & $-9 \%$ & \\
\hline
\end{tabular}

* = significance level at $p<.05$ family-wise error rate 
TABLE 8

TUKEY TEST RESULTS OF INDIAN PARTICIPANTS
COMPARING AV-SCORES AND A-SCORES AT EACH SNR

\begin{tabular}{ccccc}
\hline \hline $\begin{array}{c}\text { AV Modality } \\
\text { SNR (dB) }\end{array}$ & & $\begin{array}{c}\text { A Modality } \\
\text { SNR (dB) }\end{array}$ & $\begin{array}{c}\text { Mean Difference } \\
\text { (AV-A) }\end{array}$ & Significance \\
\hline \hline+6 & versus & +6 & $8 \%$ & \\
0 & versus & 0 & $13 \%$ & $*$ \\
-6 & versus & -6 & $24 \%$ & $*$ \\
-12 & versus & -12 & $30 \%$ & $*$ \\
-18 & versus & -18 & $19 \%$ & $*$ \\
\hline
\end{tabular}

$*=$ significance level at $p<.05$ family-wise error rate

Effects of Language Group and SNR on AV-scores and A-scores

Figure 7 compares mean psychometric functions between American and Indian participants for the AV modality. The psychometric function of the American participants was plotted above (i.e., had higher mean AV-scores) the psychometric function of the Indian participants at all SNRs. Specifically, the two functions separated the most at poorer SNRs and converged, but never met, at higher SNRs. Effects of language group and SNR on AV-scores were tested for statistical significance for American and Indian participants with a two-way (between-subject X within-subject) ANOVA. As shown in Table 9, significant differences $(p<.001)$ were measured between language groups and among SNRs. A significant interaction $(p<.001)$ also was measured between language group and SNRs. Therefore, $\mathrm{H}_{0} 7$ was not accepted. $A \eta^{2}$ measure indicated effects of language group were related to $56 \%$ of the variability 
in AV-scores; effects of SNR were related to 69\% of the variability in AV-scores; and an interaction between language group and SNR was related to $31 \%$ of the variability in AV-scores. Planned pairwise comparisons at each SNR were conducted among mean AV-scores for American and Indian participants using the Holm's sequential Bonferroni procedure. As shown in Table 10, AV-scores were significantly higher ( $\mathrm{p}<.05$ family-wise error rate) for American participants than for Indian participants at all SNRs. The differences in mean AV-scores ranged from only $6 \%$ higher for American participants at most favorable SNR (+6 dB) to $48 \%$ at the poorer SNR (-18dB). In other words, differences in AV-scores between American and Indian participants grew systematically as the SNR became poorer, thereby reflecting a relatively strong interaction between SNR and language group. 


\section{FIGURE 7}

\section{PSYCHOMETRIC FUNCTIONS SHOWING MEANS AND SDS OF AV-SCORES}

FOR AMERICAN AND INDIAN PARTICIPANTS

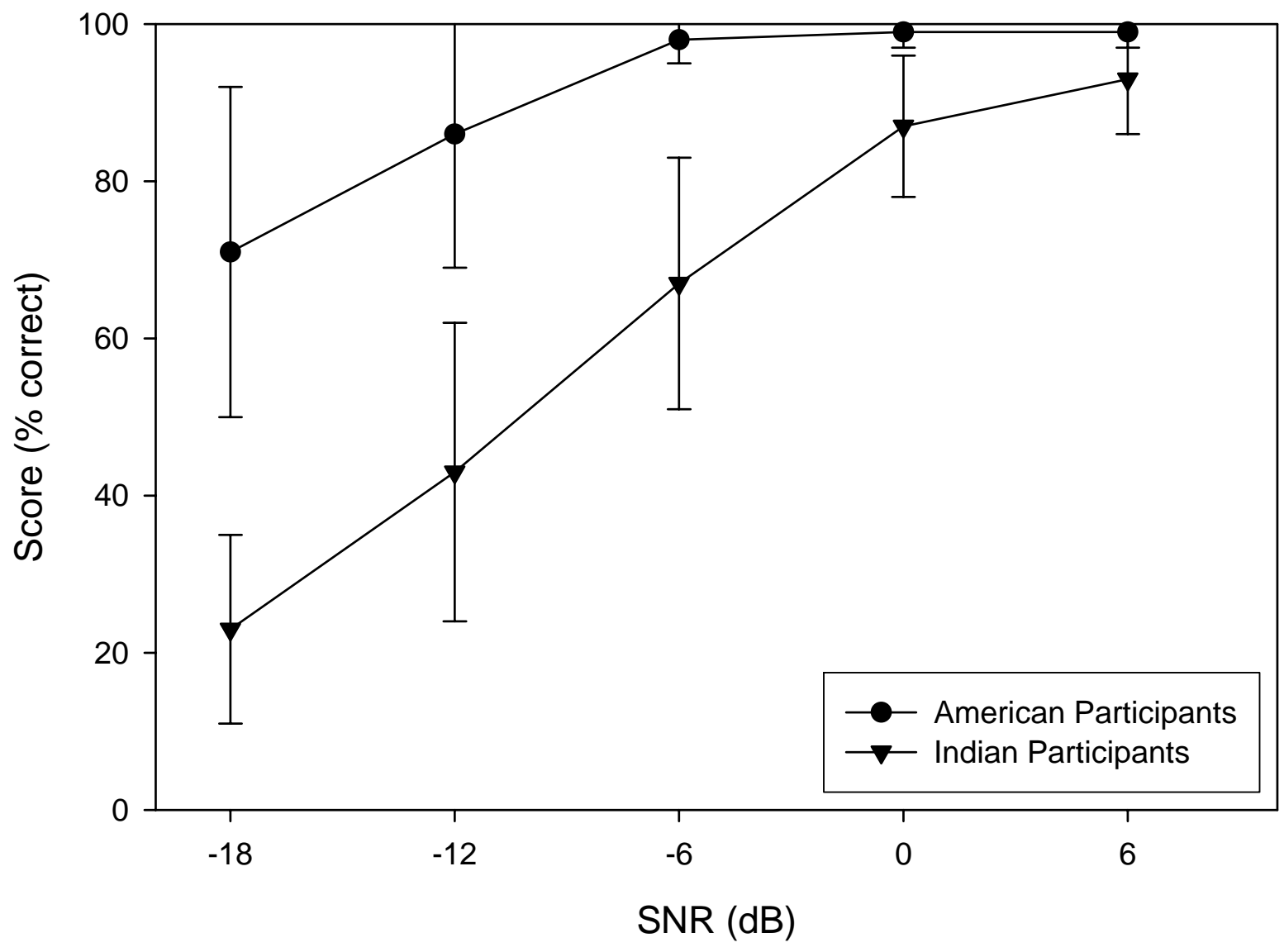


TABLE 9

TWO-WAY ANOVA TESTING EFFECTS OF LANGUAGE GROUP AND SNR ON AV-SCORES

\begin{tabular}{|c|c|c|c|c|c|c|}
\hline Source & $\begin{array}{c}\text { Type III } \\
\text { Sum of } \\
\text { Squares }\end{array}$ & df & $\begin{array}{c}\text { Mean } \\
\text { Square }\end{array}$ & F & Sig. & $\begin{array}{c}\text { Partial } \\
\text { Eta } \\
\text { Squared }\end{array}$ \\
\hline Corrected Model & $18.459(\mathrm{a})$ & 9 & 2.051 & 126.099 & .000 & .796 \\
Intercept & 175.476 & 1 & 175.476 & 10788.356 & .000 & .974 \\
Language & 5.914 & 1 & 5.914 & 363.575 & .000 & .556 \\
SNR & 10.456 & 4 & 2.614 & 160.716 & .000 & .689 \\
Language x SNR & 2.089 & 4 & .522 & 32.113 & .000 & .307 \\
Error & 4.717 & 290 & .016 & & & \\
Total & 198.652 & 300 & & & & \\
Corrected Total & 23.176 & 299 & & & & \\
\hline
\end{tabular}


TABLE 10

MEAN DIFFERENCES IN AV-SCORES

BETWEEN AMERICAN AND INDIAN PARTICIPANTS AT EACH SNR

\begin{tabular}{ccccc}
\hline \hline $\begin{array}{c}\text { AV Modality } \\
\text { SNR (dB) }\end{array}$ & $\begin{array}{c}\text { American Participants } \\
\text { Mean }\end{array}$ & $\begin{array}{c}\text { Indian Participants } \\
\text { Mean }\end{array}$ & $\begin{array}{c}\text { American-Indian } \\
\text { Mean Difference }\end{array}$ & Significance \\
\hline \hline+6 & $99 \%$ & $93 \%$ & $6 \%$ & $*$ \\
0 & $99 \%$ & $87 \%$ & $12 \%$ & $*$ \\
-6 & $98 \%$ & $67 \%$ & $32 \%$ & $*$ \\
-12 & $86 \%$ & $43 \%$ & $43 \%$ & $*$ \\
-18 & $71 \%$ & $23 \%$ & $48 \%$ & $*$ \\
\hline
\end{tabular}

$*=$ significance level at $p<.05$ family-wise error rate

Figure 8 compares mean psychometric functions between American and Indian participants for the A modality. The psychometric function of the American participants was plotted above (i.e., had higher mean A-scores) the psychometric function of the Indian participants at all SNRs. Specifically, the two functions separated the most at intermediate SNRs and converged, but never met, at poorer SNRs. Effects of language group and SNR on A-scores were tested for statistical significance for American and Indian participants with a two-way (between-subject X within-subject) ANOVA. As shown in Table 11, significant differences $(p<.001)$ were measured between language groups and among SNRs. A significant interaction $(p<.001)$ also was measured between language group and SNR. Therefore, $\mathrm{H}_{0} 8$ was not accepted. $\mathrm{A} \mathrm{y}^{2}$ measure indicated effects of language group were related to $31 \%$ of the variability in Ascores; effects of SNR were related to $86 \%$ of the variability in A-scores; and an interaction between language group and SNR was related to $12 \%$ of the variability in A-scores. Planned pairwise comparisons at each SNR were conducted among mean A-scores for American and 
Indian participants using the Holm's Sequential Bonferroni procedure. As shown in Table 12, Ascores were significantly higher ( $\mathrm{p}<.05$ family-wise error rate) for American participants than for Indian participants at all SNRs. The differences in mean A-scores, however, were greatest at the intermediate SNR (-6 dB) and least at the extreme SNRs (+6 dB, $-18 \mathrm{~dB})$. In other words, while an interaction between language group and SNR was evident for the A-scores, it was not nearly as strong as the interaction between language group and SNR for AV-scores.

\section{FIGURE 8}

PSYCHOMETRIC FUNCTIONS SHOWING MEANS AND SDS OF A-SCORES FOR AMERICAN AND INDIAN PARTICIPANTS

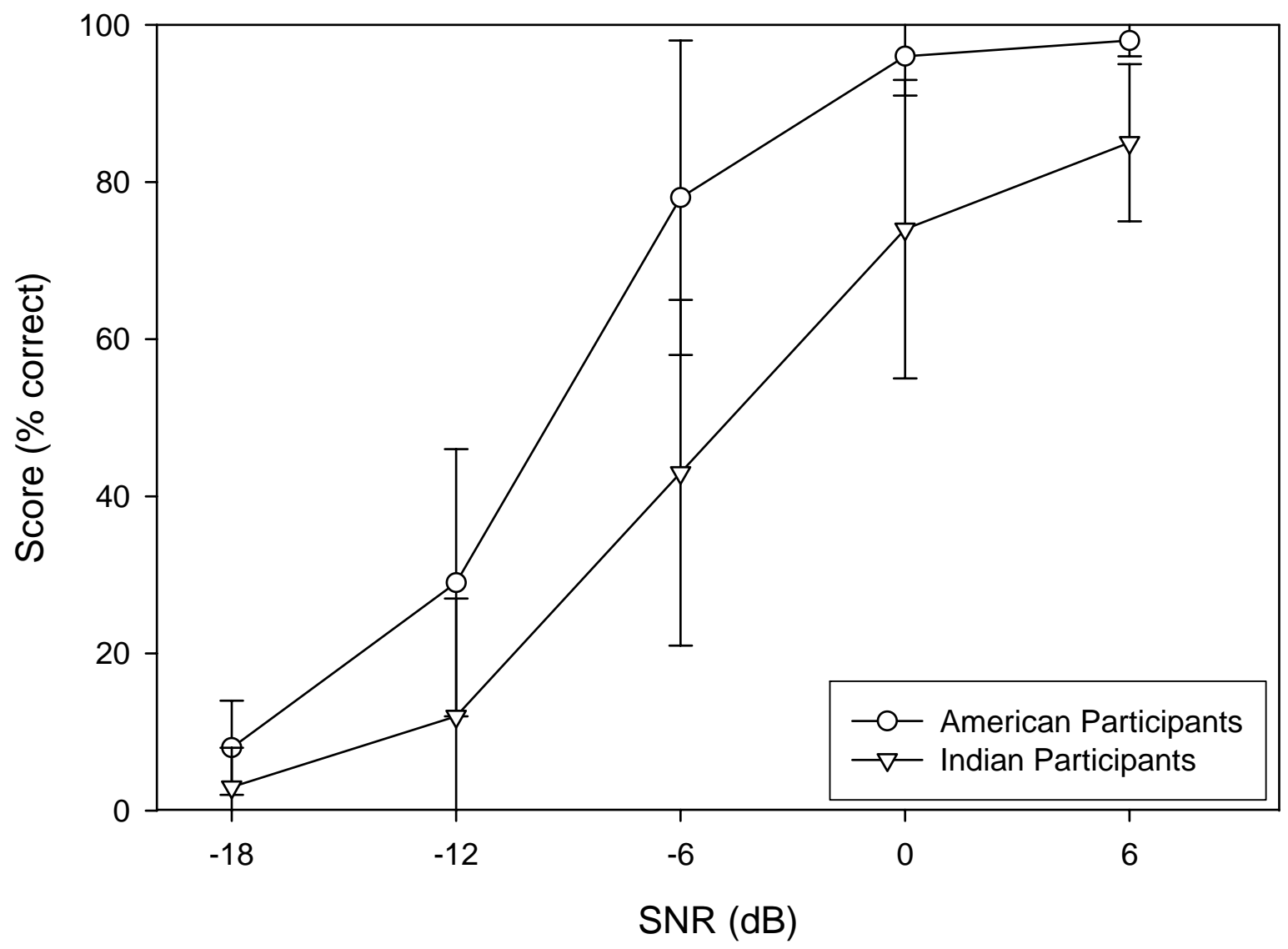


TABLE 11

TWO-WAY ANOVA TESTING EFFECTS OF LANGUAGE GROUP AND SNR ON A-SCORES

\begin{tabular}{|c|c|c|c|c|c|c|}
\hline & $\begin{array}{c}\text { Type III } \\
\text { Sum of } \\
\text { Squares }\end{array}$ & $\mathrm{df}$ & $\begin{array}{c}\text { Mean } \\
\text { Square }\end{array}$ & $\mathrm{F}$ & Sig. & $\begin{array}{c}\text { Partial } \\
\text { Eta } \\
\text { Squared }\end{array}$ \\
\hline Corrected Model & $38.623(\mathrm{a})$ & 9 & 4.291 & 218.007 & .000 & .871 \\
Intercept & 83.382 & 1 & 83.382 & 4235.839 & .000 & .936 \\
Language & 2.547 & 1 & 2.547 & 129.367 & .000 & .308 \\
SNR & 35.315 & 4 & 8.829 & 448.499 & .000 & .861 \\
Language x SNR & .762 & 4 & .190 & 9.676 & .000 & .118 \\
Error & 5.709 & 290 & .020 & & & \\
Total & 127.714 & 300 & & & & \\
Corrected Total & 44.332 & 299 & & & & \\
\hline
\end{tabular}


TABLE 12

MEAN DIFFERENCES IN A-SCORES

BETWEEN AMERICAN AND INDIAN PARTICIPANTS AT EACH SNR

\begin{tabular}{ccccc}
\hline \hline $\begin{array}{c}\text { A Modality } \\
\text { SNR (dB) }\end{array}$ & $\begin{array}{c}\text { American Participants } \\
\text { Mean }\end{array}$ & $\begin{array}{c}\text { Indian Participants } \\
\text { Mean }\end{array}$ & American-Indian & Significance \\
\hline \hline+6 & $98 \%$ & $85 \%$ & $13 \%$ & $*$ \\
0 & $96 \%$ & $74 \%$ & $22 \%$ & $*$ \\
-6 & $78 \%$ & $43 \%$ & $35 \%$ & $*$ \\
-12 & $29 \%$ & $12 \%$ & $17 \%$ & $*$ \\
-18 & $8 \%$ & $3 \%$ & $5 \%$ & $*$ \\
\hline
\end{tabular}

$*=$ significance level at $p<.05$ family-wise error rate

Effects of Language Group and SNR on VE-scores

As shown in Figure 9, mean VE-scores of American participants ranged from over 30\% at poorer $(-18 \mathrm{~dB},-12 \mathrm{~dB}) \mathrm{SNRs}$ to less than $3 \%$ at favorable $(0 \mathrm{~dB},+6 \mathrm{~dB}) \mathrm{SNRs}$. That is, VEscores of American participants grew systematically higher as the SNRs became poorer.

Conversely, mean VE-scores of Indian participants were similar across SNRs ranging from 6\% at $+6 \mathrm{~dB}$ SNR to $15 \%$ at $-12 \mathrm{~dB}$ SNR. That is, unlike the VE-scores of American participants, VEscores of Indian participants did not grow systematically with changes in SNR; instead, they showed only minor changes across SNRs. 
FIGURE 9

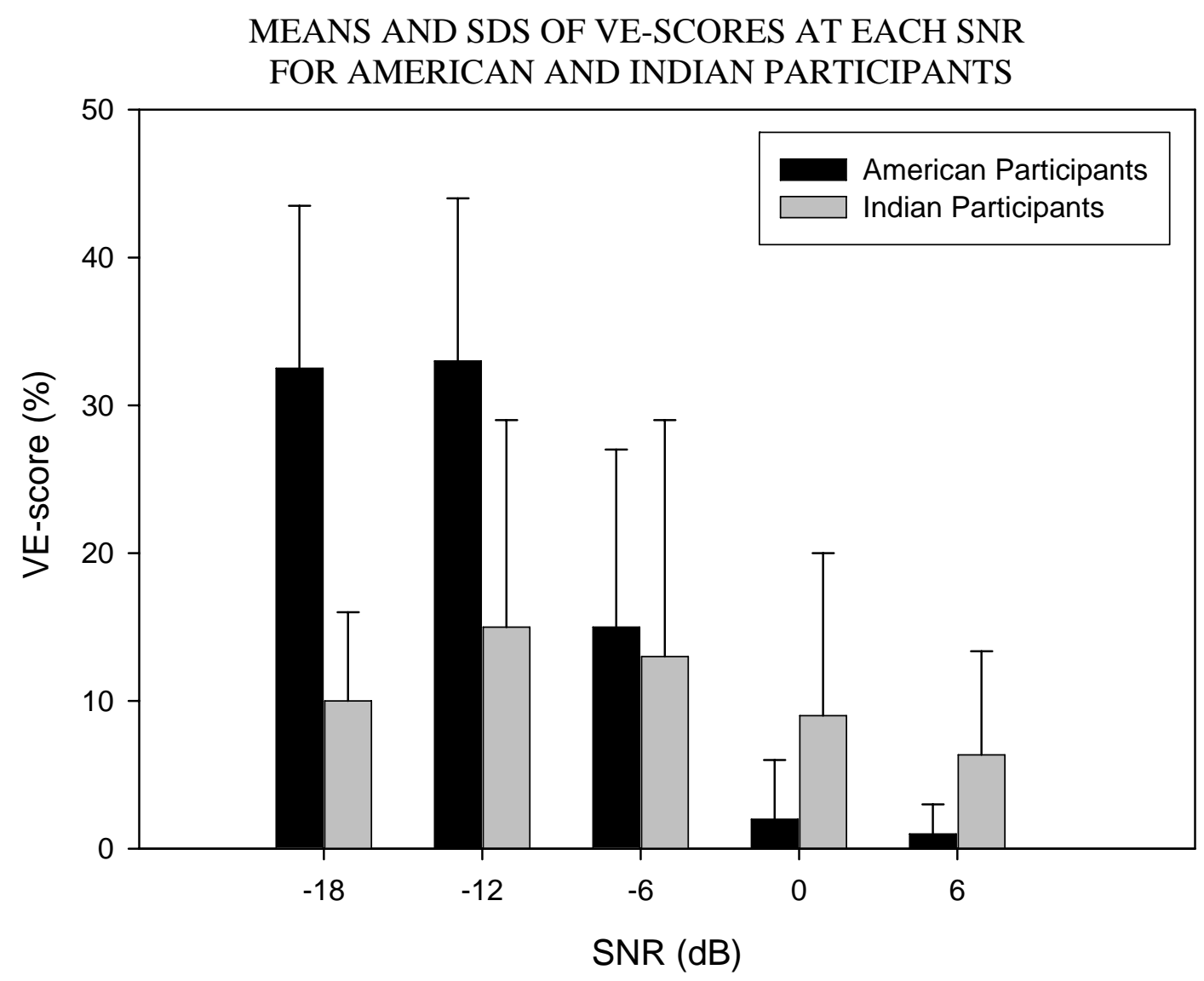

VE-scores of American and Indian participants were analyzed for statistical significance at each SNR using a two-way (within-subject X within-subject) ANOVA. As shown in Table 13, significant differences $(p<.001)$ were measured between language groups and among SNRs. A significant interaction $(p<.001)$ also was measured between language group and SNR. Therefore, $\mathrm{H}_{0} 9, \mathrm{H}_{0} 10, \mathrm{H}_{0} 11$, and $\mathrm{H}_{0} 12$ were not accepted. $\mathrm{A} \mathrm{\eta}^{2}$ indicated that effects of language group were related to $7 \%$ of the variability in VE-scores; effects of SNR were related to 37\% of the variability in VE-scores; and an interaction between language group and SNR was related to $25 \%$ of the variability in VE-scores. 
TABLE 13

TWO-WAY ANOVA SHOWING EFFECTS OF LANGUAGE GROUP AND SNR ON VE-SCORES OF AMERICAN AND INDIAN PARTICIPANTS

\begin{tabular}{|c|c|c|c|c|c|c|}
\hline Source & $\begin{array}{c}\text { Type III } \\
\text { Sum of } \\
\text { Squares }\end{array}$ & df & $\begin{array}{c}\text { Mean } \\
\text { Square }\end{array}$ & $\mathrm{F}$ & Sig. & $\begin{array}{c}\text { Partial Eta } \\
\text { Squared }\end{array}$ \\
\hline Corrected Model & $3.333(\mathrm{a})$ & 9 & .370 & 31.773 & .000 & .496 \\
Intercept & 5.617 & 1 & 5.617 & 481.963 & .000 & .624 \\
Language & .255 & 1 & .255 & 21.898 & .000 & .070 \\
SNR & 1.980 & 4 & .495 & 42.470 & .000 & .369 \\
Language x SNR & 1.098 & 4 & .274 & 23.546 & .000 & .245 \\
Error & 3.380 & 290 & .012 & & & \\
Total & 12.330 & 300 & & & & \\
Corrected Total & 6.712 & 299 & & & & \\
\hline
\end{tabular}

Holm's Sequential Bonferroni procedure was conducted to evaluate planned pairwise differences between mean VE-scores of American and of Indian participants at different SNRs. As shown in Table 14, mean VE-scores of American participants at the three poorer SNRs (-18dB, $-12 \mathrm{~dB}$, and $-6 \mathrm{~dB}$ ) were significantly higher ( $p<.05$ family-wise error rate) than mean VE-scores at the two most favorable SNRs ( $+6 \mathrm{~dB}$ and $0 \mathrm{~dB}$ ). In contrast to American participants, mean VEscores of Indian participants did not differ significantly ( $p<.05$ family-wise error rate) at all but one SNR (see Table 15). Finally, planned pairwise comparisons were analyzed between mean VE-scores of American and Indian participants at each SNR. As shown in Table 16, VE-scores were significantly different ( $p<.05$ family-wise error rate) between American and Indian 
participants at all SNRs except the intermediate SNR of -6 dB. Specifically, VE-scores were significantly higher for Indian participants than American participants at favorable SNRs, but significantly higher for American participants than Indian participants at poorer SNRs.

Effects of Language Group on AV-score @ (A) SNR-50

Appendix P shows the raw (A) SNR-50 data and the raw AV-score @SNR-50 data for each of the 30 American participants and 30 Indian participants. Likewise, Figure 10 and Figure 11 display the mean (A) SNR-50 results and the mean AV-score @ (A) SNR-50 results for American and Indian participants, respectively, based upon their psychometric functions for the AV and A modalities. The (A) SNR-50 for American participants (mean $=-9.3 \mathrm{~dB}$, SNR, SD = 2.6) was achieved at nearly a $5 \mathrm{~dB}$ poorer SNR than the mean (A) SNRs-50 for Indian participants (mean $=-4.4 \mathrm{~dB} \mathrm{SNR}, \mathrm{SD}=3.6$ ). A t-test for independent samples indicated the mean (A) SNR-50 of American participants was significantly poorer [ $t(29)=-5.35, p<.001]$ than the mean (A) SNR-50 of Indian participants. Therefore, $\mathrm{H}_{0} 12$ was not accepted. In other words, the American participants could understand the same amount (i.e., half) of the keywords in the sentences at a poorer SNR than the Indian participants. 
TABLE 14

COMPARISON OF VE-SCORES AMONG SNRS FOR AMERICAN PARTICIPANTS

\begin{tabular}{|c|c|c|c|c|}
\hline SNR (dB) & & SNR $(\mathrm{dB})$ & $\begin{array}{c}\text { VE-score } \\
\text { Mean Difference } \\
\end{array}$ & Significance \\
\hline+6 & versus & 0 & $1.5 \%$ & \\
\hline+6 & versus & -6 & $14 \%$ & * \\
\hline+6 & versus & -12 & $32 \%$ & * \\
\hline+6 & versus & -18 & $32 \%$ & * \\
\hline 0 & versus & -6 & $13 \%$ & $*$ \\
\hline 0 & versus & -12 & $30 \%$ & * \\
\hline 0 & versus & -18 & $30 \%$ & $*$ \\
\hline-6 & versus & -12 & $18 \%$ & $*$ \\
\hline-6 & versus & -18 & $18 \%$ & $*$ \\
\hline-12 & versus & -18 & $0 \%$ & \\
\hline
\end{tabular}


TABLE 15

COMPARISON OF VE-SCORES AMONG SNRS FOR INDIAN PARTICIPANTS

\begin{tabular}{|c|c|c|c|c|}
\hline SNR (dB) & & $\mathrm{SNR}(\mathrm{dB})$ & $\begin{array}{c}\text { VE-score } \\
\text { Mean Difference } \\
\end{array}$ & Significance \\
\hline+6 & versus & 0 & $3 \%$ & \\
\hline+6 & versus & -6 & $7 \%$ & \\
\hline+6 & versus & -12 & $9 \%$ & $*$ \\
\hline+6 & versus & -18 & $4 \%$ & \\
\hline 0 & versus & -6 & $4 \%$ & \\
\hline 0 & versus & -12 & $6 \%$ & \\
\hline 0 & versus & -18 & $1 \%$ & \\
\hline-6 & versus & -12 & $2 \%$ & \\
\hline-6 & versus & -18 & $4 \%$ & \\
\hline-12 & versus & -18 & $6 \%$ & \\
\hline
\end{tabular}

* = significance level at $p<.05$ family-wise error rate 
TABLE 16

COMPARISON OF VE-SCORES BETWEEN AMERICAN AND INDIAN PARTICIPANTS AT EACH SNR

\begin{tabular}{ccccc}
\hline \hline SNR (dB) & $\begin{array}{c}\text { American Participants } \\
\text { Mean VE-score }\end{array}$ & $\begin{array}{c}\text { Indian Participants } \\
\text { Mean VE-score }\end{array}$ & Mean Difference & Significance \\
\hline \hline+6 & $1 \%$ & $6 \%$ & $-5 \%$ & $*$ \\
0 & $2 \%$ & $9 \%$ & $-7 \%$ & $*$ \\
-6 & $15 \%$ & $13 \%$ & $2 \%$ & \\
-12 & $33 \%$ & $15 \%$ & $18 \%$ & $*$ \\
-18 & $33 \%$ & $10 \%$ & $23 \%$ & $*$ \\
\hline
\end{tabular}

* = significance level at $p<.05$ family-wise error rate

Likewise, the AV-score @ (A) SNR-50 for American participants (mean = 91\%, SD = .12) was nearly $17 \%$ higher than the mean AV-score @ (A) SNRs-50 for Indian participants (mean $=74 \%, \mathrm{SD}=.12)$. A t-test for independent samples indicated the mean AV-score @ (A) SNR-50 of American participants was significantly higher $[t(29)=6.39, p<.001]$ than the mean AV-score @ (A) SNR-50 of Indian participants. Therefore, $\mathrm{H}_{0} 13$ was not accepted. In other words, AV-scores of American participants were significantly higher than AV-scores of Indian participants when both groups were listening at a SNR in which their A-scores were the same. 
FIGURE 10

MEAN (A) SNR-50 AND MEAN AV-SCORE @ (A) SNR-50 FOR AMERICAN PARTICIPANTS

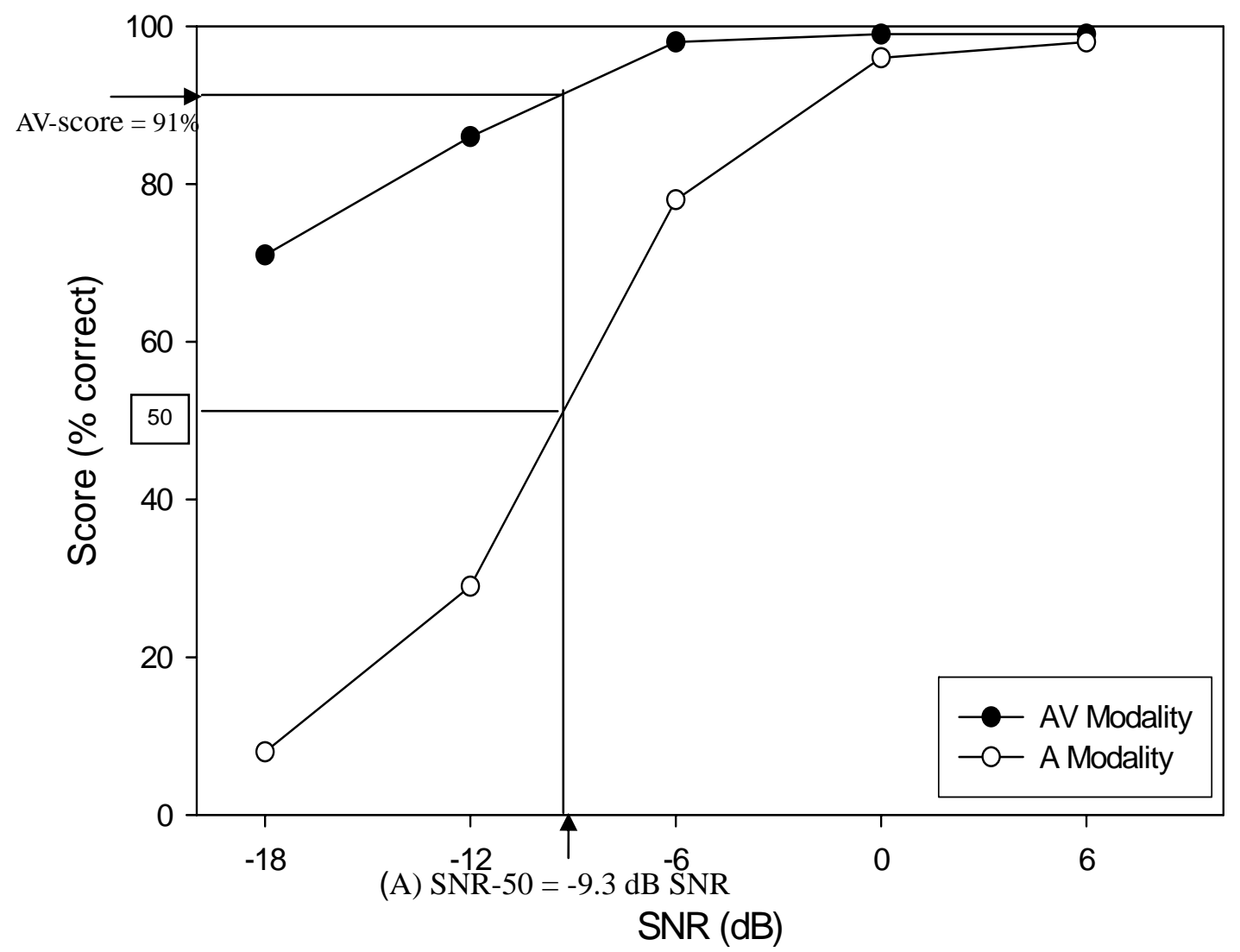

Correlation between (A) SNR-50 and AV-score @ (A) SNR-50

Figure 12 is a scatter plot displaying the association between each American participant's (A) SNR-50 and their AV-score @ (A) SNR-50. A Pearson Product-Moment Correlation indicated no significant correlation $[r(28)=.28, p>.05]$ between (A) SNR-50 and AV-score @ (A) SNR-50 for American participants. In other words, AV scores were not necessarily higher for American participants who had (A) SNR-50s at either more favorable SNRs or poorer SNRs. This may be due, at least in part, to a ceiling effect in which many of American participants improved up to 50\% more (i.e., achieved at or near a 100\% AV-score) in the AV modality at the 
SNR they had a 50\% in the A modality. In contrast, Figure 13 is another scatter plot displaying the association between each Indian participant’s (A) SNR-50 and their AV-score @ (A) SNR-50. A Pearson Product-Moment Correlation indicated a significant positive correlation $[r(28)=.49$, $p<.001$ ] between (A) SNR-50 and AV-score @ (A) SNR-50 for Indian participants. In other words, AV-scores tended to be higher for Indian participants who understood half of the keywords in the sentences at more favorable SNRs. Conversely AV-scores tended to be lower for Indian participants who understood half of the keywords at poorer SNRs. This may be due, at least in part, to no ceiling effect for nearly all Indian participants. That is, none of them improved up to $50 \%$ more (i.e., achieved at or near a $100 \%$ AV-score) in the AV modality at the SNR they had a $50 \%$ in the A modality.

Association between AV-scores @ (A) SNR-50 and Linguistic Measures

The AV-scores @ (A) SNR-50 of the 30 Indian participants was correlated with nine linguistic measures: (1) TOEFL score, (2) months of living in the United States, (3) age when starting to learn English, (4) self-rated competence speaking American English, (5) self-rated competence understanding American English, (6) self-rated competence reading American English, (7) self-rated competence writing American English, (8) median judges' rating of speech comprehensibility, and (9) median judges’ rating of foreign accentedness. Nine separate Pearson Product-Moment Correlations indicated no significant correlations ( $p>.05$ family-wise error rate) between AV-scores @ (A) SNR-50 and any of nine linguistic measures for (Table 17). 
FIGURE 11

MEAN(A) SNR-50 AND MEAN AV-SCORE @ (A) SNR-50 FOR INDIAN PARTICIPANTS

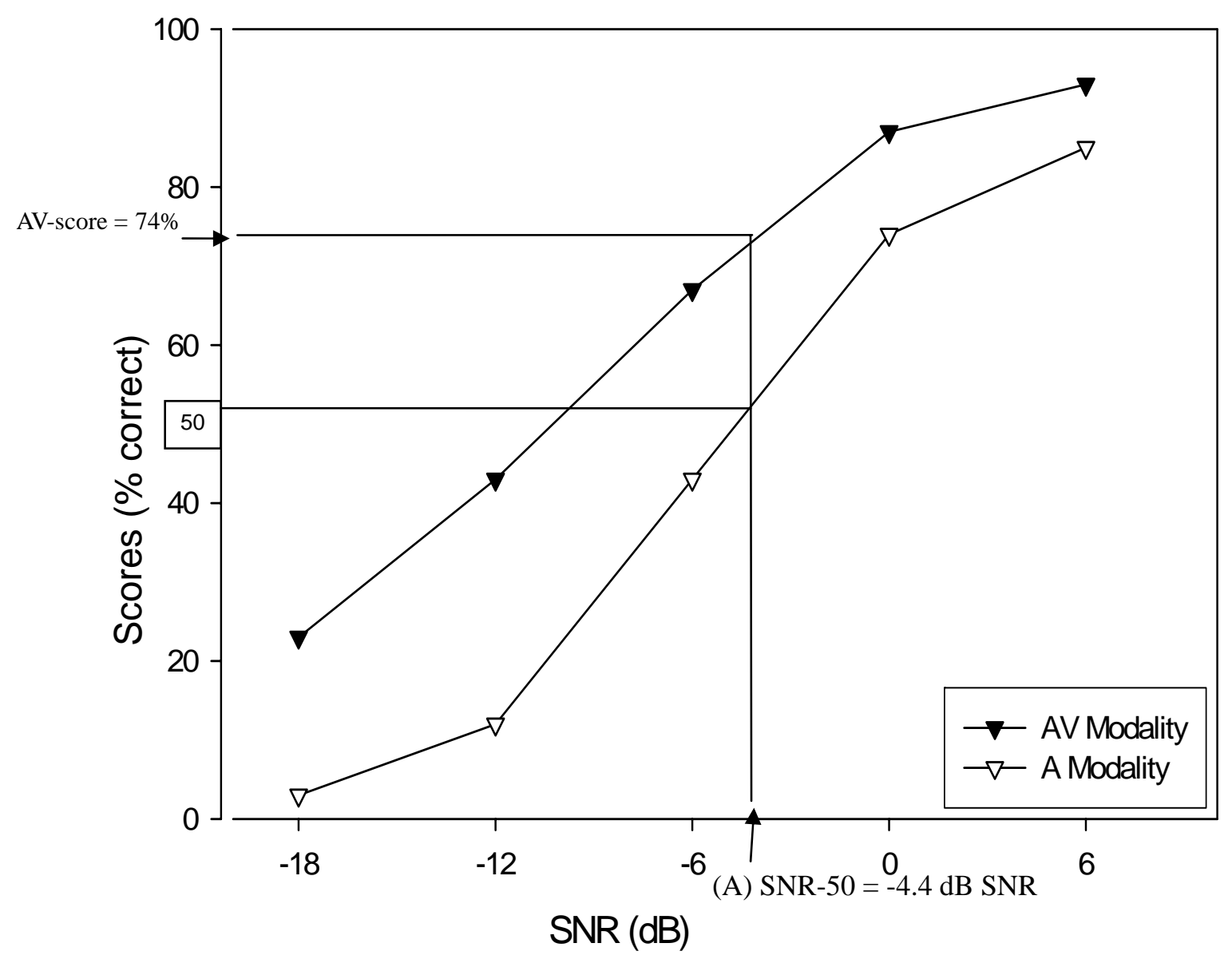


FIGURE 12

CORRELATION BETWEEN (A) SNR-50 AND AV-SCORE @ (A) SNR-50 FOR AMERICAN PARTICIPANTS

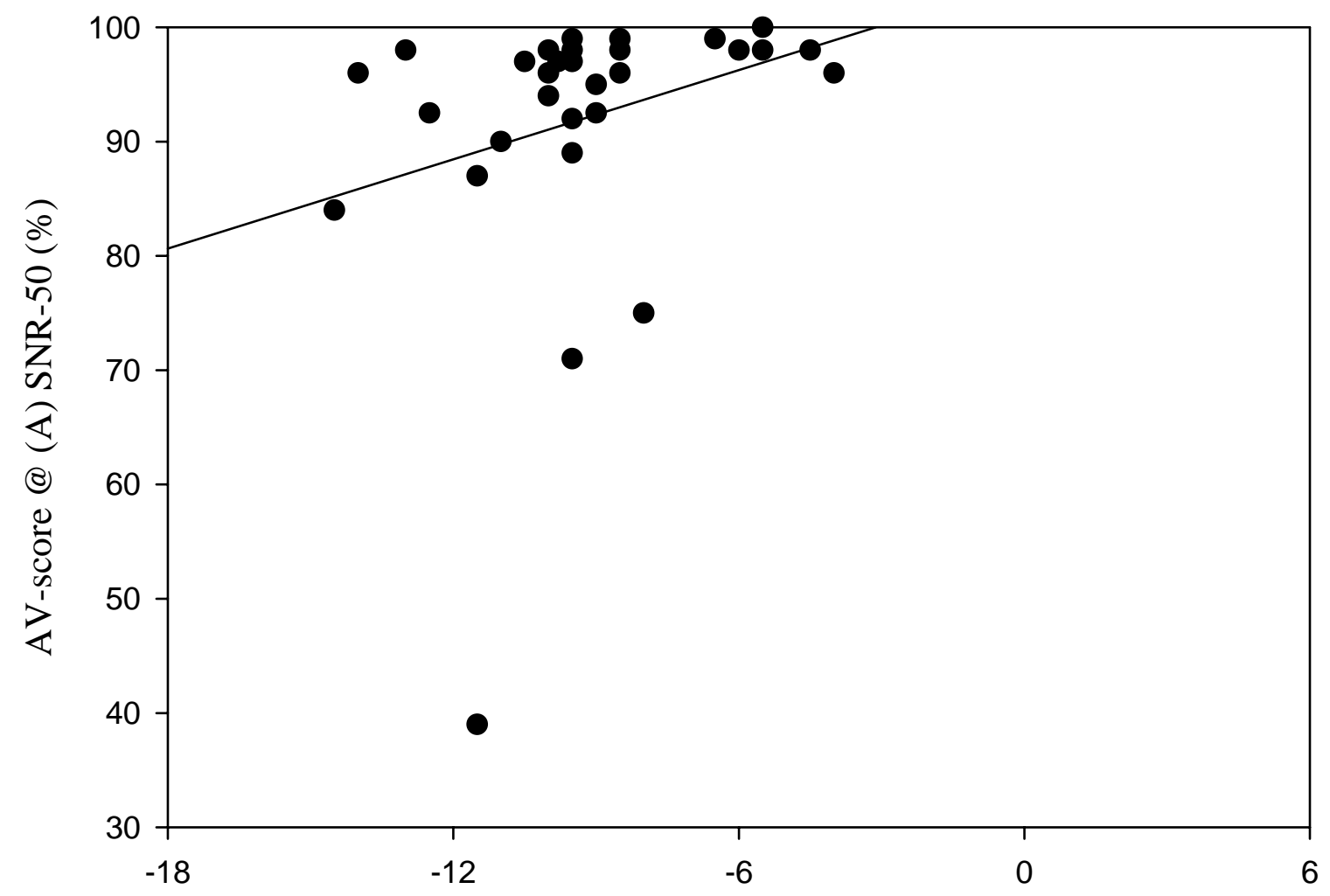

(A) SNR-50 (dB) 
FIGURE 13

CORRELATION BETWEEN (A) SNR-50 AND AV-SCORE @ (A) SNR-50 FOR INDIAN PARTICIPANTS

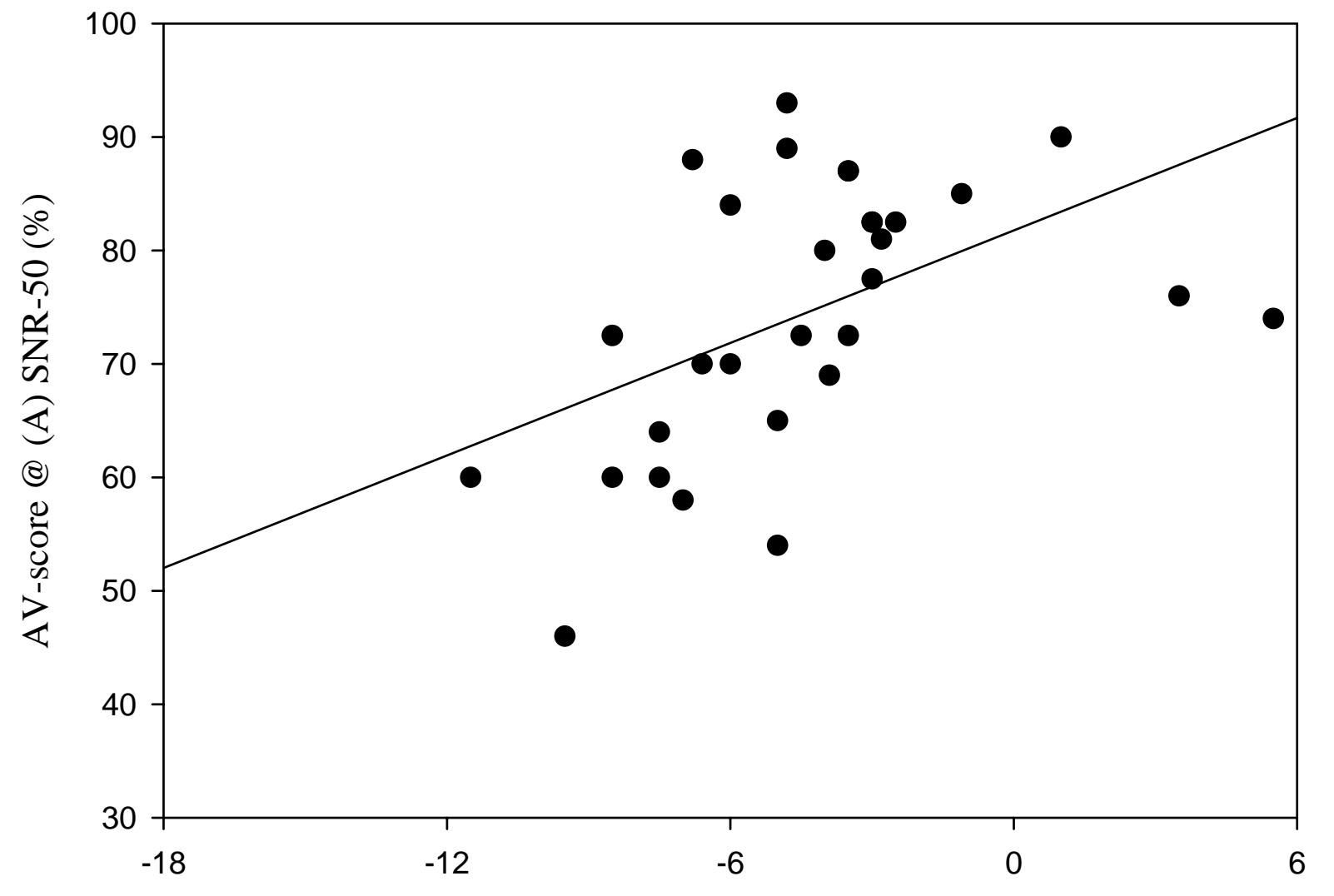

(A) SNR-50 (dB)

The AV-scores @ (A) SNR-50 of all 60 participants were correlated with two measures: (1) the median of judges' ratings of participants' speech comprehensibility, and (2) the median of judges’ ratings of their foreign accentedness. A Kendall distribution-free test for independence indicated a significant correlation $(T=-.54, p<.001)$ between AV-score @ (A) SNR-50 and speech comprehensibility. As shown in Figure 14, increases in the difficulty of speech comprehensibility were associated with decreases in the AV-scores @ (A) SNR-50. This was related to American participants having similar and higher AV-scores @ SNR-50 accompanied by similar and high speech comprehensibility; whereas, Indian participants had variable and 
lower AV-scores @ (A) SNR-50 accompanied by variable and lower speech comprehensibility. Another Kendall indicated a significant correlation $(\mathrm{T}=-.49, p<.001)$ between AV-score @ (A) SNR-50 and foreign accentedness. As shown in Figure 15, increases in foreign accentedness were associated with decreases in the AV-scores @ (A) SNR-50. This was, again, primarily related to American participants having similar and higher AV-scores @ SNR-50 accompanied by similar and low foreign accentedness; whereas, Indian participants had variable and lower AV-scores@ (A) SNR-50 accompanied by variable and higher foreign accentedness.

FIGURE 14

CORRELATION BETWEEN AV-SCORE @ (A) SNR-50

AND COMPREHENSIBILITY RATING

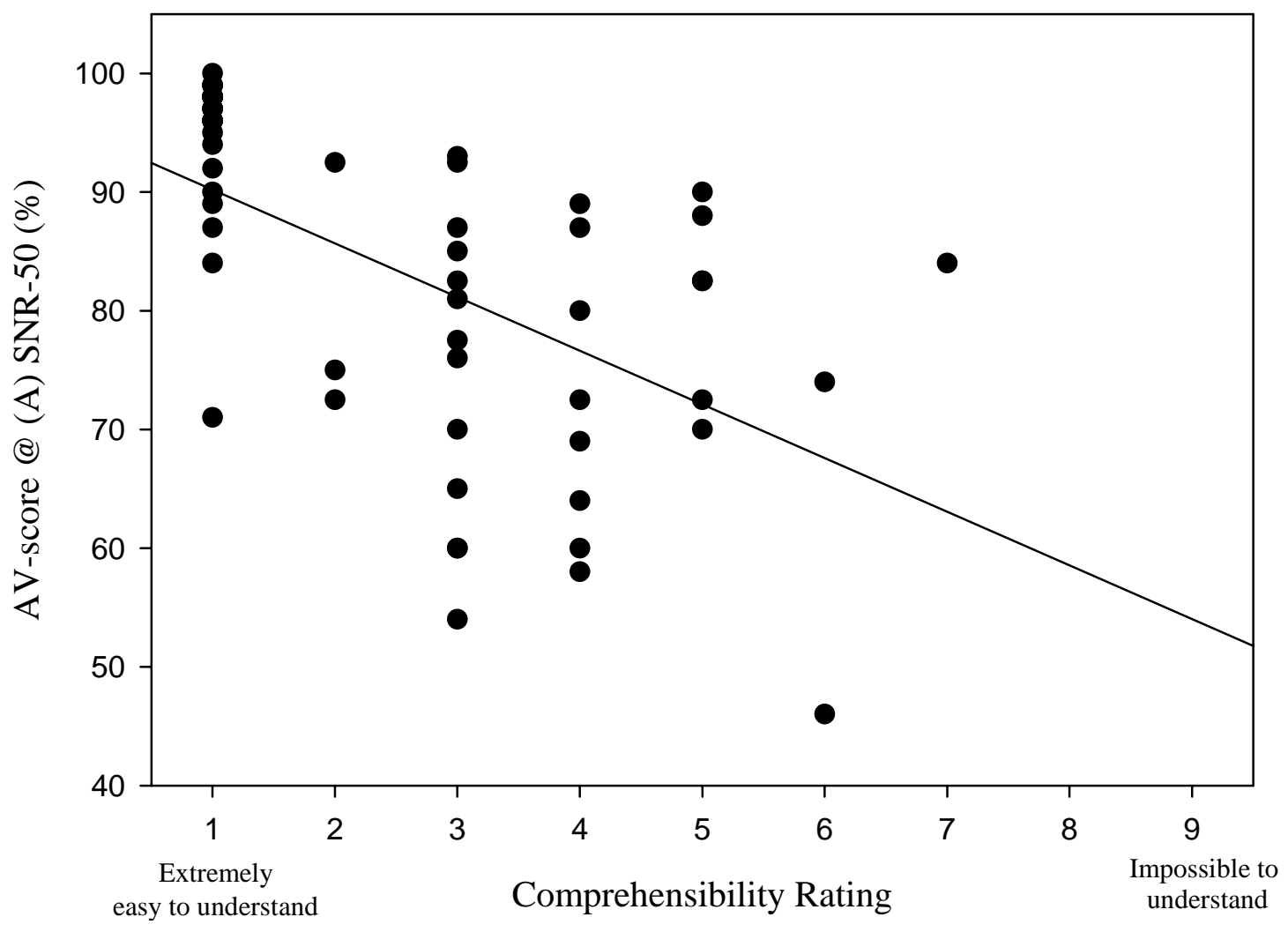




\section{FIGURE 15}

CORRELATION BETWEEN AV-SCORE @ (A) SNR-50 AND FOREIGN ACCENTEDNESS RATING

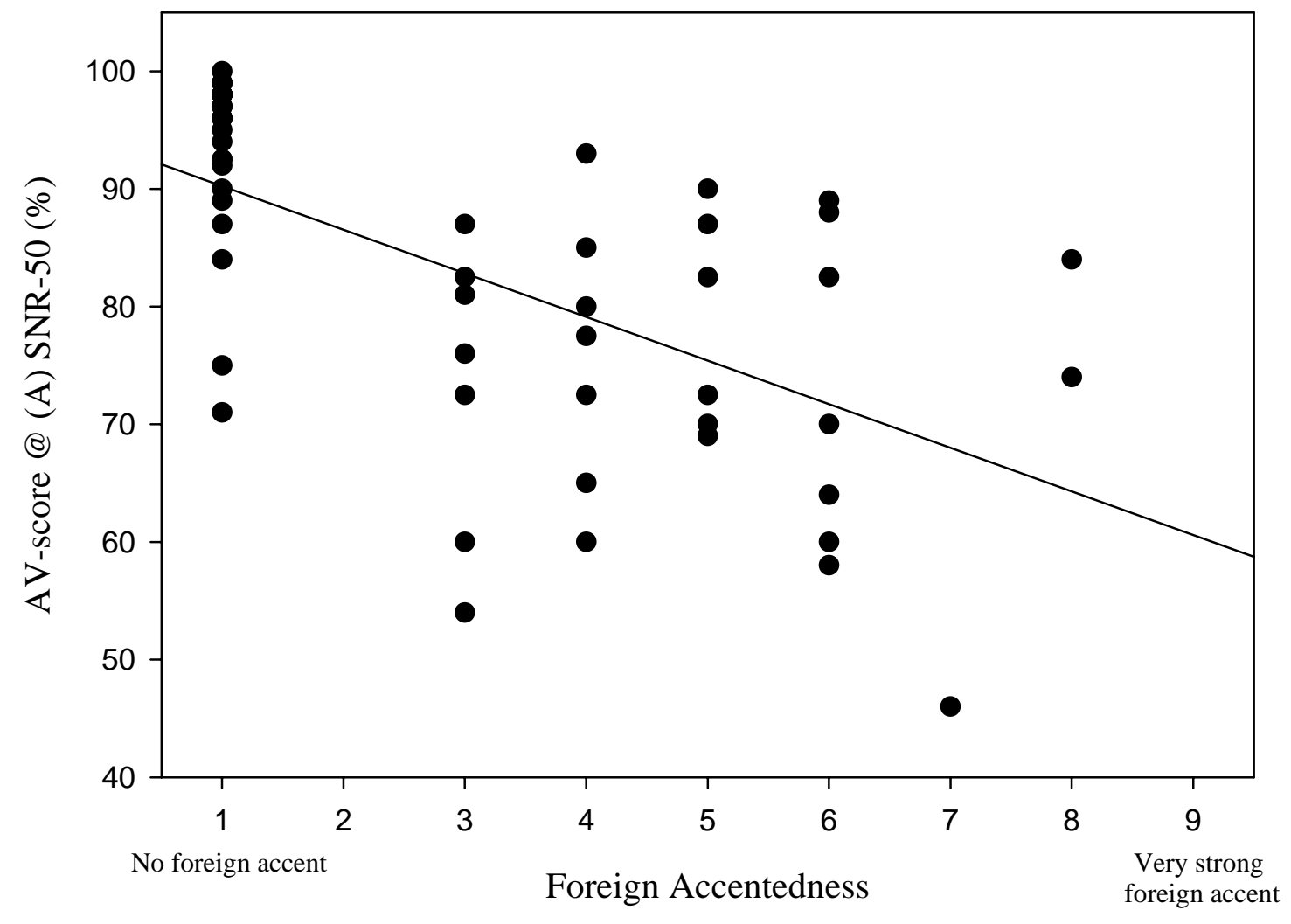




\section{TABLE 17}

CORRELATION BETWEEN AV-SCORE @ (A) SNR-50 AND LINGUISTIC MEASURES

\begin{tabular}{|c|c|c|c|c|c|c|c|c|c|}
\hline $\begin{array}{c}\text { AV-score @ } \\
\text { (A) SNR-50 }\end{array}$ & $\begin{array}{c}\text { Speech } \\
\text { Comprehensibility }\end{array}$ & $\begin{array}{c}\text { Foreign } \\
\text { Accentedness }\end{array}$ & TOEFL & $\begin{array}{c}\text { Length of } \\
\text { Residence } \\
\text { in US }\end{array}$ & $\begin{array}{c}\text { Age of } \\
\text { Learning }\end{array}$ & Speaking & Understanding & Reading & Writing \\
\hline $\begin{array}{c}\text { Correlation } \\
\text { Coefficient }\end{array}$ & -.04 & .07 & -.11 & -.15 & -.04 & .01 & -.32 & -.23 & -.13 \\
Significance* & .84 & .72 & .56 & .43 & .83 & .95 & .09 & .22 & .49 \\
\hline
\end{tabular}

* No correlations significant at $p>.05$

Effects of Gender on AV-score @ (A) SNR-50

Because a statistically significant difference was measured in the distribution of male and female participants in the American and Indian groups, the investigator further evaluated effects of gender on speechreading measures. An exploratory analysis of raw data (see Appendix N) suggested the four male American participants and 26 female American participants had similar AV-scores, similar A-scores, and similar VE-scores. Another exploratory analysis of raw data (see Appendix O) suggested the seven female Indian participants and 23 female Indian participants had similar AV-scores, similar A-scores, and similar VE-scores. Consequently inferential statistics were not applied to these measures but were applied to assess effects of gender on the one measure that best combined AV and A-scores: the AV-score @ (A) SNR-50. As shown in Table 18, mean AV-score @ (A) SNR-50 and SDs were nearly identical between American male and American female participants and were nearly identical between Indian male and female participants. Furthermore, the AV-score @ (A) SNR-50 of the four American males participants averaged $16 \%$ higher than of the seven Indian female participants. Two separate Wilcoxon Rank-Sum tests indicated the AV-scores @ (A) SNR-50 of American male and American female participants did not differ significantly $(\mathrm{z}=.73, p>.05)$ and the AV-scores @ (A) SNR-50 of Indian male and Indian female participants did not differ significantly ( $\mathrm{z}=.12$, 
p>.05). Moreover, a third Wilcoxon Rank-Sum test indicated the AV-scores @ (A) SNR-50 of the Indian female and the American male participants did not differ significantly $(\mathrm{z}=1.02$, $p>$.05). In total, these results suggest the significant differences in gender distributions between American and Indian participants did not yield significant effects on speechreading measures.

TABLE 18

MEAN AV-SCORES @ (A) SNR-50 FOR FEMALES AND MALES OF AMERICAN AND INDIAN PARTICIPANTS

\begin{tabular}{|c|ccc|ccc|}
\hline \multirow{2}{*}{} & \multicolumn{2}{|c|}{$\begin{array}{c}\text { American Participants } \\
\text { [AV-score @ (A) SNR-50] }\end{array}$} & \multicolumn{3}{c|}{$\begin{array}{c}\text { Indian Participants } \\
\text { [AV-score @ (A) SNR-50] }\end{array}$} \\
& Both (30) & Female(26) & Male (4) & Both (30) & Female (7) & Male (23) \\
\hline Mean & $91 \%$ & $92 \%$ & $90 \%$ & $74 \%$ & $74 \%$ & $75 \%$ \\
SD & 0.12 & 0.12 & 0.1 & 0.12 & 0.14 & 0.12 \\
\hline
\end{tabular}




\section{CHAPTER V \\ SUMMARY AND DISCUSSION}

\section{Summary of Present Study}

The present study was designed to examine effects of speechreading and SNR on understanding MAE heard by Indian adults compared to American adults. Although both groups showed considerable variability in speechreading results, statistical analyses indicated American participants had significantly higher ESS-scores than Indian participants for both AV and A-only modalities at all SNRs. American participants also had significantly higher VE-scores than Indian participants at $-18 \mathrm{~dB}$ and $-12 \mathrm{~dB}$ SNRs. Conversely, Indian participants had significantly higher VE-scores than American participants at $0 \mathrm{~dB}$ and $+6 \mathrm{~dB}$ SNRs. America participants also were able to achieve 50\% A-scores on psychometric functions [i.e., (A) SNR-50] at significantly poorer SNRs than Indian participants. Likewise AV-scores @ (A) SNR-50 for American participants were significantly higher than the AV-scores @ (A) SNR-50 of Indian participants. No significant correlation was measured between (A) SNR-50 and AV-score @ (A) SNR-50 for American participants. A positive significant correlation between (A) SNR-50 and AV-score @ (A) SNR-50 was measured for Indian participants. In other words, the primary overall finding of this study was American participants benefitted significantly more than Indian participants from speechreading at poorer SNRs than at favorable SNRs, whereas Indian participants benefitted significantly more from speechreading than American participants at favorable SNRs. Other major findings were Indian participants required more auditory cues to speechread than American participants; Indian participants required more favorable SNRs to understand the ESS auditorily than American participants; but even when Indian participants understood ESS as well as the American participants auditorily, they still did not speechread ESS as well as American 
participants. What variables could have accounted for the speechreading differences between American participants and Indian participants?

Nonlinguistic Variables

American and Indian participants had similar ages (i.e., 21 to 39 years old), similar education levels (i.e., graduate students enrolled in WSU), and similar sensory abilities (i.e., vision and hearing within normal limits) suggesting these were not confounding variables in the study. There were, however, a significantly higher number of males than females among Indian participants and a significantly higher number of females than males among American participants. Some studies have suggested that females performed better on speechreading measures than males (Dancer et al., 1994; Daly, Bench, \& Chappell, 1996). A recent study of Tye-Murray et al. (2007b), however, suggested any differences in speechreading between males and females are negligible compared to other variables affecting speechreading abilities. The findings of the current study were consistent with Tye-Murray et al. (2007b). The mean AV-score @ (A) SNR-50 for American male versus female participants and for Indian male versus female participants were not significantly different, suggesting the large speechreading differences between American and Indian participants in this study were not due to gender differences between groups. Finally, Dancer et al. (1994) reported that speechreading performance was not influenced by participants’ educational levels. No researchers, however, have addressed whether speechreading abilities may vary among persons from different educational fields. It is unlikely, but still unclear, whether a field of study influenced speechreading abilities of American participants (graduate students from Communication Sciences and Disorders and Psychology with, presumably, better verbal skills) and Indian participants (Engineering graduate students with, presumably, better quantitative skills). 


\section{Linguistic Variables}

A number of linguistic differences between American and Indian participants may have accounted for the significant differences in speechreading results between the two groups. All American participants spoke English as their first, and only, language. All American participants were born and raised in the United States and nearly all of them spoke a MAE-- which was the accent as the speaker of the ESS on the DVD. The three judges of participants reading the Rainbow Passage also rated the speech comprehensibility of nearly all American participants as “extremely easy to understand,” and rated all American participants as having "no foreign accent.” In contrast, all Indian participants spoke English as a second-language and, when they did speak English, they spoke it with an Indian accent presumably influenced more by British English than MAE. All Indian participants were born and raised in India. They started learning English at an average age of 5 years, and they had lived in the United States for an average of 9 months. On the questionnaire, Indian participants, on average, rated their competency in reading, writing, speaking, and understanding English lower than American participants. The three judges also rated the speech comprehensibility of the Indian participants as significantly more difficult to understand as the American participants and rated the foreign accentedness of every Indian participant as higher than every American participant. In other words, despite having TOEFL scores high enough to enter graduate school, the Indian participants had poorer English proficiency than American participants.

These major linguistic differences may have accounted, in large part, for the Indian participants showing much poorer understanding of ESS than American participants under both AV and A modalities. This suggestion is consistent with previous researchers who reported that second-language speakers of English often had difficulty utilizing contextual cues in sentences 
under degraded listening conditions (Cutler, Weber, Smits, \& Cooper, 2004). When people listen to even a simple sentence, some words easily understood in the sentence provide contextual cues; however, syntactical, semantic, and phonological cues require the listener to have greater previous experience with the language (Ueda, Akahane-Yamada, Komaki, \& Adachi, 2007). Some researchers, furthermore, have suggested that certain cognitive skills such as visual word decoding, lexical identification, phonological processing, and verbal inference-making may correlate with speechreading performance (Anderson, Lyxell, Rönnberg, \& Spens, 2001). Likewise, when the simple, yet unfamiliar, ESS were presented at poorer SNRs, Indian participants may have had greater cognitive demands to understand the ESS because they were less experienced than American participants in listening to MAE. Consequently, American participants could speechread better than Indian participants when fewer auditory cues were available. Conversely, when the ESS were presented at favorable SNRs, Indian participants benefitted more from speechreading because more auditory cues were available to integrate with visual cues, thereby adding more redundancy to understand the ESS. In other words, language proficiency in a second-language may be an important variable not only for understanding speech auditorily, but for the auditory-visual integration needed for understanding speech by speechreading.

Theoretical Implications

Early studies of speechreading (Erber, 1969; Sumby \& Pollack, 1954) indicated that American speakers benefitted most from speechreading at poorer SNRs. These studies also supported a principle of multisensory integration called “inverse effectiveness,” defined as a reciprocal relationship in which weaker auditory stimuli are associated with stronger visual benefits. Results of the current study for American participants as a whole, and especially for 
specific participants were consistent with early speechreading findings. For instance, American participant \#41 obtained a 100\% A-score, a 100\% AV-score, and a 0\% VE-score at +6 dB SNR, indicating no benefit from speechreading at this favorable SNR (see Appendix N). Conversely, this American participant obtained a 0\% A-score, a 92\% AV-score, and a 46\% VE-score at -18 dB SNR. In other words, participant \#41 benefitted most from speechreading at the poorest SNR where weak auditory cues were associated with stronger visual benefits—a classic example of "inverse effectiveness." Results of American participants in this study, however, conflicted with Ross et al. (2007) who reported that their American adult participants in a speechreading study obtained their best VE-scores at an intermediate SNR $(-12 \mathrm{~dB})$ rather than at the poorest SNRs. In the current study, Indian participants benefitted more from speechreading than American participants at more favorable SNRs. This finding is more consistent with Ross et al. (2007), who explained that some minimal levels of auditory cues are necessary with concurrent visual cues to produce the strongest speechreading benefits. For instance, Indian participant \#19 obtained a 0\% A-score, a 12\% AV-score, and a 6\% VE-score at -18 dB SNR. This Indian participant, however, obtained a 74\% A-score, a 96\% AV-score, and a 17\% VE-score at $+6 \mathrm{~dB}$ SNR. In other words, this participant benefitted less from speechreading at the poorest SNRs and more from speechreading at the favorable SNRs where auditory cues were more available to integrate with visual cues—an example not supporting "inverse effectiveness.”

Finally, motor theory claims that when listeners try to understand what a speaker says, the listener compares the speaker's message to how the listener would pronounce the spoken message. By analogy, when American participants saw and heard the MAE speaker talking on the videotape, they may have compared the way the speaker said the ESS to how they might have said the ESS. Because what they saw was similar to the way they would have pronounced the 
ESS, speechreading may have been more beneficial for American participants, especially at poorer SNRs. Conversely, Indian participants saw and heard the MAE speaker speaking the ESS differently than how they may have pronounced the sentences with their Indian accent. Therefore, speechreading may not have helped the Indian participants to speechread the ESS as much as it helped the American participants.

Practical Implications

Previous researchers have reported that auditory abilities of second-language speakers of English decline in adverse listening environments but often are comparable to first-language speakers of English in favorable listening environments. The investigator, therefore, initially expected that both American and Indian participants in this study would show comparable AVscores and A-scores at favorable SNRs. Results, however, showed that at even favorable SNRs of $0 \mathrm{~dB}$ and $+6 \mathrm{~dB}$ (commonly encountered in many work, educational, recreational, and home environments), Indian participants did not understand the ESS as well as American participants. Specifically American participants had mean AV-scores and A-scores at $100 \%$ at $0 \mathrm{~dB}$ and $+6 \mathrm{~dB}$ SNRs. Indian participants, however, had mean AV- scores around $90 \%$ at $0 \mathrm{~dB}$ and $+6 \mathrm{~dB}$ SNRs; and their mean A-scores were 10-15\% lower than American participants at $0 \mathrm{~dB}$ and $+6 \mathrm{~dB}$ SNRs. American participants, moreover, had mean AV-scores @ (A) SNR-50 that averaged over 90\%. On the other hand, Indian participants had mean AV-scores @ (A) SNR-50 that averaged less than $75 \%$.

Differences in speech understanding difficulties in noise were even more pronounced for specific American and Indian participants. American participant \#48 had a 90\% AV-score at an (A) SNR-50 of -11 dB SNR. Indian participant \#42 also had a 90\% AV-score @ (A) SNR-50, but it was at $1 \mathrm{~dB}$ SNR. That is, both participants may have achieved comparable amounts of 
auditory-visual integration through speechreading but at a $12 \mathrm{~dB}$ higher SNR for the Indian participant. These differences in speechreading between American and Indian participants, moreover, were for relatively simple ESS. Indian participants likely will have even more difficulty than American participants understanding the complex and varied types of MAE messages spoken in everyday environments (e.g., by a boss at a noisy construction site; when conversing around a table with friends at a bar; or when trying to follow a complicated PowerPoint lecture in a dark classroom where the teacher's face may not be visible).

\section{Future Research}

A number of studies are suggested by the results of the current study.

1. Previous researchers have reported that people from some countries watch a speaker's face more when conversing with one another than people from other countries. It is unclear whether the American participants in this study speechread better than the Indian participants because American participants watched the speaker's face more on a TV during the speechreading test. In this study, faces and torsos of each participant was video-recorded when they were tested on all 10 lists of ESS. These recordings will be analyzed by the investigator to measure whether Indian participants watched the speaker's face more, or less, or the same as American participants to understand the ESS.

2. In this study, American participants and Indian participants were compared to measure speechreading performance. More research is needed to understand if second-language speakers of English from other countries than Indian would have speechreading similar to the Indian participants. 
3. In the current study, participants listened to a MAE speaker to measure speechreading performance. It is unclear whether the Indian participants would have speechread better if the speaker had had an Indian accent. It would be informative to assess speechreading performance by using a matched-guise technique For instance, an actor would be videotaped saying ESS with both an Indian accent and a MAE. Speechreading performance of Indian participants would then be compared between the Indian-accented speech and the MAE-accented speech. Results may support a motor theory of speech perception if the Indian participants understood the ESS spoken with the Indian accent better than with the MAE accent. 
REFERENCES 


\section{LIST OF REFERENCES}

American National Standards Institute. (1989). Specification for audiometers, ANSI S3.6-1989. New York, NY.

American Speech-Language-Hearing Association (1997). Guidelines for audiologic screening: ASHA panel on audiologic assessment. American Speech-Language-Hearing Association.

Andersson, U., Lyxell, B., Rönnberg, J., \& Spens, K-E. (2001). Cognitive correlates of visual speech understanding in hearing-impaired individuals. Journal of Deaf Studies and Deaf Education, 6, 103-115.

Annamalai, E. (2004). Nativization of English in India and its effect on multilingualism. Journal of Language \& Politics, 3, 151-162.

Baker, C. (1993). Foundations of bilingual education and bilingualism. Clevendon, Avon, England: Multilingual Matters Multilingual Matters Ltd.

Barley, M. (1971). CID everyday sentence test of speechreading ability. In J. Jeffers \& M. Barley, Speechreading (lipreading) (pp. 328-333). Springfield: Charles C. Thomas.

Bentler, R. A. (2000). List equivalency and test-retest reliability of the speech in noise test. American Journal of Audiology, 9, 84-100.

Bernthal, J. E., \& Bankson, N. W. (1993). Articulation and phonological disorders (3rd Ed.). Englewood Cliffs, NJ: Prentice-Hall, Inc.

Bilger, R., Nuetzel, J., Rabinowitz, W., \& Rzeczkowski, C. (1984). Standardization of a test of speech perception in noise. Journal of speech and Hearing Research, 27, 32-48.

Burnham, D. (1998). Language specificity in the development of auditory-visual speech perception. In R. Campbell, B. Dodd, \& D. Burnham, (Eds.), Hearing by eye II: Advances in psychology of speechreading and auditory-visual speech (pp.27-60). East Sussex: UK, Psychology Press Ltd, Publishers.

Buus, S., Florentine, M., Scharf, B., \& Canevet, G. (1986). Native, French listeners’ perception of American-English in noise. Inter-Noise 86, 895-898.

Carhart, R., Johnson, C., \& Goodman, J. (1975). Perceptual masking of spondees by combinations of talkers. The Journal of The Acoustical Society of America, Supplement 58 , S35.

Census of India (1999).Office of registrar general \& census commissioner, India. Retrieved November 26, 2008 from http://censusindia.gov.in/AboutUs/Census_Organisation/about.html 
Cienkowski, K. M., \& Speaks, C. (2000). Subjective vs. objective intelligibility of sentences in listeners with hearing loss. Journal of Speech, Language, and Hearing Research, 43, 1205-1210.

Conboy, B. T., Rivera-Gaxiola, M., Klarman, L., Aksoylu, E., \& Kuhl, P. (2007). Associations between native and nonnative speech sound discrimination and language development at the end of the first year. Retrieved October 28, 2008 from http://128.197.86.186/posters/29/ConboyBUCLD2004.pdf

Cooke, M., Garcia Lecumberri, M. L., \& Barker, J. (in press). The foreign language cocktail party problem: Energetic and informational masking effects in non-native speech perception. The Journal of The Acoustical Society of America.

Cooper, W. E. (1974). Cognitive feature analysis in speech perception. Perception and Psychophysics, 16, 201-204.

Crandell, C. C., \& Smaldino, J. J. (1996). Speech perception in noise by children for whom English is a second language. American Journal of Audiology, 5, 47-51.

Culter, A., Weber, A. Smits, R., \& Cooper, N. (2004). Patterns of English phoneme confusions by native and nonnative listeners. The Journal of The Acoustical Society of America, 116, 3668-3678.

Dancer, J., Krain, M., Thompson, C., Davis, P., \& Glenn, J. (1994). A cross-sectional investigation of speechreading in Adults: Effects of age, gender, practice, and education. The Volta Review, 96, 31-40.

Daly, N., Bench, J., \& Chappell, H. (1996). Gender differences in speechreadability. Journal of Academy of Rehabilitative Audiology, 29, 27-40.

Davis, H., \& Silverman, S. R. (1978). (Eds.), Hearing and deafness. ( $3^{\text {rd }}$ Ed). New York, NY: Holt, Rinehart and Winston.

Demorest, M. E., \& Bernstein, L. E. (1992). Sources of variability of speechreading sentences: A generalizability analysis. Journal of Speech and Hearing Research, 35, 876-891.

Dent, L., Simmons, F., White, R., \& Roberts, L. (1987). Speech perception by four singlechannel cochlear implant users. Journal of Speech Hearing Research, 30,483-490.

Derwing, T.M., Munro, M.J., \& Wiebe, G.E. (1998). Evidence in favor of a broad framework for pronunciation instruction. Language Learning, 48, 393-410.

Derwing, T.M., \& Rossiter, M.J. (2003). The effects of pronunciation instruction on the accuracy, fluency and complexity of L2 accented speech. Applied Language Learning, 13, 1-18.

Diehl, R. L., \& Kluender, K. R. (1989). On the objects of speech perception. Ecological Psychology, 1, 121-144. 
Duffy, J. R., \& Giolas, T. G. (1974). Sentence intelligibility as a function of key word selection. Journal of Speech and Hearing Research, 17, 631-637.

Educational Testing Service (2007). Test of English as a Foreign Language. Retrieved December 1, 2007 from http://www. ets.org

Eisenstein, M., \& Verdi, G. (1985). The intelligibility of social dialects for working-class adult learners of English. Language Learning, 35, 287-98.

Elliot, D. B., Sanderson, K., \& Conkey, A. (1990). The reliability of the Pelli-Robson contrast sensitivity chart. The Journal of The British College of Ophthalmic Opticians, 10, 21-24.

Erber, N. P. (1969). Interaction of audition and vision in the recognition of oral speech stimuli. Journal of Speech and Hearing Research, 12, 423-425.

Erber, N. P. (1972). Auditory, visual, and auditory-visual recognition of consonants by children with normal and impaired hearing. Journal of Speech and Hearing Research, 15, 413422.

Erber, N. P. (1974). Effects of angle, distance, and illumination on visual reception of speech by profoundly deaf children. Journal of Speech and Hearing Research, 17, 94-98.

Fishman, J. A. (1971). The sociology of language. In J. Fishman (Ed.), Advances in the sociology of language (Vol.1, pp.217-404). The Hague: Mouton.

Festen, J. M., \& Plomp, R. (1990). Effects of fluctuating and interfering speech on the speechreception threshold for impaired and normal hearing. The Journal of The Acoustical Society of America, 88, 1725-1736.

Flege, J. E. (1988). Factors affecting degree of perceived foreign accent in English sentences. The Journal of the Acoustical Society of America, 84, 70-79.

Flege, J. E., \& Liu, S. (2001). The effect of experience on adults' acquisition of a second language. Studies in Second Language Acquisition, 23, 527-552.

Florentine, M. (1985). Non-native listeners’ perception of American-English in noise. InterNoise 85, 1021-1024.

Franklin, C. A., Jr., Thelin, J. W., Năbělek, A. K., \& Burchfield, S. B. (2006). The effect of speech presentation level on acceptance of background noise in listeners with normal hearing. Journal of The American Academy of Audiology, 17, 141-146.

Freyman, R., Balakrishnan, U., \& Helfer, K. S. (2004). Effect of number of masking talkers and auditory priming on informational masking in speech recognition. The Journal of The Acoustical Society of America, 115, 2246-2256.

Fujisaki, H., \& Kunisaki, O. (1975). Analysis and recognition of voiceless fricative consonants in Japanese. The Journal of the Acoustical Society of Japan, 31, 741-742. 
Fuster-Duran, A. (1996). Perception of conflicting audio-visual speech: An examination across Spanish and German. In D. G. Stork \& M. E. Hennecke (Eds.), Speechreading by humans and machines (pp. 135-143). Berlin:Springer-Verlag.

Garcia Lecumberri, M. L. G., \& Cooke, M. (2006). Effect of masker type on native and nonnative consonant perception in noise. The Journal of The Acoustical Society of America, 119, 2445-2454.

Gass, S., \& Varonis, E. M. (1984). The effect of familiarity on the comprehensibility of nonnative speech. Language Learning, 34, 65-68.

Gelfand, S. A. (2004). Speech perception. In S. A. Gelfand, Hearing: An introduction to psychological and physiological acoustics (pp.433-468). New York, NY: Marcel Dekker.

Giolas, T. G., \& Duffy, J. R. (1973). Equivalency of CID and revised CID sentence lists. Journal of Speech and Hearing Research, 16, 549-555.

Gordon-Brannan, M., \& Hodson, B. (2000). Intelligibility/severity measurements of Prekindergarten children's speech. American Journal of Speech-Language Pathology, 9, 141-150.

Grant, K. W., Walden, B. E., \& Seitz, P. F. (1998). Auditory-visual speech recognition by hearing-impaired subjects: Consonant recognition, sentence recognition, and auditoryvisual integration. The Journal of The Acoustical Society of America, 103, 2677-2690.

Green, K. P. (1996). Studies of McGurk effect: Implications for theories of speech perception. The Journal of the Acoustical Society of Japan, 1652-1655.

Green, K. P., \& Kuhl P. K. (1989). The role of visual information in the processing of place and manner features in speech perception. Perception \& Psychophysics, 45, 34-42.

Green, K. P., \& Miller, J. L. (1985). On the role of visual rate information in phonetic perception. Perception \& Psychophysics, 38, 269-276.

Green, K. P., Kuhl, P. K., \& Meltzoff, A. N. (1988). Factors affecting the integration of auditory and visual information in speech: The effect of vowel environment. The Journal of the Acoustical Society of America, 84, S155.

Grosjean, S. (1998). Studying bilinguals: Methodological and conceptual issues. Language and Cognition, 1, 131-149.

Guion, S., Flege, J., Akahane-Yamada, R., \& Pruitt, J. (2000). An investigation of current models of second language speech perception: The case of Japanese adults' perception of English consonants. The Journal of the Acoustical Society of America, 107, 2711-2724.

Hardison, D. M. (2003). Acquisition of second-language speech: Effects of visual cues, context, and talker variability. Applied Psycholinguistics, 24, 495-522. 
Harris, J. D., Haines, H. L., Kelsey, P. A., \& Clark, T. D. (1961). The relation between speech intelligibility and electroacoustic characteristics of low fidelity circuitry. Journal of Auditory Research, 1, 357-381.

Healy, E. W., \& Montgomery, A. A. (2006). Consistency of sentence intelligibility across difficult listening situations. Journal of Speech, Language, and Hearing Research, 49, 823-834.

Hinkle, R. R. (1979). An investigation of list equivalency for auditory, visual and auditory-visual performance using revised CID sentences. Unpublished doctoral dissertation, Purdue University, Indiana.

Hood, J. D., \& Dixon, R. F. (1969). Physical characteristics of speech rhythm of deaf and normal hearing speakers. Journal of Communication Disorders, 2, 20-28.

International Council of Ophthalmology (2007). International standards: Vision requirements for driving safety section 4-which visual functions might be tested? Retrieved September 26, 2008 from http://www.icoph.org/standards/driving4test.html

Johnson, F. M., Hicks, L. H., Goldberg, T., \& Myslobodsky, M. S. (1988). Sex differences in lipreading. Bulletin of the Psychonomic Society, 26, 100-108.

Johnson, K., \& Mullennix, J. W. (Eds.) (1996). Talker variability in speech processing. San Diego, CA: Academic Press.

Johnson, J.S., \& Newport, E.L. (1989). Critical period effects in second language learning: The influence of maturational state on the acquisition of English as a second language. Cognitive Psychology, 21, 60-99.

Kishon-Rabin, L., \& Henkin, Y. (2000). Age-related changes in the visual perception of phonologically significant contrasts. British Journal of Audiology, 34, 363-374.

Koh Chin, H-K., \& Rajika, B. (2007). Opendoors: Report on international educational exchange. Institute of International Education.

Kuhl, P. K., \& Meltzoff, A. N. (1984). The intermodal representation of speech in infants. Infant Behavior and Development, 7, 361-3181.

Kuhl, P., Tsao, F-M., \& Liu, H-M. (2003). Foreign-language experience in infancy: Effects of short-term exposure and social interaction on phonetic learning. Proceedings of the National Academy of Sciences of the United States of America, 100, 9096-9101.

Lenneberg, E. H. (1967). Biological foundations of language. New York: John Wiley \& Sons, Inc.

Liberman, A. M., \& Mattingly, I. G. (1985). The motor theory of speech perception revised. Cognition, 21, 1-36. 
MacLeod, A., \& Summerfield, Q. (1987). Quantifying the contribution of vision to speech perception in noise. British Journal of Audiology, 21, 131-141.

MacLeod, A., \& Summerfield, Q. (1990). A procedure for measuring auditory and audio-visual speech-reception thresholds for sentences in noise: Rationale, evaluation, and recommendations for use. British Journal of Audiology, 24, 29-43.

Mallikarjun, B. (2004). Fifty years of language planning for modern Hindi. Language in India, 4. Retrieved December 2007 from http://www.languageinindia.com

Mann, V., \& Repp, B. (1980). Influence of vocalic on text on perception of the [ $]$-[s] distinction. Perception \& Psychophysics, 28, 213-228.

Massaro, D. W., Cohen, M. M., \& Smeele, P. M. (1995). Cross-linguistic comparisons in the integration of visual and auditory speech. Memory \& Cognition, 23, 113-131.

Massaro, D. W., Tsuzaki, M., Cohen, M. M., Gesi, A., \& Heredis, R. (1993). Bimodal speech perception: An examination across languages. Journal of Phonetics, 21, 445-478.

Mayo, L. H., Florentine, M., \& Buss, S. (1997). Age of second-language acquisition and perception of speech in noise. Journal of Speech-Language-Hearing Research, 40, 686693.

McGurk, H., \& MacDonald, J. (1976). Hearing lips and seeing voices. Nature, 265, 746-748.

Miller, G. A. (1947). The masking of speech. Psychological Bulletin, 44, 105-129.

Moore, B. C. (2001). Speech perception. In B. C. Moore, An introduction to the psychology of hearing ( $4^{\text {th }}$ Ed., pp. 272-305). San Diego, CA: Academic Press.

Munro, M. J., \& Derwing, T. M. (1995a). Foreign accent, comprehensibility, and intelligibility in the speech of sound language learners. Language Learning, 45, 73-97.

Munro, M. J., \& Derwing, T. M. (1995b). Modeling perceptions of the accentedness and comprehensibility of L2 speech: The role of speaking rate. Studies in Second Language Acquisition. 23, 451-468.

Năbělek, A. K., Tampas, J. W., \& Burchfield, S. B. (2004). Comparison of speech perception in background noise with acceptance of background noise in aided and unaided conditions. Journal of Speech, Language, and Hearing Research, 47, 1001-1011.

Nielsen, K. (2004). Segmental differences in the visual contribution to speech intelligibility. Interspeech 2004-ICSLP, 2533-2536.

Pai, P. (2005). Multilingualism, multiculturalism, and education: Case study of Mumbai city. In J. Cohen, K. T. McAlister, K. Rolstad, \& J. MacSwan (Eds.), $4^{\text {th }}$ International symposium of Billingualism. Somerville, MA: Cascadilla Press. 
Pelli, D. G., Robson, J. G., \& Wilkins, A. J. (1988). The design of a new letter chart for measuring contrast sensitivity, Clinical Vision Sciences, 2, 187-199.

Petkovsek, M. (1961). The eyes have it. Hearing News, 29, 5-9.

Plant, G. L., \& Macrae, J. H. (1981). The NAL lipreading test development, standardization and validation. Australian Journal of Audiology, 3, 49-57.

Rabinowitz, W., Eddington, D., Delhorne, L., \& Cueno P. (1992). Relations among different measures of speech reception in subjects using a cochlear implant. The Journal of The Acoustical Society of America, 92, 1869-1881.

Reed, C. (1985). The implications of the Tadoma method of speechreading for spoken lanague processing.

Reisberg, D., McLean, J., \& Goldfield, A. (1987). Easy to hear but hard to understand: A lipreading advantage with intact auditory stimuli. In B. Dodd \& R. Campbell (Eds.), Hearing by eye: The psychology of lip reading. Hillsdale, NJ: Lawrence Erlbaum Associates.

Repp, B. H., Manuel, S. Y., Liberman, A. M., \& Studdert-Kennedy, M. (1983). Exploring the McGurk effect [Abstract]. Bulletin of Psychonomic Society, 358.

Rhebergen, K. S., Versfeld, N., \& Dreschler, W. A. (2005). Release from informational masking by time reversal of native and non-native interfering speech (L). The Journal of The Acoustical Society of America, 118, 1274-1277.

Rippy, J. V., Dancer, J., \& Pittenger, J. B. (1983). List equivalency of the CID everyday sentences (Harris revision) under three signal-to-noise ratios. Ear and Hearing, 4, 251254.

Rosenblum, L. (2008). Primacy of multimodal speech perception. In D. B. Pisoni \& R. E. Remez (Eds.), The Handbook of speech perception (pp.51-78). Malden, MA: Blackwell Publishing Ltd.

Rosenblum, L. D., \& Saldanã, H. M. (1996). An audiovisual test of kinetic primitives for visual speech perception. Journal of Experimental Psychology: Human Perception and Performance, 22, 318-331.

Rosenfeld, M., Oltman, P., \& Sheppard, K. (2004). Investigating the validity TOEFL: A feasibility study using content criterion-related strategies. TOEFL Research Report, 71, Princeton, NJ: Educational Testing Service. (RR-03-18).

Ross, L. A., Saint-Amour, D., Leavitt, V. M., Javitt, D. C., \& Foxe, J. J. (2007). Do you see what I am saying? Exploring visual enhancement of speech comprehension in noisy environments. Cerebral Cortex, 17, 1147-1153.

Ruhlen, M. (1975). A guide to the language of the world. Stanford: Stanford University Press. 
Sargent, E. W., Herrmann, B., Hollenbeak, C. S., \& Bankaitis, A. E. (2002). The minimum speech test battery in profound unilateral hearing loss. Academy of Otology \& Neurotology, 22, 480-486.

Schiavetti, N., Metz, D. E., \& Sitler, R. W. (1981). Construct validity of direct magnitude estimation and interval scaling of speech intelligibility: Evidence from a study of the hearing impaired. Journal of Speech and Hearing Research, 24, 441-445.

Schiavetti, N., Sitler, R. W., Metz, D. E., \& Houde, R. A. (1984). Prediction of contextual speech intelligibility from isolated word intelligibility measures. Journal of Speech and Hearing Research, 27, 623-626.

Seitz, P. F., \& Grant, K. W. (1997). Hearing-impaired perceiver's encoding and retrieval speeds for auditory, visual, and audio-visual spoken words. The Journal of Tthe Acoustical Society of America, 101, 3155.

Sekiyama, K., Braida, L.D., Nishino, K., Hayashi, M., \& Tuyo, M.M. (1995). The McGurk effect in Japanese and American Perceivers. Paper presented at The International Congress of Phone, Stockholm.

Sekiyama, K., \& Tohkura, Y. (1991). McGurk effect in non-English listeners: Few visual effects for Japanese subjects hearing Japanese syllables of high auditory intelligibility. The Journal of The Acoustical Society of America, 90, 1797-1805.

Sekiyama, K., \& Tohkura, Y. (1993). Inter-language differences in the influence of visual cues in speech perception. Journal of Phonetics, 21, 427-444.

Sekiyama, K. (1994). Differences in auditory-visual speech perception between Japanese and Americans: McGurk effect as a function of incompatibility. The Journal of The Acoustical Society of Japan, 15, 143-158.

Sekiyama, K. (1997). Cultural and linguistic factors in audiovisual speech processing: The McGurk effect in Chinese subjects. Perception and Psychophysics, 59, 73-80.

Sherrington, C. S. (1920). Integrative action of the nervous system. New Haven: Yale University Press.

Shigeno, S. (2000). Influence of vowel context on the audio-visual speech perception of voiced stop consonants. Japanese Psychological Research, 42, 155-167.

Silverman, S. R., \& Hirsh, I. J. (1955). Problems related to the use of speech in clinical audiometry. Annals of Otology, Rhinology, \& Laryngology, 64, 1234-1244.

Simpson, S., \& Cooke, M. (2005). Consonant identification in N-talker babble in a nonmonotonic function of N. The Journal of The Acoustical Society of America, 118, 2775-2778. 
Sims, D. G. (1975). The validation of the CID everyday sentence test for use with the severely hearing impaired. Journal of The Academy of Rehabilitative Audiology, 8, 70-79.

Sims, D. G., \& Bicks, S. (2008). CID Everyday Sentences. National Technical Institute for the Deaf.

Sommers, M. S., Tye-Murray, N., \& Spehar, B. (2005). Auditory-visual speech perception and auditory visual enhancement in normal-hearing younger and older adults. Ear and Hearing, 26, 263-275.

Southwood, M. H., \& Flege, J. E. (1999). Scaling foreign accent; direct magnitude estimation versus interval scaling. Clinical Linguistics \& Phonetics, 13, 335-349.

Speaks, C., Parker, B., Harris, C., \& Kuhl, P. (1972). Intelligibility of connected discourse. Journal of Speech and Hearing Research, 15, 590-602.

Sperry, J. L., Wiley, T. L., \& Chial, M. R. (1997). Word recognition performance in various background competitors. Journal of American Academy of Audiology, 8, 71-80.

Stevens, G. (2006). The age-length-onset problem in research on second language acquisition among immigrants. Language Learning, 56, 671-692.

Storti, C. (2007). Speaking of India: Bridging the communication gap when working with Indians. Boston: Intercultural press.

Studebaker, G. A., Sherbecoe, R. L., McDaniel, D. M., \& Gwaltney, C. A. (1999). Monosyllabic word recognition at higher-than-normal speech and noise levels. The Journal of The Acoustical Society of America, 105, 2431-2444.

Sumby, W. H., \& Pollack, I. (1954). Visual contribution to speech intelligibility in noise. The Journal of The Acoustical Society of America, 26, 212-215.

Summerfield, Q., MacLeod, A., McGrath, M., \& Brooke, M. (1989). Lips, teeth, and the benefits of lipreading. In A. W. Young, \& H. D. Ellis (Eds.), Handbook of Research on Face Processing (pp. 223-233). North-Holland: Elsevier Science.

Tabachnick, B. G. \& Fidell, L. S. (2007). Cleaning up your act. In B. G. Tabachinick, \& L.S. Fidell Using multivariate statistics ( $5^{\text {th }}$ Ed., pp.60-116). Boston: Pearson Education, Inc.

Takata, Y., \& Năbělek, A. (1990). English consonant recognition in noise and in reverberation by Japanese and American listeners. The Journal of The Acoustical Society of America, 88, 643-666.

Tye-Murray, N. (2004). Aural rehabilitation plans for older adults. In N. Tye-Murray, Foundations of aural rehabilitation: Speechreading ( $2^{\text {nd }}$ Ed., pp. 339-369). Clifton park, NY: Thomson Delmar Learning. 
Tye-Murray, N., Sommers, M. S., \& Spehar, B. (2007a). Audiovisual integration and lipreading abilities of older adults with normal and impaired hearing. Ear and Hearing, 28, 656-668.

Tye-Murray, N., Sommers, M. S., \& Spehar, B. (2007b). The effects of Age and gender on lipreading abilities. Journal of the American Academy of Audiology, 18, 883-892.

Ueda, K., Akahane-Yamada, R., Komaki, R., \& Adachi, T. (2007). Identification of English /r/ and /l/ in noise: The effects of baseline performance. Acoustical Science and Technology, 28, 251-258.

US Census Bureau (2000). Language use and English-speaking ability: 2000. Retrieved December 1, 2008 from http://www.census.gov/prod/2003pubs/c2kbr-29.pdf

Van Engen, K. J., \& Bradlow, A. R. (2007). Sentence recognition in native- and foreign-language multi-talker background noise. The Journal of The Acoustical Society of America, 121, 519-526.

Van Wijngaarden, S. J., Steeneken, H. J., \& Houtgast, T. (2002). Quantifying the intelligibility of speech in noise for non-native listeners. The Journal of The Acoustical Society of America, 111, 1906-1916.

von Hapsburg, D., \& Pena, E. (2002). Understanding bilingualism and its impact on speech audiometry. Journal of Speech, Language, and Hearing Research, 45, 202-213.

Watt, W. (2007). How visual acuity is measured. Retrieved December 2, 2007 from http://www.mdsupport.org/library/acuity.html

Watson, C. S., Qui, W. W., Chamberlain, M. M., \& Li, X. (1996). Auditory and visual speech perception: Confirmation of a modality-independent source of individual differences in speech recognition. The Journal of The Acoustical Society of America, 100, 1153-1162.

Werker, J. F., Frost, P., \& McGurk, H. (1992). Cross-language influences on bimodal speech perception, Canadian Journal of Psychology, 46, 551-568.

Woods, R. L., \& Woods, J. M. (1995). The role of contrast sensitivity charts and contrast letter charts in clinical practice. Clinical and Experimental Optometry, 78, 43-57. 


\section{APPENDIXES}




\section{APPENDIX A}

\section{PARTICIPANTS PRE-SELECTION CRITERIA}

Your task : 1) Listen to simple sentences and write down what the speaker said 2) Listen to simple sentences while watching the speaker's face on the TV and write down what the spcaker said

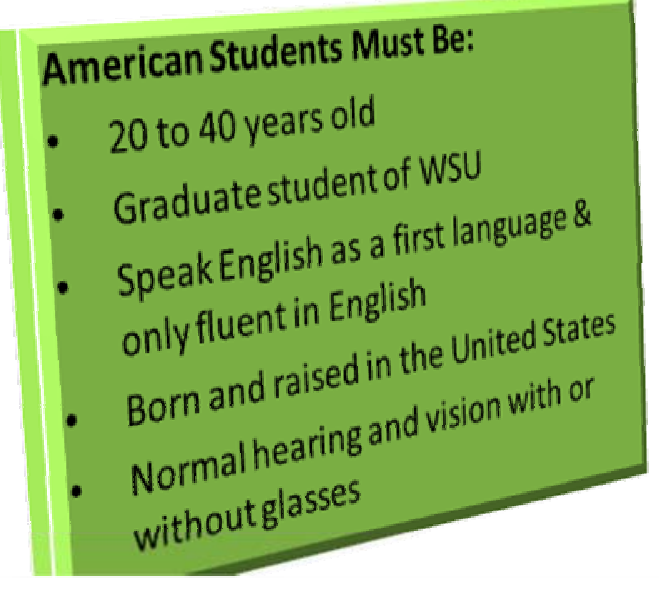

Benefits:

- Free vision screenings

(visual acuity and contrast sensitivity)

- Free hearing screening by a licensed audiologist

- Will be paid $\$ 10$ for $60-75$ minutes of your time

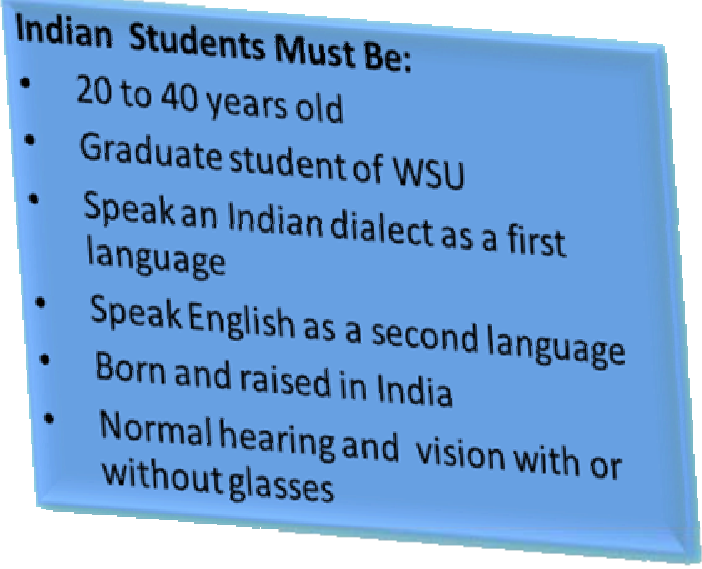

Contact information: Yori at Dept. of Communication Sciences \& Disorders at 978-3298 or e-mail at yxkanekama@wichita.edu 


\title{
APPENDIX B
}

\section{CONSENT FORM FOR AMERICAN PARTICIPANTS}

\author{
0.53 \\ WICHITA STATE UNIVERSITY \\ College of Health Professions \\ Department of Communication Sciences and Disorders \\ CONSENT FORM \\ (First-Language Speakers of English)
}

PURPOSE: You are invited to participate in a study of effects of lipreading on understanding American English by first-language speakers of English. We hope to obtain information about whether first-language and second-language speakers of English differ in how they combine lipreading with hearing to understand Mainstream American English.

PARTICIPANT SELECTION: We are seeking 30 to 35 participants for this study. You were selected as a possible participant in this study because you are an adult from the United States, you speak English as your first language, and you are a graduate student at Wichita State University.

EXPLANATION OF PROCEDURES: If you decide to participate, you will complete this pilot study in one session that will last between 30 and 75 minutes. You will first complete a written questionnaire about your age, any history of hearing and visual problems, and your language background speaking a first language. You then will be tape-recorded reading a brief English paragraph to assess the degree of your accent; you will complete a 5-minute vision screening to assess if your vision is within a normal range (with eyeglasses, if needed); and you will complete a 10-minute hearing screening to assess if your hearing is within a normal range.

If you pass the hearing and vision screenings, you will continue in the study. You will be seated at a desk in a sound booth with a TV screen in front of you. You will listen to 110 simple sentences through the loudspeaker of the TV. Meanwhile, background noise will also be played at various loudness levels from two other loudspeakers. Half of the time you will listen to the sentences while watching the speaker's face on the TV. The other half of the time you will listen to the sentences with the TV screen covered, so you will not be able to see the speaker's face. After you listen to each sentence, you will write on a piece of paper, word for word, what you thought the speaker said. Finally, you will be video-taped while listening to the sentences to assess your listening behaviors. 


\section{APPENDIX B (continued)}

DISCOMFORT/RISKS: There are no known risks or discomforts when completing this study. The background noise levels when listening to the sentences are not loud enough to cause any irritation or hearing loss. To minimize any fatigue, you will be given a short break after completing the questionnaire, reading sample, and vision and hearing screening; as well as a break at any time thereafter upon your request.

BENEFITS: You will receive a $\$ 10.00$ cash and a receipt for your participation in this study. You also will be given a free vision and hearing screening. The vision screening will be completed by the investigator who has been trained to give this type of vision screening. If you do not pass the vision screening, you will be referred to Dr. Alex Chaparro of the Human Factors division of the WSU Department of Psychology. The hearing screening will be completed by the investigator who is a licensed audiologist. If you do not pass the hearing screening, at your request, the audiologist will immediately complete a more detailed hearing test free of charge. If a hearing problem is indicated, you will be referred for further audiological and/or medical evaluation and treatment. Finally, this study may help us to understand how first-language and second-language speakers of English combine lipreading with hearing together to understand speech.

CONFIDENTIALITY: Results of this study may be published in a professional journal or presented at a professional conference. Any identifying information about you obtained will remain confidential. Specifically, your name will be assigned a number which will be used on your questionnaire, audiotape, videotape, and test results. None of your videotape will be shown to the public. To further ensure information is kept confidential your questionnaire, videotape, and test results will be locked within the principle investigator's (David Downs) office for three years.

COMPENSATION OR TREATMENT: Wichita State University does not provide medical treatment or other forms of reimbursement to participants injured as a result of or in connection of study conducted by Wichita State University or its faculty, staff, or students.

REFUSAL/WITHDRAWAL: Participation in this study is entirely voluntary. Your decision whether or not to participate will not affect your future relations with Wichita State University. If you agree to participate in this study, you are free to withdraw from the study at any time without penalty.

CONTACT: If you have any questions about this research, please contact one of the investigators during regular business hours: David Downs, $\mathrm{PhD}$, Department of Communication Sciences and Disorders, Wichita State University, 1845 Fairmount, Wichita, KS 67260-0075, telephone (316) 978-5404 or Yori Kanekama, MA at the same address, telephone (316) 9783298. 


\section{APPENDIX B (continued)}

If you have questions pertaining to your rights as a research project, or about research-related injury, you can contact the Office of Research Administration, Wichita State University, Wichita, KS 67260-0007, telephone (316) 978-3285.

You are under no obligation to participate in this study. Your signature indicates that you have read the information provided above and have voluntarily decided to participate.

You will be given a copy of this consent form to keep.

Signature of Participant

Date

Signature of Investigator

Date

Contact information:

Telephone:

E-mail:

1845 N. Fairmount, Wichita, KS 67260-0075

Telephone: (316) 978-3240 • Fax: (316) 978-3291 • E-mail: csd@wichita.edu • Website: www.wichita.edu/csd 


\title{
APPENDIX C
}

\section{CONSENT FORM FOR INDIAN PARTICIPANTS}

\author{
0.53 \\ WICHITA STATE UNIVERSITY \\ College of Health Professions \\ Department of Communication Sciences and Disorders \\ CONSENT FORM \\ (Second-Language Speakers of English)
}

PURPOSE: You are invited to participate in a study of effects of lipreading on understanding Mainstream American English by second-language speakers of English. We hope to obtain information about whether first-language and second-language speakers of English differ in how they combine lipreading with hearing to understand Mainstream American English.

PARTICIPANT SELECTION: We are seeking 30 to 35 participants for this study. You were selected as a possible participant in this study because you are an adult from India, you speak an Indian dialect as your first language, you speak English as an additional language, and you are a graduate student in the College of Engineering at Wichita State University.

EXPLANATION OF PROCEDURES: If you decide to participate, you will complete this pilot study in one session that will last between 30 and 75 minutes. You will first complete a written questionnaire about your age, any history of hearing and visual problems, your TOEFL score, and your language background speaking first and second languages. You then will be taperecorded reading a brief English paragraph to assess the degree of your accent; you will complete a 5-minute vision screening to assess if your vision is within a normal range (with eyeglasses, if needed); and you will complete a 10-minute hearing screening to assess if your hearing is within a normal range.

If you pass the hearing and vision screenings, you will continue in the study. You will be seated at a desk in a sound booth with a TV screen in front of you. You will listen to 100 simple sentences through the loudspeaker of the TV. Meanwhile, background noise will also be played at various loudness levels from two other loudspeakers. Half of the time you will listen to the sentences while watching the speaker's face on the TV. The other half of the time you will listen to the sentences with the TV screen covered, so you will not be able to see the speaker's face. After you listen to each sentence, you will write on a piece of paper, word for word, what you thought the speaker said. Finally, you will be video-taped while listening to the sentences to assess your listening behaviors. 


\section{APPENDIX C (continued)}

DISCOMFORT/RISKS: There are no known risks or discomforts when completing this study. The background noise levels when listening to the sentences are not loud enough to cause any irritation or hearing loss. To minimize any fatigue, you will be given a short break after completing the questionnaire, reading sample, and vision and hearing screening; as well as a break at any time thereafter upon your request.

BENEFITS: You will receive a $\$ 10.00$ cash and a receipt for your participation in this study. You also will be given a free vision and hearing screening. The vision screening will be completed by the investigator who has been trained to give this type of vision screening. If you do not pass the vision screening, you will be referred to Dr. Alex Chaparro of the Human Factors division of the WSU Department of Psychology. The hearing screening will be completed by the investigator who is a licensed audiologist. If you do not pass the hearing screening, at your request, the audiologist will immediately complete a more detailed hearing test free of charge. If a hearing problem is indicated, you will be referred for further audiological and/or medical evaluation and treatment. Finally, this study may help us to understand how first-language and second-language speakers of English combine lipreading with hearing together to understand speech.

CONFIDENTIALITY: Results of this study may be published in a professional journal or presented at a professional conference. Any identifying information about you obtained will remain confidential. Specifically, your name will be assigned a number which will be used on your questionnaire, audiotape, videotape, and test results. None of your videotape will be shown to the public. To further ensure information is kept confidential your questionnaire, videotape, and test results will be locked within the principle investigator's (David Downs) office for three years.

COMPENSATION OR TREATMENT: Wichita State University does not provide medical treatment or other forms of reimbursement to participants injured as a result of or in connection of study conducted by Wichita State University or its faculty, staff, or students.

REFUSAL/WITHDRAWAL: Participation in this study is entirely voluntary. Your decision whether or not to participate will not affect your future relations with Wichita State University. If you agree to participate in this study, you are free to withdraw from the study at any time without penalty.

CONTACT: If you have any questions about this research, please contact one of the investigators during regular business hours: David Downs, $\mathrm{PhD}$, Department of Communication Sciences and Disorders, Wichita State University, 1845 Fairmount, Wichita, KS 67260-0075, telephone (316) 978-5404 or Yori Kanekama, MA at the same address, telephone (316) 9783298. 


\section{APPENDIX C (continued)}

If you have questions pertaining to your rights as a research project, or about research-related injury, you can contact the Office of Research Administration, Wichita State University, Wichita, KS 67260-0007, telephone (316) 978-3285.

You are under no obligation to participate in this study. Your signature indicates that you have read the information provided above and have voluntarily decided to participate.

You will be given a copy of this consent form to keep.

Signature of Participant

Signature of Investigator

Contact information:

Telephone:

E-mail:
Date

Date

1845 N. Fairmount, Wichita, KS 67260-0075

Telephone: (316) 978-3240 • Fax: (316) 978-3291 • E-mail: csd@wichita.edu • Website: www.wichita.edu/csd 


\section{APPENDIX D \\ QUESTIONNAIRE FOR AMERICAN PARTICIPANTS}

\section{Screening Questionnaire for First-Language Speakers of English}

1) Date of Birth:

Age:

2) Do you have normal or near normal hearing? (Circle one)

- No

- Yes

Please explain

3) Do you have normal or near normal vision (with eyeglasses if needed)? (Circle one)

- No

- Yes

Please explain

4) Where were you born?

5) Where were you raised?

6) Where were your parents born? Mother Father

7) What is the first language you ever spoke as a child?

Please specify

8) What is the first dialect you ever spoke as a child?

Please specify

9) Are you proficient in, or have you had prolonged exposure to, a language other than English? (Circle one)

- No

- Yes

Please elaborate

10) Which dialect do you mainly speak?

Please specify

11) If you speak multiple dialects, which dialect do you mainly speak?

Please specify

12) When you talk to your friends, which dialect do you mainly speak?

Please specify 


\section{APPENDIX D (continued)}

13) Indicate which of the following dialect do you speak fluently (Circle one):

- Mainstream American English

- Non-Mainstream American English (Specify)

14) Which dialect did you learn first? (Circle one)

- Mainstream American English

- Non-Mainstream American English (Specify)

- I learned both at the same time

15) Which dialect was spoken in your home when you were child?

Please specify

16) Currently I am most comfortable speaking in (Circle one):

- Mainstream American English

- Non-Mainstream American English (Specify)

- I am equally comfortable in both languages

17) During a typical day I speak \% Mainstream American English and \% Non-Mainstream American English.

18) Currently, what dialect do you primarily speak at home? (Circle one)

- Mainstream American English

- Non-Mainstream American English (Specify)

19) Indicate your level of competence in the following areas by circling the appropriate number:

Speaking in Mainstream American English:

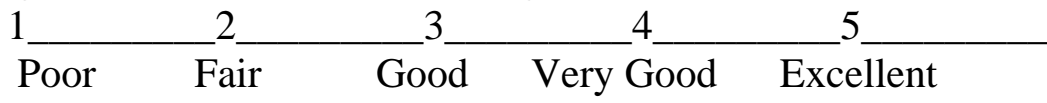

Understanding spoken Mainstream American English:

$1{ }^{2} \quad$ Foor ${ }^{2} \stackrel{3}{4}+5$

Reading adult-level material in English:

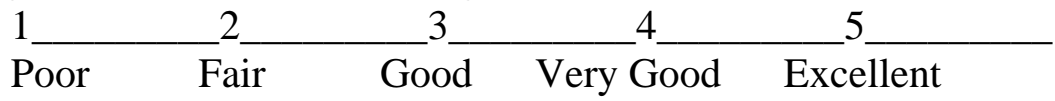

Writing adult-level material in English:

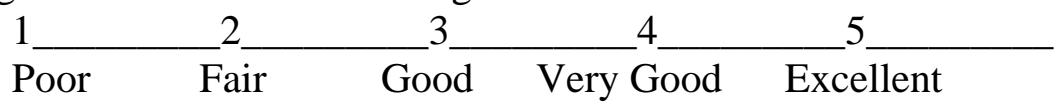




\section{APPENDIX D (continued)}

Speaking in Non-Mainstream American English:

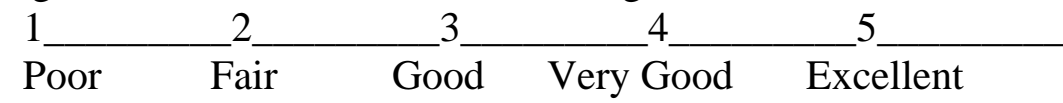

Understanding spoken Non-Mainstream American English:

\begin{tabular}{|c|c|c|c|c|}
\hline 1 & 2 & 3 & 4 & 5 \\
\hline Poor & Fair & Good & Very Good & Excellent \\
\hline
\end{tabular}




\section{APPENDIX E}

\section{QUIESTONNAIRE FOR INDIAN PARTICIPANTS}

\section{Screening Questionnaire for Second-Language Speakers of English}

1) Date of Birth:

Age:

2) TOEFL score:

3) Do you have normal or near normal hearing? (Circle one)

- No

- Yes

Please explain

4) Do you have normal or near normal vision (with eyeglasses if needed)? (Circle one)

- No

- Yes

Please explain

5) Where were you born?

6) Where were your parents born? Mother Father

7) What is the first language you ever spoke as a child?

Please specify

8) What is the first dialect you ever spoke as a child?

Please specify

9) Are you proficient in, or have you had prolonged exposure to, a language other than dialects spoken in India and English? (Circle one)

- No

- Yes

Please elaborate

10) How many Indian dialects do you personally speak in India?

Please specify

11) Which Indian dialect do you mainly speak in India?

Please specify

12) If you speak multiple Indian dialects, which dialect do you mainly speak in the United States?

Please specify 


\section{APPENDIX E (continued)}

13) When you talk to your Indian friends while you are in the United States, which language or Indian dialect do you mainly speak?

Please specify

14) Indicate which of the following languages do you speak fluently (Circle one):

- An Indian dialect (Specify)

- American English

- Non-American English (Specify)

15) Which language did you learn first? (Circle one)

- An Indian dialect (Specify)

- American English

- Non-American English (Specify)

- I learned both at the same time

16) Which language was spoken in your home when you were child? Please specify

17) How long have you been in the United States?

Please specify

18) How old were you when you began to learn English?

Age

19) Why did you learn English? (Circle one)

- I lived in the city in which English was the primary language spoken.

- I was born and grew up speaking English at home.

- I began to learn English when I started school.

- Other (please be specific)

20) Currently I am most comfortable speaking in (Circle one):

- An Indian dialect (Specify)

- American English

- Non-American English (Specify)

- I am equally comfortable in both languages

21) During a typical day I speak American English, and \% American English, $\%$ Non$\%$ Indian dialect.

22) Currently, what language do you primarily speak at home? (Circle one)

- An Indian dialect (Specify)

- American English

- Non-American English (Specify) 


\section{APPENDIX E (continued)}

23) Indicate your level of competence in the following areas by circling the appropriate number:

Speaking in Indian dialect:

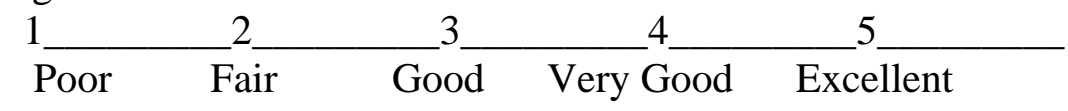

Understanding spoken Indian dialect:

1 Poor $^{2} \quad$ Fair Good 3 Very Good Excellent

Reading adult-level material in Indian dialect:

\begin{tabular}{|c|c|c|c|c|}
\hline & 2 & 3 & 4 & 5 \\
\hline Poor & Fair & Good & Very Good & Excellent \\
\hline
\end{tabular}

Writing adult-level material in Indian dialect:

1 Poor Fair Good ${ }^{2} \quad$ Very Good Excellent

Speaking in American English:

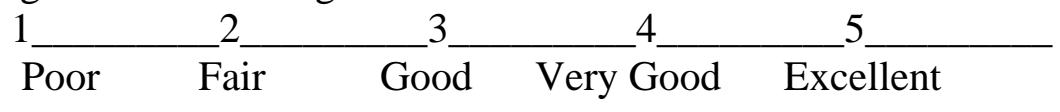

Understanding spoken American English:

\begin{tabular}{|c|c|c|c|c|}
\hline 1 & 2 & 3 & 4 & 5 \\
\hline Poor & Fair & Good & Very Good & Excellent \\
\hline
\end{tabular}

Reading adult-level material in English:

\begin{tabular}{|c|c|c|}
\hline 1 & 2 & 3 \\
\hline Poor & Fair & Good \\
\hline
\end{tabular}

Writing adult-level material in English:

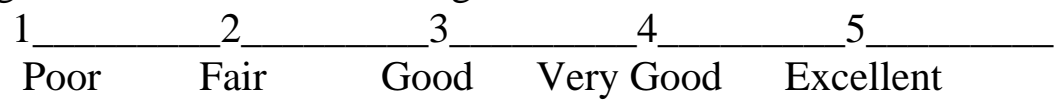




\section{APPENDIX F}

\section{RESPONSES FOR QUESTIONNAIRE FOR AMERICAN PARTICIPANTS}

1) Date of birth \& Age

- Mean age: 25.9 years old

- SD: 4.9 years

- Range: 22-39 years

2) Do you have normal or near normal hearing?

- All participants answered Yes.

3) Do you have normal or near normal vision (with eyeglasses if needed)?

- All participants answered Yes.

4) Where were you born?

\begin{tabular}{|c|c|c|c|}
\hline State & \# of Participants & State & \# of Participants \\
\hline Arizona & 1 & Massachusetts & 1 \\
\hline California & 1 & Missouri & 1 \\
\hline Florida & 1 & Nebraska & 1 \\
\hline Illinois & 1 & Texas & 2 \\
\hline Iowa & 2 & Wisconsin & 1 \\
\hline Kansas & 18 & & \\
\hline
\end{tabular}

5) Where were you raised?

\begin{tabular}{|c|c|c|c|}
\hline State & \# of Participants & State & \# of Participants \\
\hline Arizona & 1 & Kansas & 19 \\
\hline California & 2 & Missouri & 1 \\
\hline Florida & 1 & Oklahoma & 1 \\
\hline Illinois & 1 & Texas & 1 \\
\hline Iowa & 2 & Wisconsin & 1 \\
\hline
\end{tabular}


APPENDIX F (continued)

6) Where were your parents born?

\begin{tabular}{|c|c|c|c|}
\hline Mother & \# of Participants & Father & \# of Participants \\
\hline Iowa & 4 & California & 1 \\
\hline Kansas & 14 & Colorado & 1 \\
\hline Missouri & 1 & Florida & 1 \\
\hline Oklahoma & 2 & Illinois & 1 \\
\hline Illinois & 1 & Iowa & 2 \\
\hline Wisconsin & 2 & Kansas & 16 \\
\hline Colorado & 1 & Missouri & 1 \\
\hline South Dakota & 1 & Oklahoma & 3 \\
\hline Texas & 1 & & 1 \\
\hline Michigan & 1 & Texas & 1 \\
\hline $\begin{array}{c}\text { Panama } \\
\text { (foreign country) }\end{array}$ & 1 & Washington & 2 \\
\hline $\begin{array}{c}\text { Vietnam } \\
\text { (foreign country) }\end{array}$ & 1 & Wisconsin & 2 \\
\hline
\end{tabular}

7) What is the first language you ever spoke as a child?

- All participants answered English

8) What is the first dialect you ever spoke as a child?

- 29 participants answered midwestern dialect

- 1 participant answered southern dialect

9) Are you proficient in, or have you had prolonged exposure to, a language other than English?

- 27 participants answered No

- 3 participants answered Yes

- 1participant answered her/his spouse a native Spanish speaker

- 1 participant answered ASL and basic Spanish

- 1 participant answered studied Spanish 5 years but not fluent

10) Which dialect do you mainly speak?

- 29 participants answered Midwestern dialect

- 1 participants answered southern dialect

11) If you speak multiple dialects, which dialect do you mainly speak?

- 29 participants answered Midwestern dialect

- 1 participant answered southern dialect but now speak close to MAE 


\section{APPENDIX F (continued)}

12) When you talk to your friends, which dialect do you mainly speak?

- 29 participants answered midwestern dialect

- 1 participant answered mainly speak southern dialect but now speak close to MAE

13) Indicate which of the following dialect do you speak fluently:

- 29 participants answered MAE

- 1 participant answered southern dialect

14) Which dialect did you learn first?

- 29 participants answered MAE

- 1 participant answered southern dialect

15) Which dialect was spoken in your home when you were child?

- 29 participants answered Midwestern dialect

- 1 participant answered southern dialect

16) Currently I am most comfortable speaking in:

- 29 participants answered MAE

- 1 participants answered MAE and southern dialects

17) During a typical day I speak:

- MAE: 29 participants for $100 \%, 1$ participant for $50 \%$

- Non-MAE: 1 participant for $50 \%$

18) Currently, what dialect do you primarily speak at home?

- 30 participants answered MAE

19) Indicate your level of competence in the following areas by circling the appropriate number:

Speaking in Mainstream American English:

- 25 participants rated as "excellent”

- 4 participants rated as "very good"

Understanding spoken Mainstream American English:

- 27 participants rated as "excellent"

- 3 participants rated as "very good"

Reading adult-level material in English:

- 25 participants rated as "excellent"

- 5 participants rated as "very good" 


\section{APPENDIX F (continued)}

Writing adult-level material in English:

- 21 participants rated as "excellent"

- 9 participants rated as "very good"

Speaking in Non-Mainstream American English:

- 5 participants rated as "very good"

- 4 participants rated as "good"

- 10 participants rated as "fair"

- 11 participants rated as "poor"

Understanding spoken Non-Mainstream American English:

- 4 participants rated as "excellent"

- 9 participants rated as "very good"

- 8 participants rated as "good"

- 6 participants rated as "fair"

- 1 participant rated as "poor" 


\section{APPENDIX G}

RESPONSES FOR SCREENING QUESTIONNAIRE FOR INDIAN PARTICIPANTS

1) Date of Birth \& Age

- Mean age: 22.8 years old

- SD 2.5 years old

- Range 21-33 years old

2) TOEFL score

- Mean score: 89.8

- SD 8.7

- Range 79-108

3) Do you have normal or near normal hearing?

- All participants answered Yes

4) Do you have normal or near normal vision (with eyeglasses if needed)?

- All participants answered Yes

5) Where were you born?

- All participants answered India

6) Where were your parents born?

- All participants answered both parents were born in India

7) What is the first language you ever spoke as a child?

\begin{tabular}{|c|c|}
\hline Language & \# of Participants \\
\hline Hindi & 1 \\
\hline Kannada & 1 \\
\hline Marathi & 2 \\
\hline Tamil & 7 \\
\hline Telugu & 18 \\
\hline Tulu & 1 \\
\hline
\end{tabular}

8) What is the first dialect you ever spoke as a child?

\begin{tabular}{|c|c|}
\hline Dialect & \# of Participants \\
\hline Amma & 2 \\
\hline Hindi & 2 \\
\hline Marathi & 2 \\
\hline Mum & 1 \\
\hline Tamil & 5 \\
\hline Telugu & 17 \\
\hline Tulu & 1 \\
\hline
\end{tabular}




\section{APPENDIX G (continued)}

9) Are you proficient in, or have you had prolonged exposure to, a language other than dialects spoken in India and English?

- 29 participants answered No

- 1 participant answered French

10) How many Indian dialects do you personally speak in India?

\begin{tabular}{|l|c|}
\hline \multicolumn{1}{|c|}{ Dialects } & \# of Participants \\
\hline Telugu, Hindi, Oriya, Kannada, \& Tamil & 2 \\
\hline Tamil & 5 \\
\hline Tamil, Hindi, \& Telugu & 2 \\
\hline Kannada \& Hindi. & 1 \\
\hline Hindi, Telugu, \& Malayam & 12 \\
\hline Hindi \& Marathi & 1 \\
\hline Hindi \& Tamil & 1 \\
\hline Telugu & 2 \\
\hline Tulu, Kannada \& Hindi & 1 \\
\hline Telugu, Hindi, \& Marathi & 3 \\
\hline
\end{tabular}

11) Which Indian dialect do you mainly speak in India?

\begin{tabular}{|l|c|}
\hline \multicolumn{1}{|c|}{ Dialects } & \# of Participants \\
\hline Hindi Telugu, Tamil & 2 \\
\hline Hindi & 3 \\
\hline Telugu. & 13 \\
\hline Telugu \& Hindi & 3 \\
\hline Tamil & 4 \\
\hline Hindi \& Tamil & 1 \\
\hline Marathi & 1 \\
\hline Tulu \& Kannada & 1 \\
\hline Telugu, Hindi, \& Marathi & 1 \\
\hline Marathi \& Hindi & 1 \\
\hline
\end{tabular}




\section{APPENDIX G (continued)}

12) If you speak multiple Indian dialects, which dialect do you mainly speak in the United States?

\begin{tabular}{|c|c|}
\hline Dialects & \# of Participants \\
\hline Hindi & 7 \\
\hline Tamil & 6 \\
\hline Telugu & 17 \\
\hline
\end{tabular}

13) When you talk to your Indian friends while you are in the United States, which language or Indian dialect do you mainly speak?

\begin{tabular}{|l|c|}
\hline \multicolumn{1}{|c|}{ Dialects } & \# of Participants \\
\hline Telugu & 13 \\
\hline Telugu \& English & 2 \\
\hline English \& Tamil & 1 \\
\hline Kannada \& Tamil & 1 \\
\hline Tamil \& Hindi & 1 \\
\hline English \& Hindi & 1 \\
\hline Telugu \& Hindi & 4 \\
\hline Kannada, Hindi, \& English & 1 \\
\hline Tamil & 3 \\
\hline Hindi & 2 \\
\hline English & 1 \\
\hline
\end{tabular}




\section{APPENDIX G (continued)}

14) Indicate which of the following languages do you speak fluently:

\begin{tabular}{|l|l|c|}
\hline \multicolumn{2}{|c|}{ Language } & \# of Participants \\
\hline \multirow{4}{*}{ Indian dialect: } & Telugu & 17 \\
\cline { 2 - 3 } & Tamil & 7 \\
\cline { 2 - 3 } & Tulu & 1 \\
\cline { 2 - 3 } & Hindi & 1 \\
\cline { 2 - 3 } & Hindi, Telugu, \& Marathi & 1 \\
\cline { 2 - 3 } & No description & 1 \\
\hline American English & UK English & 1 \\
\hline \multirow{2}{*}{ Non-American English } & No description & 7 \\
\cline { 2 - 3 } & & 3 \\
\hline *6 participants circled 2 & \multicolumn{2}{|l}{} \\
\hline
\end{tabular}

15) Which language did you learn first?

\begin{tabular}{|l|l|c|}
\hline \multicolumn{2}{|c|}{ Language } & \# of Participants \\
\hline \multirow{4}{*}{ Indian dialect } & Marathi \& Hindi & 1 \\
\cline { 2 - 3 } & Marwari & 1 \\
\cline { 2 - 3 } & Telugu \& Hindi & 1 \\
\cline { 2 - 3 } & Telugu & 13 \\
\cline { 2 - 3 } & Tulu & 1 \\
\cline { 2 - 3 } & Tamil \& Hindi & 1 \\
\cline { 2 - 3 } & Tamil & 5 \\
\cline { 2 - 3 } & No description & 3 \\
\hline American English & & 1 \\
\hline Non-American & UK English & 2 \\
\cline { 2 - 3 } English & No description & 3 \\
\hline I learned both at the same time & 4 \\
\hline * 6 participants circled 2 & \\
\hline
\end{tabular}




\section{APPENDIX G (continued)}

16) Which language was spoken in your home when you were child?

\begin{tabular}{|c|c|}
\hline Dialects & \# of Participants \\
\hline Hindi & 1 \\
\hline Telugu & 18 \\
\hline Tulu & 1 \\
\hline Tamil & 7 \\
\hline Marathi & 2 \\
\hline Kannada & 1 \\
\hline
\end{tabular}

17) How long have you been in the United States?

- Mean months: 9.13

- SD: 17.9

- Range: 2 to 96 months

18) How old were you when you began to learn English?

- Mean age: 4.8 years old

- SD: 1.9 years

- Range: 3 to 11 years

19) Why did you learn English?

- All participants answered "I began to learn English when I started school."

20) Currently I am most comfortable speaking in:

\begin{tabular}{|l|l|c|}
\hline \multicolumn{2}{|c|}{ Language } & \# of Participants \\
\hline \multirow{3}{*}{ Indian dialect } & Tulu & 1 \\
\cline { 2 - 3 } & Telugu & 4 \\
\cline { 2 - 3 } & No description & 2 \\
\hline American English & 1 \\
\hline Non-American English & No description & 1 \\
\hline I learned both at the same time & 22 \\
\hline$* 4$ participants circled 2 & \\
\hline
\end{tabular}




\section{APPENDIX G (continued)}

21) During a typical day I speak :

- American English; 30\% (2), 5\% (1), 10\% (1), 70\% (1), 60\% (3), 20\% (5), $45 \%$

(1), $40 \%(4), \underline{30 \%(4), \underline{50 \%(2)}}$

- Non-American English; 10\% (1), 20\% (2), 35\% (1), 5\% (1), 30\% (4), 60\% (3),

$\underline{50 \%(6)}$,

- Indian dialect; $\underline{35 \%}$ (1), 45\% (1), 30\% (2), 95\% (1), 20\% (2), $40 \%$ (5), $55 \%$ (1), $\underline{60 \%(5)}, \underline{70 \%(3)}, \underline{50 \%(8)}$

22) Currently, what language do you primarily speak at home?

\begin{tabular}{|l|l|c|}
\hline \multicolumn{2}{|c|}{ Language } & \# of Participants \\
\hline \multirow{4}{*}{ Indian dialect } & Telugu & 16 \\
\cline { 2 - 3 } & Hindi & 1 \\
\cline { 2 - 3 } & Telugu \& Hindi & 1 \\
\cline { 2 - 3 } & Tamil & 7 \\
\cline { 2 - 3 } & Kannada & 1 \\
\cline { 2 - 3 } & Marathi & 2 \\
\hline American English & & 2 \\
\hline Non-American English & 0 \\
\hline
\end{tabular}

23) Indicate your level of competence in the following areas by circling the appropriate number:

Speaking in Indian dialect:

- 17 participants rated as "excellent"

- 12 participants rated as "very good”

Understanding spoken Indian dialect:

- 21 participants rated as "excellent"

- 7 participants rated "very good"

- 2 participants rated as "good"

Reading adult-level material in Indian dialect:

- 10 participants rated as "excellent"

- 14 participants rated as "very good"

- 6 participants rated as "good" 
APPENDIX G (continued)

Writing adult-level material in Indian dialect:

- 9 participants rated as "excellent"

- 13 participants rated as "very good"

- 6 participants rated as "good"

- 2 participants rated as "fair"

Speaking in American English:

- 11 participants rated as "very good"

- 15 participants rated as "good"

- 4 participants rated as "fair"

Understanding spoken American English:

- 4 participants rated as "excellent"

- 10 participants rated as "very good"

- 11 participants rated as "good"

- 5 participants rated as "fair"

Reading adult-level material in English:

- 4 participants rated "excellent"

- 15 participants rated "very good"

- 9 participants rated "good"

- 1 participant rated as "fair"

- 1 participant rated as "poor"

Writing adult-level material in English:

- 3 participants rated as "excellent"

- 13 participants rated as "very good"

- 10 participants rated as "good"

- 3 participants rated as "fair"

- 1 participant rated as "poor" 
APPENDIX H

RAINBOW PASSAGE

When the sunlight strikes raindrops in the air, they act like a prism and form a rainbow. The rainbow is a division of white light into many beautiful colors. These take the shape of a long round arch, with its path high above, and its two ends apparently beyond the horizon. There is, according to legend, a boiling pot of gold at one end. People look, but no one ever finds it. When a man looks for something beyond his reach, his friends say he is looking for the pot of gold at the end of the rainbow. 


\section{APPENDIX I-1}

\section{DISTANCE VISUAL ACUITY TEST INSTRUCTION}

A participant will stand at four meters from a Smelled eye chart with center of chart at eye level for a participant. The experimenter will verbally instruct the participants as follows: "Stand on the marked line and read down the row of letters on the chart when I point to it. As you read down, each row of the letters reduce in size. If you are not sure what the letters are, please guess at the letters. When you read the letters, keep your eyes fully open and try not to squint. Do you have any questions?”

\section{APPENDIX I-2}

\section{CONTRAST SENSITIVITY TEST INSTRUCTION}

A participant will stand at one meter from a chart. The instruction for this test will be as follows: "Stand on this marked line. Read the groups of three letters from left to right when I point to it. As you read down each group, the letters reduce in contrast. If you are not sure what the letters are, please guess at the letters. Please try not to squint your eyes or sway your body. Do you have any questions? ”

\section{APPENDIX I-3}

\section{HEARING TEST INSTRUCTION}

A participant will respond to the presence of a pure tone signal presented through headphones during the screening test. The instruction for the participants will be as follows: "You are going to hear some pure tones. When you hear the tones, raise your hand. If you are not sure, please guess at the tone.” 


\section{APPENDIX J}

\section{PARTICIPANT'S INSTRUCTION FOR ESS}

You will see (and/or hear) one hundred sentences under auditory only, visual only and audio-visual conditions. These sentences are arranged in ten lists of ten sentences per list. Each list contains various types and lengths of sentences. There will be a continuous noise in the background for auditory only and audio-visual conditions. In the auditory only condition, a TV monitor will be covered by the back cloth so you cannot see. You are to write whatever you perceive the sentence to be, and you are encouraged to guess. When you complete each sentence, raise your hand. This will be a sign to proceed to next sentence. Before we begin, you will see (and/or hear) ten practice items under each condition. So you can practice before we begin. Do you have any questions? 


\section{APPENDIX K}

\section{TEST FORM}

1.

2.

3.

4.

5.

6.

7.

8.

9.

10. 


\section{APPENDIX L}

\section{CHABA CRITERIA}

From Davis and Silverman (1970, p.492) as condensed from Silverman and Hirsh (1955).

A set of sentence has been prepared as Central Institute for the Deaf to represent "everyday American speech.” The specification for such a sample were laid down by a Working Group (Chairman, Dr. Grant Fairbanks) of the Armed Forces-National Research Council Committee on Hearing and of Bio-Acoustics. Some of the more important characteristics are as follows:

1. The vocabulary is appropriate to adults.

2. The words appear with high frequency in one or more of well-known word counts of the English language.

3. Proper names and proper nouns are not used.

4. Common nonslang idioms and contractions are used freely.

5. Phonetic loading and "tongue-twisting" are avoided.

6. Redundancy is high.

7. The level of abstraction is low.

8. Grammatical structure varies freely.

9. Sentence length varies in the following proportion:

Two to four words 1

Five to nine words 2

Ten to twelve words 1

10. Sentence forms are in the following proportion:

$\begin{array}{llll}\text { Declarative } & 6 & \text { Imperative } & 2 \\ \text { Rising interrogative } & 1 & \text { Fall interrogative } & 1\end{array}$




\section{APPENDIX M}

\section{CID EVEYDAY SPEECH SENTENCES}

\section{List 1}

1. Walking's my favorite exercise.

2. Here's a nice quiet place to rest.

3. Our Janitor sweeps the floors every night.

4. It would be much easier if everyone would help.

5. Good morning.

6. Open your window before you go to bed.

7. Do you think that she should stay out so late?

8. How do you feel about changing the time when we begin work?

9. Here we go.

10. Move out of the way!

List 2

1. The water's too cold for swimming.

2. Why should I get up so early in the morning?

3. Here are your shoes.

4. It's raining.

5. Where are you going?

6. Come here when I call you!

7. Don't try to get out of it this time!

8. Should we let little children go to the movies by themselves?

9. There isn't enough paint to finish the room.

10. Do you want an egg for breakfast?

List 3

1. Everybody should brush his teeth after meals.

2. Everything's all right.

3. Don't use up all the paper when you write your letter.

4. That's right.

5. People ought to see a doctor once a year.

6. Those windows are so dirty I can't see anything outside.

7. Pass the bread and butter please!

8. Don't forget to pay your bill before the first of the month.

9. Don't let the dog out of the house!

10. There's a good ballgame this afternoon. 


\section{APPENDIX M (continued)}

List 4

1. It's time to go.

2. If you don't want the old magazines, throw them out.

3. Do you want to wash up?

4. It's a real dark night so watch your driving.

5. I'll carry the package for you.

6. Did you forget to shut off the water?

7. Fishing in a mountain stream is my idea of a good time.

8. Fathers spend more time with their children than they used to.

9. Be careful not to break your glasses!

10. I'm sorry.

List 5

1. You can catch the bus across the street.

2. Call her on the phone and tell her the news.

3. I'll catch up with you later.

4. I'll think it over.

5. I don't want to go to the movies tonight.

6. If your tooth hurts that much you ought to see a dentist.

7. Put that cookie back in the box!

8. Stop fooling around!

9. Time’s up.

10. How do you spell your name?

List 6

1. Music always cheers me up.

2. My brother's in town for a short while on business.

3. We live a few miles from the main road.

4. This suit needs to go to the cleaners.

5. They ate enough green apples to make them sick for a week.

6. Where have you been all this time?

7. Have you been working hard lately?

8. There's not enough room in the kitchen for a new table.

9. Where is he?

10. Look out! 


\section{APPENDIX M (continued)}

\section{List 7}

1. I'll see you right after lunch.

2. See you later.

3. While shoes are awful to keep clean.

4. Stand there and don't move until I tell you!

5. There's a big piece of cake left over from dinner.

6. Wait for me at the corner in front of the drugstore.

7. It's no trouble at all.

8. Hurry up!

9. The morning paper didn't say anything about rain this afternoon or tonight.

10. The phone call's for you.

\section{List 8}

1. Believe me!

2. Let's get a cup of coffee.

3. Let's get out of here before it's too late.

4. I hate driving at night.

5. There was water in the cellar after that heavy rain yesterday.

6. She'll only be gone a few minutes.

7. How do you know?

8. Children like candy

9. If we don't get rain soon, we'll have no grass.

10. They're not listed in the new phone book.

\section{List 9}

1. Where can I find a place to park?

2. I like those big red apples we always get in the fall.

3. You'll get fat eating candy.

4. The show's over.

5. Why don't they paint their walls some other color?

6. What's new?

7. What are you hiding under your coat?

8. How come I should always be the one to go first?

9. I'll take sugar and cream in my coffee.

10. Wait just a minute! 


\section{APPENDIX M (continued)}

List 10

1. Breakfast is ready.

2. I don't know what's wrong with the car, but it won't start.

3. It sure takes a sharp knife to cut this meat.

4. I haven't read a newspaper since we bought a television set.

5. Weeds are spoiling the yard.

6. Call me a little later!

7. Do you have change for a five- dollar bill?

8. How are you?

9. I'd like some ice cream with my pie.

10. I don't think I'll have any dessert. 


\section{APPENDIX N}

\section{RAW DATA SHOWING AV-SCORES, A-SCORES, AND VE-SCORES FOR AMERICAN PARTICIPANTS}

\begin{tabular}{|c|c|c|c|c|c|c|c|c|c|}
\hline & $\mathrm{AV}$ & A-only & VE & $\mathrm{AV}$ & A-only & $\mathrm{VE}$ & $\mathrm{AV}$ & A-only & $\mathrm{VE}$ \\
\hline SNR & \multicolumn{3}{|c|}{ Participant \# 15} & \multicolumn{3}{|c|}{ Participant \# 17} & \multicolumn{3}{|c|}{ Participant \# 13} \\
\hline 6 & $100 \%$ & $96 \%$ & $4 \%$ & $98 \%$ & $96 \%$ & $2 \%$ & $100 \%$ & $100 \%$ & $0 \%$ \\
\hline 0 & $100 \%$ & $100 \%$ & $0 \%$ & $100 \%$ & $98 \%$ & $2 \%$ & $100 \%$ & $98 \%$ & $2 \%$ \\
\hline-6 & $100 \%$ & $88 \%$ & $11 \%$ & $92 \%$ & $68 \%$ & $18 \%$ & $98 \%$ & $98 \%$ & $0 \%$ \\
\hline-12 & $86 \%$ & $48 \%$ & $25 \%$ & $38 \%$ & $18 \%$ & $11 \%$ & $84 \%$ & $10 \%$ & $39 \%$ \\
\hline \multirow[t]{2}{*}{-18} & $74 \%$ & $0 \%$ & $37 \%$ & $42 \%$ & $2 \%$ & $20 \%$ & $86 \%$ & $8 \%$ & $41 \%$ \\
\hline & \multicolumn{3}{|c|}{ Participant \# 48} & \multicolumn{3}{|c|}{ Participant \# 50} & \multicolumn{3}{|c|}{ Participant \# 49} \\
\hline 6 & $96 \%$ & $98 \%$ & $-2 \%$ & $100 \%$ & $100 \%$ & $0 \%$ & $96 \%$ & $96 \%$ & $0 \%$ \\
\hline 0 & $100 \%$ & $100 \%$ & $0 \%$ & $100 \%$ & $100 \%$ & $0 \%$ & $96 \%$ & $100 \%$ & $-4 \%$ \\
\hline-6 & $100 \%$ & $100 \%$ & $0 \%$ & $100 \%$ & $86 \%$ & $12 \%$ & $100 \%$ & $88 \%$ & $11 \%$ \\
\hline-12 & $86 \%$ & $38 \%$ & $30 \%$ & $86 \%$ & $22 \%$ & $36 \%$ & $36 \%$ & $46 \%$ & $-6 \%$ \\
\hline \multirow[t]{2}{*}{-18} & $56 \%$ & $2 \%$ & $27 \%$ & $90 \%$ & $4 \%$ & $44 \%$ & $42 \%$ & $10 \%$ & $17 \%$ \\
\hline & \multicolumn{3}{|c|}{ Participant \# 1} & \multicolumn{3}{|c|}{ Participant \# 2} & \multicolumn{3}{|c|}{ Participant \# 3} \\
\hline 6 & $100 \%$ & $96 \%$ & $4 \%$ & $100 \%$ & $100 \%$ & $0 \%$ & $100 \%$ & $100 \%$ & $0 \%$ \\
\hline 0 & $96 \%$ & $100 \%$ & $-4 \%$ & $100 \%$ & $100 \%$ & $0 \%$ & $98 \%$ & $98 \%$ & $0 \%$ \\
\hline-6 & $98 \%$ & $50 \%$ & $32 \%$ & $88 \%$ & $94 \%$ & $-6 \%$ & $98 \%$ & $78 \%$ & $16 \%$ \\
\hline-12 & $92 \%$ & $18 \%$ & $41 \%$ & $60 \%$ & $24 \%$ & $20 \%$ & $98 \%$ & $10 \%$ & $46 \%$ \\
\hline \multirow[t]{2}{*}{-18} & $70 \%$ & $4 \%$ & $34 \%$ & $44 \%$ & $4 \%$ & $20 \%$ & $90 \%$ & $14 \%$ & $41 \%$ \\
\hline & \multicolumn{3}{|c|}{ Participant \# 41} & \multicolumn{3}{|c|}{ Participant \# 44} & \multicolumn{3}{|c|}{ Participant \# 59} \\
\hline 6 & $100 \%$ & $100 \%$ & $0 \%$ & $100 \%$ & $100 \%$ & $0 \%$ & $100 \%$ & $94 \%$ & $6 \%$ \\
\hline 0 & $100 \%$ & $98 \%$ & $2 \%$ & $100 \%$ & $100 \%$ & $0 \%$ & $98 \%$ & $94 \%$ & $4 \%$ \\
\hline-6 & $96 \%$ & $92 \%$ & $4 \%$ & $100 \%$ & $90 \%$ & $9 \%$ & $94 \%$ & $64 \%$ & $22 \%$ \\
\hline-12 & $100 \%$ & $60 \%$ & $29 \%$ & $100 \%$ & $66 \%$ & $25 \%$ & $78 \%$ & $26 \%$ & $30 \%$ \\
\hline-18 & $92 \%$ & $0 \%$ & $46 \%$ & $90 \%$ & $16 \%$ & $40 \%$ & $54 \%$ & $8 \%$ & $24 \%$ \\
\hline
\end{tabular}

* Shaded participants were male. 


\section{APPENDIX N (continued)}

\begin{tabular}{|c|c|c|c|c|c|c|c|c|c|}
\hline & $\mathrm{AV}$ & A-only & $\mathrm{VE}$ & $\mathrm{AV}$ & A-only & $\mathrm{VE}$ & $\mathrm{AV}$ & A-only & VE \\
\hline SNR & \multicolumn{3}{|c|}{ Participant \# 34} & \multicolumn{3}{|c|}{ Participant \# 32} & \multicolumn{3}{|c|}{ Participant \# 16} \\
\hline 6 & $100 \%$ & $100 \%$ & $0 \%$ & $100 \%$ & $98 \%$ & $2 \%$ & $94 \%$ & $98 \%$ & $-4 \%$ \\
\hline 0 & $100 \%$ & $90 \%$ & $9 \%$ & $100 \%$ & $82 \%$ & $15 \%$ & $98 \%$ & $88 \%$ & $9 \%$ \\
\hline-6 & $98 \%$ & $34 \%$ & $39 \%$ & $100 \%$ & $48 \%$ & $34 \%$ & $98 \%$ & $48 \%$ & $33 \%$ \\
\hline-12 & $86 \%$ & $26 \%$ & $34 \%$ & $66 \%$ & $12 \%$ & $29 \%$ & $82 \%$ & $28 \%$ & $31 \%$ \\
\hline \multirow[t]{2}{*}{-18} & $88 \%$ & $4 \%$ & $43 \%$ & $72 \%$ & $2 \%$ & $35 \%$ & $74 \%$ & $2 \%$ & $36 \%$ \\
\hline & \multicolumn{3}{|c|}{ Participant \# 57} & \multicolumn{3}{|c|}{ Participant \# 58} & \multicolumn{3}{|c|}{ Participant \# 56} \\
\hline 6 & $100 \%$ & $100 \%$ & $0 \%$ & $98 \%$ & $100 \%$ & $-2 \%$ & $100 \%$ & $100 \%$ & $0 \%$ \\
\hline 0 & $96 \%$ & $96 \%$ & $0 \%$ & $98 \%$ & $86 \%$ & $11 \%$ & $96 \%$ & $96 \%$ & $0 \%$ \\
\hline-6 & $98 \%$ & $96 \%$ & $2 \%$ & $100 \%$ & $90 \%$ & $9 \%$ & $98 \%$ & $90 \%$ & $7 \%$ \\
\hline-12 & $100 \%$ & $14 \%$ & $46 \%$ & $94 \%$ & $52 \%$ & $28 \%$ & $96 \%$ & $36 \%$ & $37 \%$ \\
\hline \multirow[t]{2}{*}{-18} & $84 \%$ & $8 \%$ & $40 \%$ & $26 \%$ & $2 \%$ & $12 \%$ & $70 \%$ & $20 \%$ & $28 \%$ \\
\hline & \multicolumn{3}{|c|}{ Participant \# 53} & \multicolumn{3}{|c|}{ Participant \# 54} & \multicolumn{3}{|c|}{ Participant \# 52} \\
\hline 6 & $100 \%$ & $96 \%$ & $4 \%$ & $100 \%$ & $100 \%$ & $0 \%$ & $100 \%$ & $100 \%$ & $0 \%$ \\
\hline 0 & $100 \%$ & $100 \%$ & $0 \%$ & $100 \%$ & $100 \%$ & $0 \%$ & $100 \%$ & $92 \%$ & $7 \%$ \\
\hline-6 & $98 \%$ & $76 \%$ & $18 \%$ & $100 \%$ & $52 \%$ & $32 \%$ & $100 \%$ & $74 \%$ & $21 \%$ \\
\hline-12 & $100 \%$ & $30 \%$ & $41 \%$ & $98 \%$ & $22 \%$ & $43 \%$ & $92 \%$ & $24 \%$ & $39 \%$ \\
\hline \multirow[t]{2}{*}{-18} & $86 \%$ & $4 \%$ & $42 \%$ & $78 \%$ & $2 \%$ & $38 \%$ & $78 \%$ & $8 \%$ & $36 \%$ \\
\hline & \multicolumn{3}{|c|}{ Participant \# 8} & \multicolumn{3}{|c|}{ Participant \# 9} & \multicolumn{3}{|c|}{ Participant \# 10} \\
\hline 6 & $98 \%$ & $94 \%$ & $4 \%$ & $100 \%$ & $100 \%$ & $0 \%$ & $100 \%$ & $98 \%$ & $2 \%$ \\
\hline 0 & $96 \%$ & $88 \%$ & $7 \%$ & $100 \%$ & $100 \%$ & $0 \%$ & $100 \%$ & $100 \%$ & $0 \%$ \\
\hline-6 & $100 \%$ & $86 \%$ & $12 \%$ & $100 \%$ & $92 \%$ & $7 \%$ & $100 \%$ & $88 \%$ & $11 \%$ \\
\hline-12 & $86 \%$ & $10 \%$ & $40 \%$ & $94 \%$ & $30 \%$ & $38 \%$ & $94 \%$ & $30 \%$ & $38 \%$ \\
\hline-18 & $58 \%$ & $20 \%$ & $21 \%$ & $98 \%$ & $14 \%$ & $45 \%$ & $92 \%$ & $10 \%$ & $43 \%$ \\
\hline
\end{tabular}

* Shaded participants were male. 


\section{APPENDIX N (continued)}

\begin{tabular}{|c|c|c|c|c|c|c|c|c|c|}
\hline & $\mathrm{AV}$ & A-only & VE & $\mathrm{AV}$ & A-only & $\mathrm{VE}$ & $\mathrm{AV}$ & A-only & VE \\
\hline SNR & \multicolumn{3}{|c|}{ Participant \# 12} & \multicolumn{3}{|c|}{ Participant \# 35} & \multicolumn{3}{|c|}{ Participant \# 51} \\
\hline 6 & $100 \%$ & $100 \%$ & $0 \%$ & $100 \%$ & $100 \%$ & $0 \%$ & $100 \%$ & $100 \%$ & $0 \%$ \\
\hline 0 & $100 \%$ & $100 \%$ & $0 \%$ & $100 \%$ & $100 \%$ & $0 \%$ & $100 \%$ & $98 \%$ & $2 \%$ \\
\hline-6 & $100 \%$ & $68 \%$ & $24 \%$ & $100 \%$ & $100 \%$ & $0 \%$ & $98 \%$ & $98 \%$ & $0 \%$ \\
\hline-12 & $98 \%$ & $26 \%$ & $41 \%$ & $96 \%$ & $22 \%$ & $42 \%$ & $92 \%$ & $34 \%$ & $35 \%$ \\
\hline \multirow[t]{2}{*}{-18} & $76 \%$ & $10 \%$ & $35 \%$ & $86 \%$ & $8 \%$ & $41 \%$ & $82 \%$ & $16 \%$ & $36 \%$ \\
\hline & \multicolumn{3}{|c|}{ Participant \# 4} & \multicolumn{3}{|c|}{ Participant \# 5} & \multicolumn{3}{|c|}{ Participant \# 55} \\
\hline 6 & $96 \%$ & $98 \%$ & $-2 \%$ & $98 \%$ & $96 \%$ & $2 \%$ & $100 \%$ & $98 \%$ & $2 \%$ \\
\hline 0 & $96 \%$ & $92 \%$ & $4 \%$ & $98 \%$ & $100 \%$ & $-2 \%$ & $100 \%$ & $98 \%$ & $2 \%$ \\
\hline-6 & $96 \%$ & $32 \%$ & $38 \%$ & $100 \%$ & $64 \%$ & $26 \%$ & $100 \%$ & $96 \%$ & $4 \%$ \\
\hline-12 & $64 \%$ & $6 \%$ & $30 \%$ & $94 \%$ & $70 \%$ & $18 \%$ & $98 \%$ & $26 \%$ & $41 \%$ \\
\hline-18 & $16 \%$ & $0 \%$ & $8 \%$ & $72 \%$ & $18 \%$ & $30 \%$ & $50 \%$ & $14 \%$ & $19 \%$ \\
\hline
\end{tabular}




\section{APPENDIX O}

\section{RAW DATA SHOWING AV-SCORES, A-SCORES, AND VE-SCORES FOR INDIAN PARTICIPANTS}

\begin{tabular}{|c|c|c|c|c|c|c|c|c|c|}
\hline & $\mathrm{AV}$ & A-only & $\mathrm{VE}$ & $\mathrm{AV}$ & A-only & $\mathrm{VE}$ & $\mathrm{AV}$ & A-only & $\mathrm{VE}$ \\
\hline SNR & \multicolumn{3}{|c|}{ Participant \# 45} & \multicolumn{3}{|c|}{ Participant \# 46} & \multicolumn{3}{|c|}{ Participant \# 47} \\
\hline 6 & $96 \%$ & $78 \%$ & $15 \%$ & $96 \%$ & $80 \%$ & $13 \%$ & $98 \%$ & $100 \%$ & $-2 \%$ \\
\hline 0 & $94 \%$ & $84 \%$ & $9 \%$ & $92 \%$ & $96 \%$ & $-4 \%$ & $96 \%$ & $98 \%$ & $-2 \%$ \\
\hline-6 & $70 \%$ & $4 \%$ & $34 \%$ & $74 \%$ & $54 \%$ & $14 \%$ & $72 \%$ & $20 \%$ & $29 \%$ \\
\hline-12 & $18 \%$ & $0 \%$ & $9 \%$ & $14 \%$ & $16 \%$ & $-1 \%$ & $54 \%$ & $6 \%$ & $25 \%$ \\
\hline \multirow[t]{2}{*}{-18} & $16 \%$ & $4 \%$ & $6 \%$ & $32 \%$ & $4 \%$ & $14 \%$ & $6 \%$ & $0 \%$ & $3 \%$ \\
\hline & \multicolumn{3}{|c|}{ Participant \# 38} & \multicolumn{3}{|c|}{ Participant \# 40} & \multicolumn{3}{|c|}{ Participant \# 42} \\
\hline 6 & $98 \%$ & $88 \%$ & $9 \%$ & $100 \%$ & $96 \%$ & $4 \%$ & $92 \%$ & $80 \%$ & $10 \%$ \\
\hline 0 & $92 \%$ & $70 \%$ & $17 \%$ & $96 \%$ & $96 \%$ & $0 \%$ & $88 \%$ & $44 \%$ & $28 \%$ \\
\hline-6 & $62 \%$ & $32 \%$ & $18 \%$ & $60 \%$ & $60 \%$ & $0 \%$ & $52 \%$ & $24 \%$ & $16 \%$ \\
\hline-12 & $54 \%$ & $4 \%$ & $26 \%$ & $62 \%$ & $4 \%$ & $30 \%$ & $62 \%$ & $6 \%$ & $29 \%$ \\
\hline \multirow[t]{2}{*}{-18} & $36 \%$ & $0 \%$ & $18 \%$ & $38 \%$ & $0 \%$ & $19 \%$ & $8 \%$ & $4 \%$ & $2 \%$ \\
\hline & \multicolumn{3}{|c|}{ Participant \# 18} & \multicolumn{3}{|c|}{ Participant \# 19} & \multicolumn{3}{|c|}{ Participant \# 20} \\
\hline 6 & $100 \%$ & $92 \%$ & $7 \%$ & $96 \%$ & $74 \%$ & $17 \%$ & $92 \%$ & $78 \%$ & $11 \%$ \\
\hline 0 & $90 \%$ & $56 \%$ & $24 \%$ & $80 \%$ & $66 \%$ & $10 \%$ & $92 \%$ & $74 \%$ & $14 \%$ \\
\hline-6 & $54 \%$ & $30 \%$ & $14 \%$ & $70 \%$ & $50 \%$ & $13 \%$ & $70 \%$ & $32 \%$ & $23 \%$ \\
\hline-12 & $44 \%$ & $0 \%$ & $22 \%$ & $20 \%$ & $0 \%$ & $10 \%$ & $74 \%$ & $8 \%$ & $34 \%$ \\
\hline \multirow[t]{2}{*}{-18} & $26 \%$ & $0 \%$ & $13 \%$ & $12 \%$ & $0 \%$ & $6 \%$ & $30 \%$ & $8 \%$ & $11 \%$ \\
\hline & \multicolumn{3}{|c|}{ Participant \# 26} & \multicolumn{3}{|c|}{ Participant \# 27} & \multicolumn{3}{|c|}{ Participant \# 28} \\
\hline 6 & $96 \%$ & $94 \%$ & $2 \%$ & $98 \%$ & $92 \%$ & $6 \%$ & $94 \%$ & $78 \%$ & $13 \%$ \\
\hline 0 & $98 \%$ & $80 \%$ & $15 \%$ & $82 \%$ & $74 \%$ & $6 \%$ & $80 \%$ & $68 \%$ & $9 \%$ \\
\hline-6 & $44 \%$ & $44 \%$ & $0 \%$ & $84 \%$ & $26 \%$ & $33 \%$ & $68 \%$ & $42 \%$ & $16 \%$ \\
\hline-12 & $64 \%$ & $24 \%$ & $23 \%$ & $34 \%$ & $4 \%$ & $15 \%$ & $32 \%$ & $4 \%$ & $14 \%$ \\
\hline-18 & $38 \%$ & $4 \%$ & $17 \%$ & $44 \%$ & $0 \%$ & $22 \%$ & $18 \%$ & $0 \%$ & $9 \%$ \\
\hline
\end{tabular}

* Shaded participants were female. 


\section{APPENDIX O (continued)}

\begin{tabular}{|c|c|c|c|c|c|c|c|c|c|}
\hline & $\mathrm{AV}$ & A-only & $\mathrm{VE}$ & $\mathrm{AV}$ & A-only & VE & $\mathrm{AV}$ & A-only & VE \\
\hline SNR & \multicolumn{3}{|c|}{ Participant \# 31} & \multicolumn{3}{|c|}{ Participant \# 33} & \multicolumn{3}{|c|}{ Participant \# 37} \\
\hline 6 & $94 \%$ & $94 \%$ & $0 \%$ & $90 \%$ & $96 \%$ & $-6 \%$ & $100 \%$ & $94 \%$ & $6 \%$ \\
\hline 0 & $90 \%$ & $64 \%$ & $19 \%$ & $96 \%$ & $100 \%$ & $-4 \%$ & $82 \%$ & $98 \%$ & $-16 \%$ \\
\hline-6 & $66 \%$ & $32 \%$ & $20 \%$ & $62 \%$ & $66 \%$ & $-3 \%$ & $92 \%$ & $34 \%$ & $35 \%$ \\
\hline-12 & $4 \%$ & $40 \%$ & $-23 \%$ & $62 \%$ & $16 \%$ & $25 \%$ & $74 \%$ & $8 \%$ & $34 \%$ \\
\hline \multirow[t]{2}{*}{-18} & $20 \%$ & $10 \%$ & $5 \%$ & $26 \%$ & $8 \%$ & $9 \%$ & $40 \%$ & $0 \%$ & $20 \%$ \\
\hline & \multicolumn{3}{|c|}{ Participant\# 43} & \multicolumn{3}{|c|}{ Participant \# 6} & \multicolumn{3}{|c|}{ Participant \# 7} \\
\hline 6 & $76 \%$ & $52 \%$ & $16 \%$ & $94 \%$ & $92 \%$ & $2 \%$ & $94 \%$ & $90 \%$ & $4 \%$ \\
\hline 0 & $60 \%$ & $38 \%$ & $14 \%$ & $84 \%$ & $78 \%$ & $5 \%$ & $96 \%$ & $60 \%$ & $26 \%$ \\
\hline-6 & $56 \%$ & $18 \%$ & $21 \%$ & $58 \%$ & $30 \%$ & $16 \%$ & $56 \%$ & $48 \%$ & $5 \%$ \\
\hline-12 & $44 \%$ & $2 \%$ & $21 \%$ & $42 \%$ & $18 \%$ & $13 \%$ & $38 \%$ & $10 \%$ & $15 \%$ \\
\hline \multirow[t]{2}{*}{-18} & $6 \%$ & $0 \%$ & $3 \%$ & $42 \%$ & $0 \%$ & $21 \%$ & $14 \%$ & $8 \%$ & $3 \%$ \\
\hline & \multicolumn{3}{|c|}{ Participant \# 21} & \multicolumn{3}{|c|}{ Participant \# 22} & \multicolumn{3}{|c|}{ Participant \# 23} \\
\hline 6 & $88 \%$ & $72 \%$ & $13 \%$ & $98 \%$ & $88 \%$ & $9 \%$ & $80 \%$ & $92 \%$ & $-11 \%$ \\
\hline 0 & $86 \%$ & $54 \%$ & $22 \%$ & $96 \%$ & $86 \%$ & $9 \%$ & $90 \%$ & $92 \%$ & $-2 \%$ \\
\hline-6 & $58 \%$ & $48 \%$ & $7 \%$ & $90 \%$ & $92 \%$ & $-2 \%$ & $72 \%$ & $90 \%$ & $-16 \%$ \\
\hline-12 & $26 \%$ & $0 \%$ & $13 \%$ & $52 \%$ & $44 \%$ & $5 \%$ & $22 \%$ & $50 \%$ & $-19 \%$ \\
\hline \multirow[t]{2}{*}{-18} & $20 \%$ & $0 \%$ & $10 \%$ & $18 \%$ & $6 \%$ & $6 \%$ & $22 \%$ & $22 \%$ & $0 \%$ \\
\hline & \multicolumn{3}{|c|}{ Participant \# 29} & \multicolumn{3}{|c|}{ Participant \# 30} & \multicolumn{3}{|c|}{ Participant \# 60} \\
\hline 6 & $78 \%$ & $68 \%$ & $8 \%$ & $94 \%$ & $76 \%$ & $15 \%$ & $94 \%$ & $78 \%$ & $13 \%$ \\
\hline 0 & $72 \%$ & $16 \%$ & $30 \%$ & $68 \%$ & $90 \%$ & $-20 \%$ & $82 \%$ & $74 \%$ & $6 \%$ \\
\hline-6 & $26 \%$ & $10 \%$ & $8 \%$ & $82 \%$ & $26 \%$ & $32 \%$ & $84 \%$ & $50 \%$ & $23 \%$ \\
\hline-12 & $26 \%$ & $4 \%$ & $11 \%$ & $34 \%$ & $0 \%$ & $17 \%$ & $32 \%$ & $44 \%$ & $-8 \%$ \\
\hline-18 & $4 \%$ & $0 \%$ & $2 \%$ & $18 \%$ & $0 \%$ & $9 \%$ & $20 \%$ & $2 \%$ & $9 \%$ \\
\hline
\end{tabular}

* Shaded participants were female. 


\section{APPENDIX O (continued)}

\begin{tabular}{|c|c|c|c|c|c|c|c|c|c|}
\hline & $\mathrm{AV}$ & A-only & $\mathrm{VE}$ & $\mathrm{AV}$ & A-only & VE & $\mathrm{AV}$ & A-only & $\mathrm{VE}$ \\
\hline SNR & \multicolumn{3}{|c|}{ Participant \# 36} & \multicolumn{3}{|c|}{ Participant \# 39} & \multicolumn{3}{|c|}{ Participant \# 25} \\
\hline 6 & $96 \%$ & $90 \%$ & $5 \%$ & $96 \%$ & $82 \%$ & $12 \%$ & $78 \%$ & $88 \%$ & $-9 \%$ \\
\hline 0 & $88 \%$ & $92 \%$ & $-4 \%$ & $86 \%$ & $74 \%$ & $10 \%$ & $86 \%$ & $70 \%$ & $12 \%$ \\
\hline-6 & $62 \%$ & $58 \%$ & $3 \%$ & $62 \%$ & $60 \%$ & $1 \%$ & $34 \%$ & $88 \%$ & $-48 \%$ \\
\hline-12 & $52 \%$ & $2 \%$ & $25 \%$ & $70 \%$ & $24 \%$ & $26 \%$ & $56 \%$ & $8 \%$ & $25 \%$ \\
\hline \multirow[t]{2}{*}{-18} & $32 \%$ & $0 \%$ & $16 \%$ & $36 \%$ & $8 \%$ & $15 \%$ & $2 \%$ & $6 \%$ & $-2 \%$ \\
\hline & \multicolumn{3}{|c|}{ Participant \# 11} & \multicolumn{3}{|c|}{ Participant \# 14} & \multicolumn{3}{|c|}{ Participant \# 24} \\
\hline 6 & $96 \%$ & $94 \%$ & $2 \%$ & $94 \%$ & $88 \%$ & $5 \%$ & $96 \%$ & $94 \%$ & $2 \%$ \\
\hline 0 & $98 \%$ & $88 \%$ & $9 \%$ & $84 \%$ & $68 \%$ & $12 \%$ & $94 \%$ & $74 \%$ & $16 \%$ \\
\hline-6 & $92 \%$ & $30 \%$ & $36 \%$ & $78 \%$ & $28 \%$ & $29 \%$ & $92 \%$ & $56 \%$ & $25 \%$ \\
\hline-12 & $28 \%$ & $18 \%$ & $5 \%$ & $34 \%$ & $2 \%$ & $16 \%$ & $48 \%$ & $0 \%$ & $24 \%$ \\
\hline-18 & $30 \%$ & $2 \%$ & $14 \%$ & $16 \%$ & $2 \%$ & $7 \%$ & $8 \%$ & $0 \%$ & $4 \%$ \\
\hline
\end{tabular}

* Shaded participants were female. 
APPENDIX P

RAW DATA SHOWING (A) SNR-50 AND AV-SCORE @ (A) SNR-50 FOR AMERICAN AND INDIAN PARTICIPANTS

\begin{tabular}{|c|c|c|c|c|c|}
\hline \multicolumn{3}{|c|}{ American Participants } & \multicolumn{3}{|c|}{ Indian Participants } \\
\hline Participant & $\begin{array}{l}\text { (A) SNR-50 } \\
\text { (dB) }\end{array}$ & $\begin{array}{c}\text { AV @ (A) } \\
\text { SNR-50 (\%) }\end{array}$ & Participant & $\begin{array}{l}\text { (A) SNR-50 } \\
\text { (dB) }\end{array}$ & $\begin{array}{c}\text { AV @ (A) } \\
\text { SNR-50 (\%) }\end{array}$ \\
\hline \# 34 & -4.5 & 98 & $\# 45$ & -3 & 82.5 \\
\hline \# 32 & -5.5 & 100 & \# 46 & -6.6 & 70 \\
\hline \# 16 & -5.5 & 98 & \# 47 & -4 & 80 \\
\hline \# 15 & -11.5 & 87 & \# 31 & -2.5 & 82.5 \\
\hline$\# 17$ & -8 & 75 & \# 33 & -8.5 & 60 \\
\hline \# 13 & -9.5 & 89 & \# 37 & -4.8 & 89 \\
\hline \# 12 & -8.5 & 99 & \# 36 & -7 & 58 \\
\hline \# 35 & -9.5 & 98 & \# 39 & -7.5 & 64 \\
\hline \# 57 & -9.5 & 99 & \# 38 & -3 & 77.5 \\
\hline \# 58 & -12.5 & 92.5 & \# 40 & -7.5 & 60 \\
\hline \# 56 & -10.5 & 97 & \# 42 & 1 & 90 \\
\hline$\# 48$ & -11 & 90 & \# 43 & 5.5 & 74 \\
\hline$\# 50$ & -9.5 & 92 & $\# 6$ & -3.9 & 69 \\
\hline$\# 49$ & -11.5 & 39 & $\# 7$ & -5 & 65 \\
\hline \# 51 & -10 & 94 & \# 11 & -4.8 & 93 \\
\hline \# 55 & -10 & 98 & \# 14 & -2.8 & 81 \\
\hline \# 53 & -9.5 & 97 & \# 18 & -1.1 & 85 \\
\hline \# 54 & -6.5 & 99 & \# 19 & -6 & 70 \\
\hline \# 52 & -9 & 95 & \# 20 & -3.5 & 87 \\
\hline$\# 1$ & -6 & 98 & \# 21 & -3.5 & 72.5 \\
\hline$\# 2$ & -9.5 & 71 & \# 22 & -11.5 & 60 \\
\hline$\# 3$ & -8.5 & 98 & \# 23 & -8.5 & 72.5 \\
\hline$\# 4$ & -4 & 96 & $\# 25$ & -9.5 & 46 \\
\hline$\# 5$ & -14.5 & 84 & $\# 24$ & -6.8 & 88 \\
\hline$\# 8$ & -9 & 92.5 & $\# 26$ & -5 & 54 \\
\hline$\# 9$ & -9.8 & 97 & $\# 27$ & -3 & 82.5 \\
\hline \# 10 & -10 & 96 & \# 28 & -4.5 & 72.5 \\
\hline \# 41 & -13 & 98 & \# 29 & 3.5 & 76 \\
\hline \# 44 & -14 & 96 & \# 30 & -3.5 & 87 \\
\hline \# 59 & -8.5 & 96 & \# 60 & -6 & 84 \\
\hline
\end{tabular}

* Shaded areas indicate results for the 4 male American participants and the 7 female Indian participants. 